\title{
EXPLORING TRAVEL TIME RELIABILITY USING BLUETOOTH DATA COLLECTION: CASE STUDY IN SAN LUIS OBISPO, CALIFORNIA
}

\author{
A Thesis \\ presented to \\ the Faculty of California Polytechnic State University, \\ San Luis Obispo \\ In Partial Fulfillment \\ of the Requirements for the Degree \\ Master of Science in Civil and Environmental Engineering
}

by

Krista Marie Purser

June 2016 
(C) 2016

Krista Marie Purser

ALL RIGHTS RESERVED 
COMMITTEE MEMBERSHIP

TITLE: Exploring Travel Time Reliability using Bluetooth Data Collection: Case Study in San Luis Obispo, California

AUTHOR: Krista Marie Purser

DATE SUBMITTED: June 2016

COMMITTEE CHAIR: $\quad$ Robert Bertini, Ph.D.

Associate Professor of Civil and Environmental Engineering

COMMITTEE MEMBER: Anurag Pande, Ph.D.

Associate Professor of Civil and Environmental Engineering

COMMITTEE MEMBER: Kimberley Mastako, Ph.D.

Lecturer of Civil and Environmental

Engineering 


\begin{abstract}
Exploring Travel Time Reliability using Bluetooth Data Collection: Case Study in San Luis Obispo, California

Krista Marie Purser
\end{abstract}

Bluetooth technology applications have improved travel time data collection efforts and allowed for collection of large data sets at a low cost per data unit. Mean travel times between pairs of points are available, but the primary value of this technique is the availability of the entire distribution of travel times throughout multiple days and time periods, allowing for a greater understanding of travel time variations and reliability. The use of these data for transportation planning, engineering and operations continues to expand. Previous applications of similar data sources have included travel demand and simulation model validation, work zone traffic patterns, transit ridership and reliability, pedestrian movement patterns, and before-after studies of transportation improvements. This thesis investigates the collection and analysis of Bluetooth-enabled travel time data along a multimodal arterial corridor in San Luis Obispo, California. Five BlueMAC devices collected multimodal travel time data in January and February 2016 along Los Osos Valley Road. These datasets were used to identify and process known sources of error such as occasions where vehicles using the roadway turn off and make an intermediate stop and multiple reads from the same vehicle; quantify travel time performance and reliability along arterial streets; and compare transit, bicycle, and pedestrian facility performance. Additionally, a travel time model was estimated based on segment characteristics and Bluetooth data to estimate average speeds and travel time distributions.

Keywords: Travel time, travel time reliability, mobility, Bluetooth, travel time modeling, multimodal reliability. 


\section{ACKNOWLEDGMENTS}

Thank you to the BlueMAC manufacturer Digiwest and their parent company Kittelson \& Associates, Inc. for their educational discount and technical support. Thank you to the Cal Poly College of Engineering for the funding of the BlueMAC devices. Thank you to the City of San Luis Obispo staff and Cal Poly students who took their time to install the devices, especially Alex Chambers, Bobby Sidhu, Kaylinn Pell, and Bryan Wheeler.

I owe endless thanks to my family and friends who have offered words of wisdom, encouragement, and patience every step of the way. I would not have succeeded without you. In addition, thank you to the peers who have made each hour spent on campus one of laughter and support. I'm honored to call you a classmate, and more fortunate to call you a friend.

Finally, I am incredibly grateful for the guidance of Drs. Bertini, Pande, and Mastako. Thank you for introducing me to my passion in Fundamentals of Transportation Engineering. Thank you for encouraging me to join the Institute of Transportation Engineers chapter, for serving as my advisor during internships, and for providing invaluable advice on leadership and vision. Thank you for constantly open office doors, for swift email responses in the late hours of the night, and for giving so much time and energy to your students. 


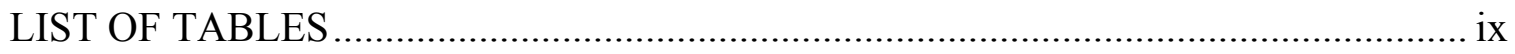

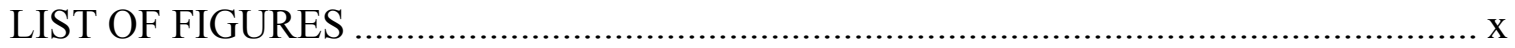

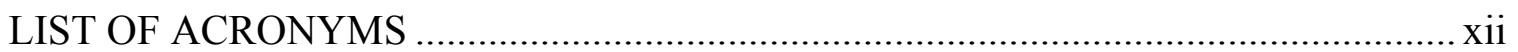

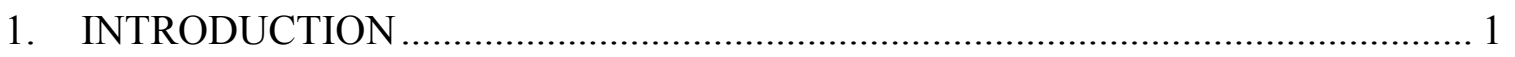

2. LITERATURE REVIEW ................................................................................ 2

2.1 Historical Methods of Travel Time Data Collection................................................... 2

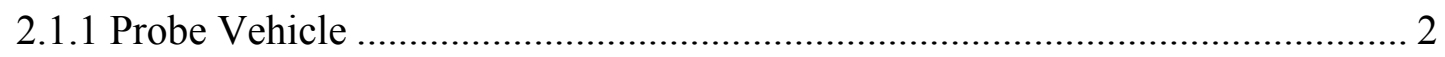

2.1.2 Remote Sensor \& Radar ........................................................................... 2

2.1.3 License Plate Match..................................................................................... 3

2.2 Bluetooth Functionality \& BlueMAC Devices ........................................................... 4

2.2.1 Overview of Bluetooth and MAC Addresses ..................................................... 4

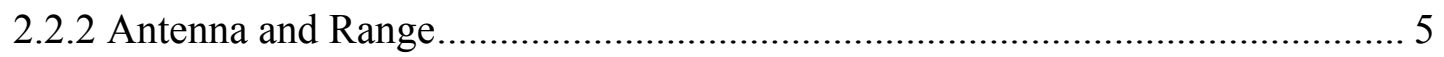

2.2.3 Data Capture and Detection Rate ................................................................... 6

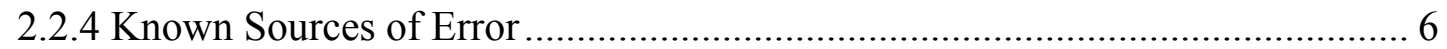

2.2.5 Comparison to Other Methods ……………………...................................... 7

2.2.6 Privacy Concerns ...................................................................................... 8

2.3 Transportation Engineering Application of Bluetooth Data Collection.................... 8

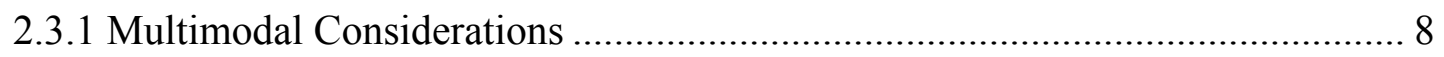

2.3.2 Intelligent Transportation Systems Evaluations ………………….................. 9

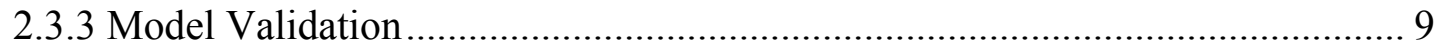

2.3.4 Mass Movement Circumstances..................................................................... 10

2.3.5 Data Processing Best Practices ...................................................................... 10

2.3.6 Travel Time Reliability and Performance Metrics............................................... 11

2.4 Modeling Travel Time …………………………......................................... 13

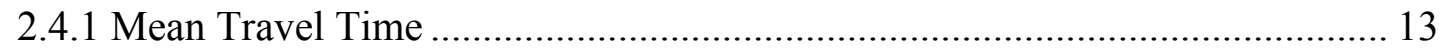

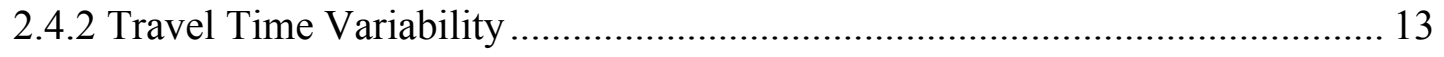

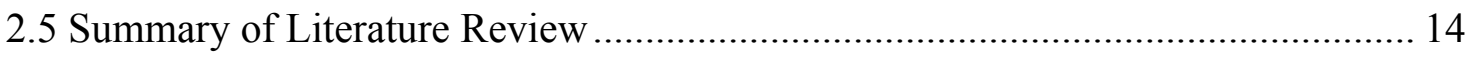

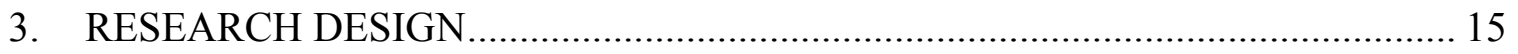




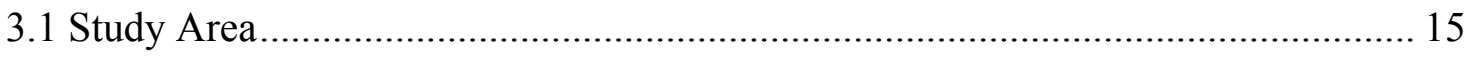

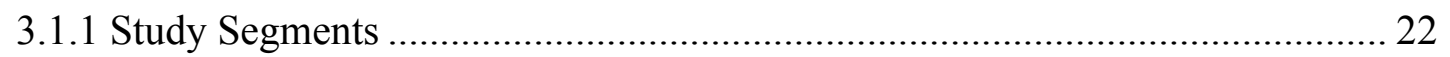

3.1.2 Surrounding Land Uses \& Future Development ............................................... 26

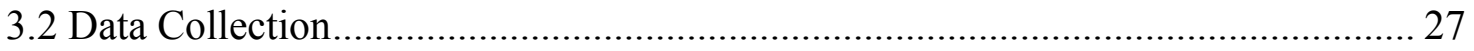

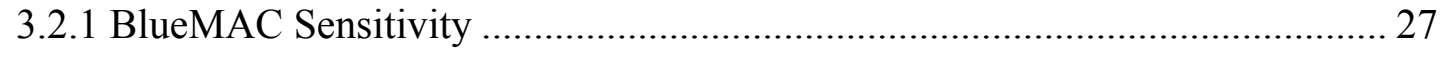

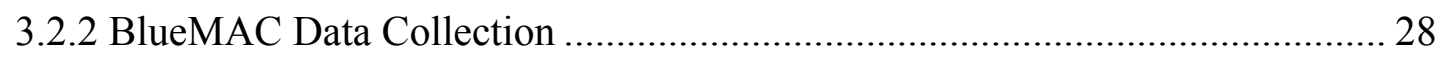

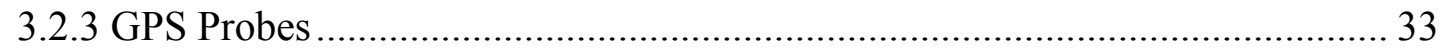

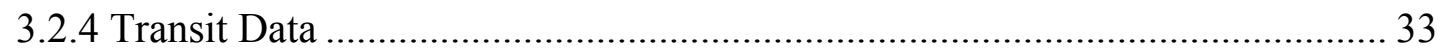

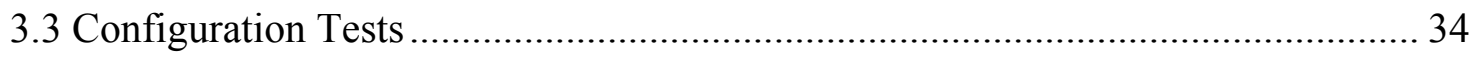

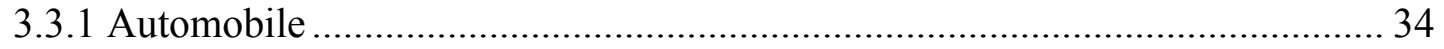

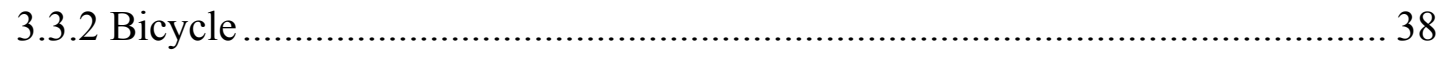

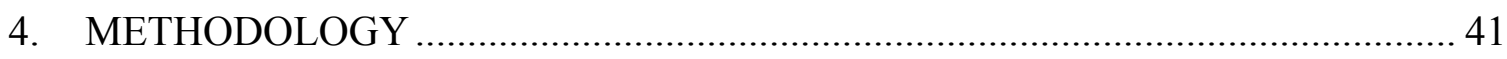

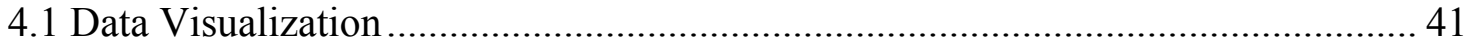

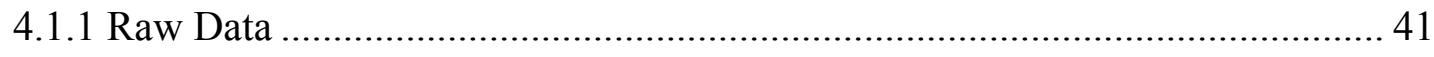

4.1.2 Outlier-Filtered .................................................................................. 48

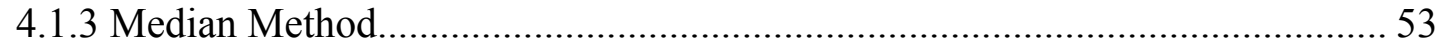

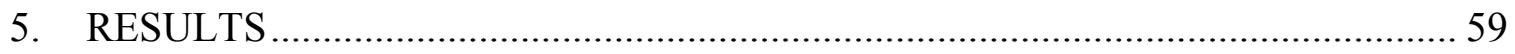

5.1 Travel Time Reliability ………………………........................................... 59

5.1.1 Calculation of Reliability Metrics ………………............................................ 59

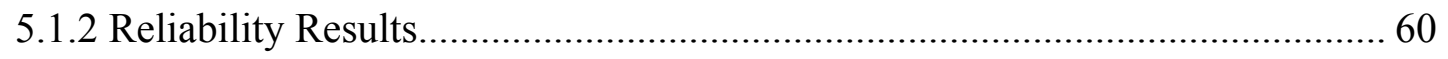

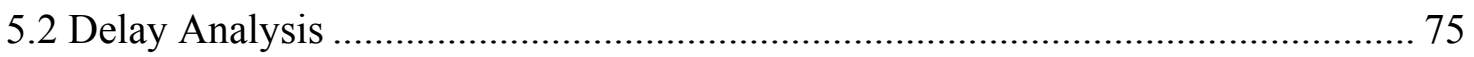

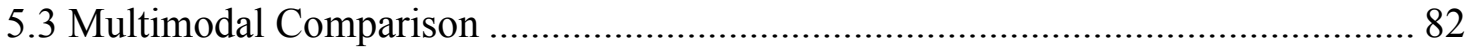

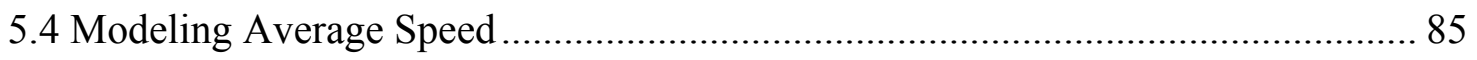

5.4.1 Identification of Model Data Inputs ............................................................... 86

5.4.2 Model Development ………………………………..................................... 86

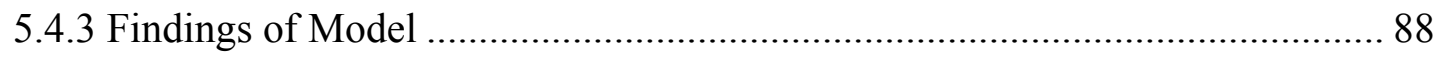

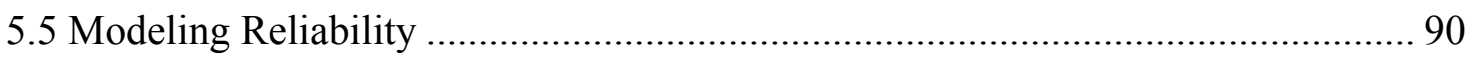

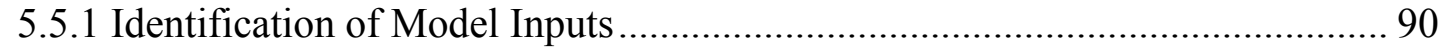

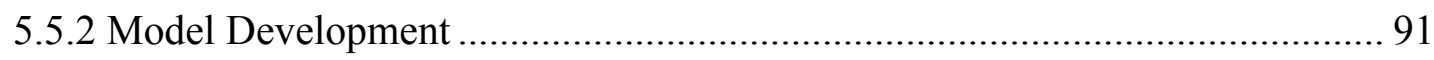

5.5.3 Findings of Model ....................................................................................... 93

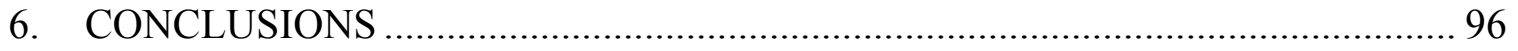




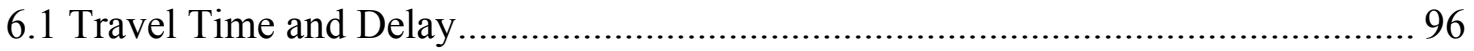

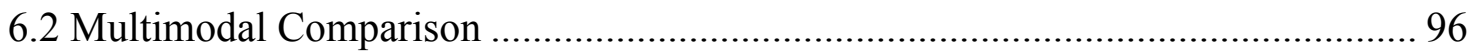

6.3 Average Speed and Reliability Model ................................................................ 97

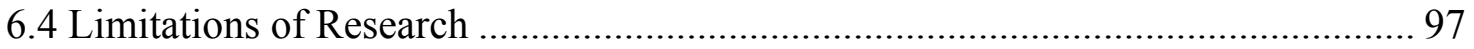

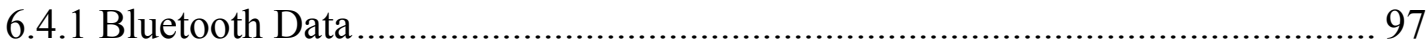

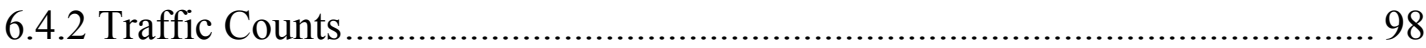

6.4.3 Collision and Incident Comparison ................................................................ 99

6.4.4 Modeling Speed and Variability ................................................................... 99

6.5 Further Analysis and Research........................................................................ 99

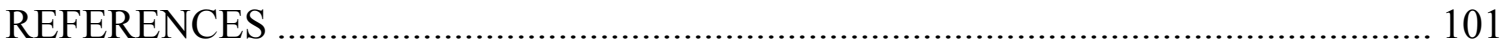




\section{LIST OF TABLES}

Table

Page

Table 1: Detection Rates by Segment, Direction, and Peak Period................................ 30

Table 2: Probe Automobile Runs.................................................................................. 34

Table 3: Probe Bicycle Runs.......................................................................................... 38

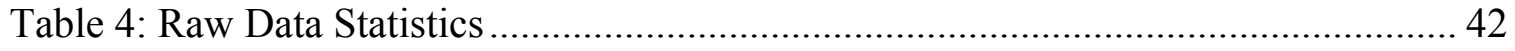

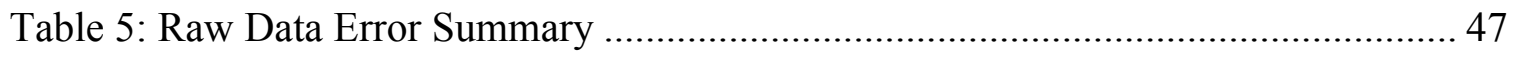

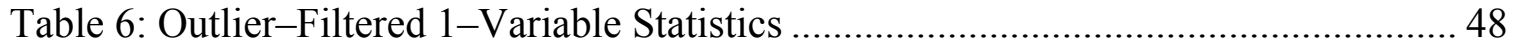

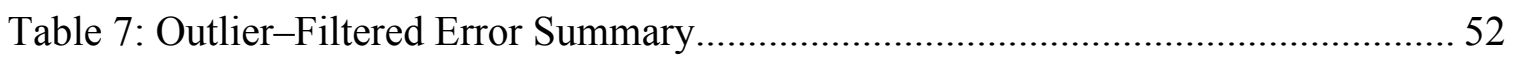

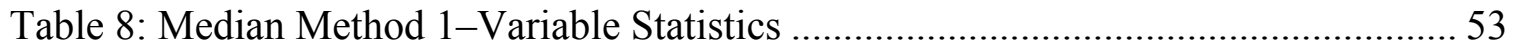

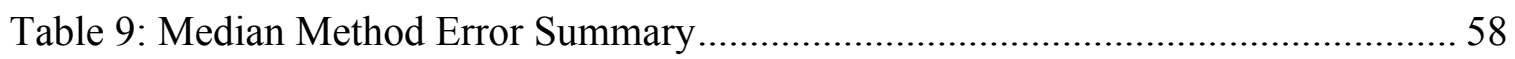

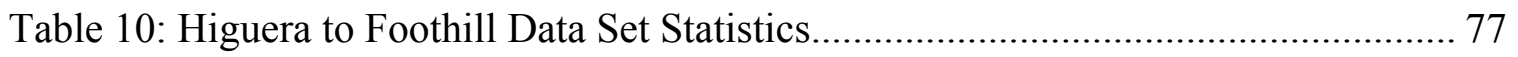

Table 11: Transit Reliability on Los Osos Valley Road .............................................. 83

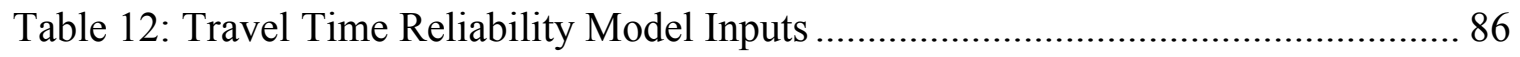

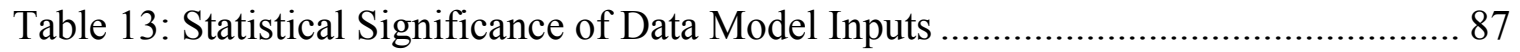

Table 14: Average Speed Model Findings.................................................................. 88

Table 15: Gamma Density Function Best-Fit Parameters............................................. 91

Table 16: K-S Results for Variability Model .............................................................. 93

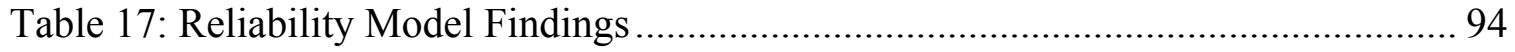




\section{LIST OF FIGURES}

Figure

Page

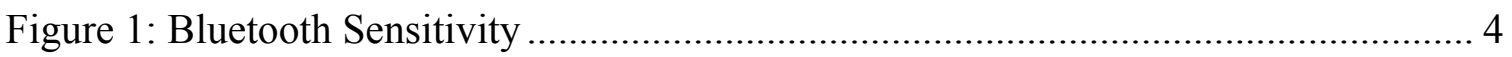

Figure 2: Bluetooth Travel Time Depiction.................................................................. 5

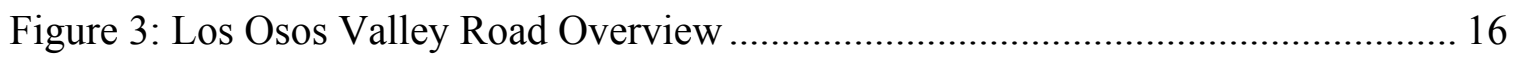

Figure 4: Bicycle and Pedestrian Facilities on Los Osos Valley Road............................. 17

Figure 5: SLO Transit on Los Osos Valley Road ....................................................... 18

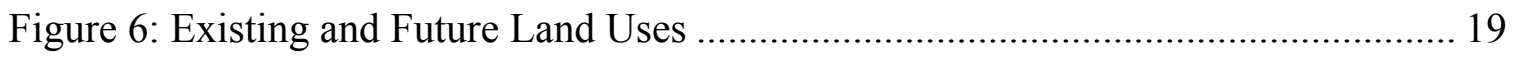

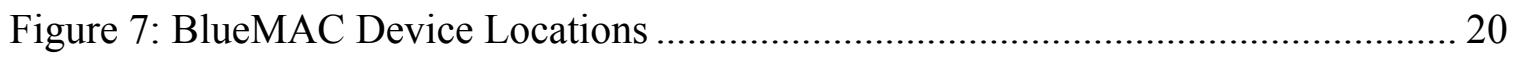

Figure 8: BlueMAC Device at Madonna Road.............................................................. 21

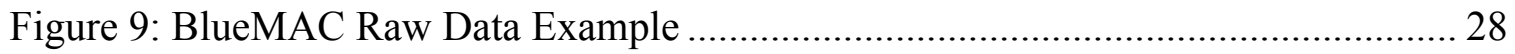

Figure 10: Devices Detected by Number of Intersections ............................................ 29

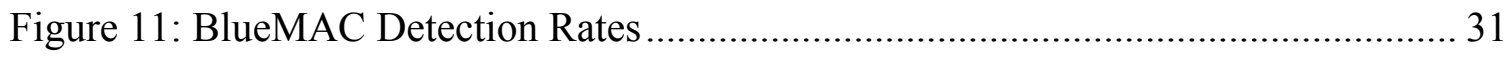

Figure 12: Madonna Road BlueMAC Detection Range ............................................. 32

Figure 13: Geo Tracker Raw Data Example............................................................... 33

Figure 14: Automobile Run \#7 Time-Space Diagram ................................................... 35

Figure 15: Automobile Run \#9 Time-Space Diagram ................................................. 36

Figure 16: Automobile Run \#11 Time-Space Diagram .............................................. 36

Figure 17: Automobile Run \#10 Time-Space Diagram .............................................. 37

Figure 18: Automobile Run \#12 Time-Space Diagram .............................................. 38

Figure 19: Bicycle Trial Run \#1 Time-Space Diagram ............................................... 39

Figure 20: Bicycle Trial Run \#2 Time-Space Diagram .............................................. 40

Figure 21: Raw Data Travel Time Example ............................................................. 41

Figure 22: Raw Data Travel Time Count Distributions - Northbound ........................... 42

Figure 23: Raw Data Travel Time Percentage Distributions - Northbound ................... 43

Figure 24: Raw Data Travel Time Count Distributions - Southbound .......................... 43

Figure 25: Raw Data Travel Time Percentage Distributions - Southbound .................... 44

Figure 26: Raw Data Time-Space Diagram for Northbound Madonna to Calle Joaquin 45

Figure 27: Raw Data Time-Space Diagram for Southbound Madonna to Calle Joaquin 45

Figure 28: Raw Data Speed Distributions for Northbound Calle Joaquin to Madonna ... 46

Figure 29: Outlier-Filtered Travel Time Count Distributions - Northbound .................. 49

Figure 30: Outlier-Filtered Travel Time Percentage Distributions - Northbound.......... 49

Figure 31: Outlier-Filtered Travel Time Count Distributions - Southbound .................. 50

Figure 32: Outlier-Filtered Travel Time Percentage Distributions - Southbound........... 50

Figure 33: Outlier-Filtered Time-Space Diagram for Northbound Madonna to Calle

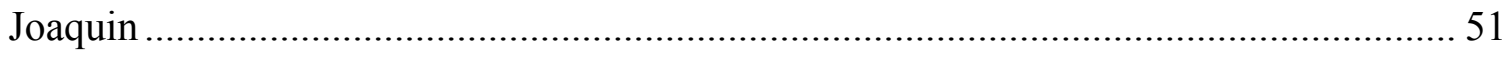

Figure 34: Outlier-Filtered Time-Space Diagram for Southbound Madonna to Calle

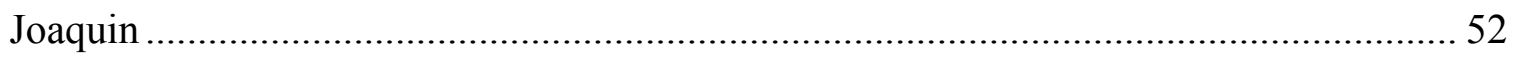

Figure 35: Median Method Travel Time Count Distributions - Northbound .................. 54 
Figure 36: Median Method Travel Time Percentage Distributions - Northbound........... 54

Figure 37: Median Method Travel Time Count Distributions - Southbound .................. 55

Figure 38: Median Method Travel Time Percentage Distributions - Southbound........... 55

Figure 39: Median Method Time-Space Diagram for Northbound Madonna to Calle

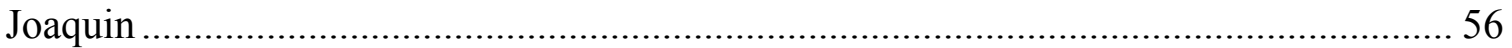

Figure 40: Median Method Time-Space Diagram for Southbound Madonna to Calle

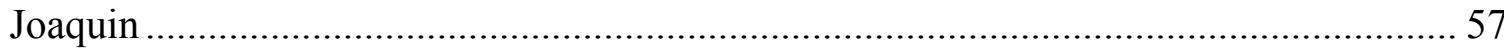

Figure 41: Northbound Higuera to Calle Joaquin Travel Time Reliability ..................... 61

Figure 42: Northbound Higuera to Calle Joaquin Reliability by Time-of-Day ............. 62

Figure 43: Northbound Calle Joaquin to Madonna Travel Time Reliability ................... 63

Figure 44: Northbound Calle Joaquin to Madonna Reliability by Time-of-Day ............ 64

Figure 45: Northbound Madonna to Laguna Travel Time Reliability ............................ 65

Figure 46: Northbound Madonna to Laguna Reliability by Time-of-Day ...................... 65

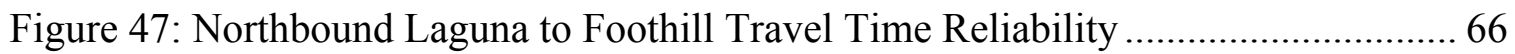

Figure 48: Northbound Laguna to Foothill Reliability by Time-of-Day........................ 67

Figure 49: Southbound Calle Joaquin to Higuera Travel Time Reliability ...................... 68

Figure 50: Southbound Calle Joaquin to Higuera Reliability by Time--of-Day .............. 69

Figure 51: Southbound Madonna to Calle Joaquin Travel Time Reliability ................... 70

Figure 52: Southbound Madonna to Calle Joaquin Reliability by Time-of-Day ............ 70

Figure 53: Southbound Laguna to Madonna Travel Time Reliability............................ 71

Figure 54: Southbound Laguna to Madonna Reliability by Time-of-Day ...................... 72

Figure 55: Southbound Foothill to Laguna Travel Time Reliability .............................. 73

Figure 56: Southbound Foothill to Laguna Reliability by Time-of-Day......................... 73

Figure 57: Coefficient of Variation Comparison ....................................................... 74

Figure 58: Level of Service vs. Coefficient of Variation.............................................. 75

Figure 59: Segment Contributions to Northbound Delay by Time-of-Day..................... 76

Figure 60: Corridor Northbound Travel Time in the AM Peak....................................... 78

Figure 61: Corridor Northbound Travel Time in the MID Peak ................................... 78

Figure 62: Corridor Northbound Travel Time in the PM Peak .................................... 79

Figure 63: Segment Contributions to Southbound Delay by Time-of-Day.................... 80

Figure 64: Corridor Southbound Travel Time in the AM Peak.................................... 81

Figure 65: Corridor Southbound Travel Time in the MID Peak .................................. 81

Figure 66: Corridor Southbound Travel Time in the PM Peak ..................................... 82

Figure 67: Northbound Transit and Automobile Standard Deviation .............................. 83

Figure 68: Southbound Transit and Automobile Standard Deviation ............................. 84

Figure 69: Northbound Transit and Automobile Coefficient of Variation ....................... 84

Figure 70: Southbound Transit and Automobile Coefficient of Variation ....................... 85

Figure 71: Observed vs. Multiple Linear Regression Model Predicted Speeds .............. 89

Figure 72: Madonna - Laguna Cumulative Density Plot ........................................... 92

Figure 73: Observed vs. Gamma Density Function Predicted Reliability...................... 94 


\section{LIST OF ACRONYMS}

\begin{tabular}{|c|c|}
\hline $\mathrm{ADT}$ & Average Daily Traffic \\
\hline $\mathrm{dB}$ & Decibel \\
\hline $\mathrm{dBi}$ & Decibel over Isotropic \\
\hline $\mathrm{dBm}$ & Decibel (references to milliwatts) \\
\hline FAST Act & Fixing America's Surface Transportation Act \\
\hline FHWA & Federal Highway Administration \\
\hline GPS & Global Positioning System \\
\hline IQR & Inter-Quartile Range \\
\hline ITS & Intelligent Transportation Systems \\
\hline $\mathrm{K}-\mathrm{S}$ & Kolmogorov-Smirnov \\
\hline MAC & Media Access Control \\
\hline MAP-21 & Moving Ahead for Progress in the $21^{\text {st }}$ Century Act \\
\hline $\mathrm{MPH}$ & Miles Per Hour \\
\hline NCHRP & National Cooperative Highway Research Program \\
\hline PII & Personally Identifiable Information \\
\hline Q1 & First Quartile \\
\hline Q3 & Third Quartile \\
\hline SHRP2 & Second Strategic Highway Research Program \\
\hline STAA & Surface Transportation Assistance Act \\
\hline $\mathrm{TMC}$ & Transportation Management Center \\
\hline VMT & Vehicle-Miles Traveled \\
\hline
\end{tabular}




\section{INTRODUCTION}

As agencies face higher congestion on their built-out roadway networks, methods of increasing capacity shift from additional lanes to increased efficiency of the current physical system. For transportation planners, engineers, and policy-makers, travel time reliability has emerged as both a vital performance measure in maximizing network benefits and an accurate means of identifying locations needing improvement. Nationwide in 2012, the Moving Ahead for Progress in the 21st Century Act (MAP-21) outlined travel time as a main criterion for allocating funding for transportation projects. More recently in 2015, the Fixing America's Surface Transportation Act (FAST Act) provides funding and guidance for research and technology programs, such as travel time estimation with emerging technologies. Additionally, the Federal Highway Association allocated funding to the second Strategic Highway Research Program (SHRP2), which sought to establish innovative solutions to improve safety, renewal, capacity, and reliability (FHWA, 2015). The public's need for travel time estimation and efficient movement extends beyond vehicular user traveler information and daily commutes to multimodal travel decisions and freight movement. The same can be seen internationally as travel time collection methods expand and are further refined.

This thesis aims to evaluate the travel time performance of Los Osos Valley Road as a case study of Bluetooth-collected data, to compare multimodal reliability, to identify effective models for peak period travel times and distributions, and to establish a reliable framework for processing of automated travel time data collection on arterials.

The literature review, research design, methodology, results, and conclusions of this thesis are described in their respective chapters. 


\section{LITERATURE REVIEW}

\subsection{Historical Methods of Travel Time Data Collection}

\subsubsection{Probe Vehicle}

Often referred to as "floating car" or test vehicle data collection, this method involves sending vehicles into the network for the sole purpose of collecting travel times. The Federal Highway Administration's (FHWA) Travel Time Data Collection Handbook defines behavior and best practices for Test Vehicle data collection. The personnel within the probe vehicle determine speed of the vehicle based on "average car," "floating car," or "maximum car" behaviors. Personnel driving average car attempt to drive the average speed of traffic, floating car attempts to safely pass as many vehicles as it has been passed, and maximum car drives the posted speed limit unless impeded by congestion or safety. Floating car is most common, though in practice the personnel will likely drive a mixture of average car and floating car. Advantages include consistency between data as

driving styles are predetermined, complete coverage of the study area, and relatively low initial costs. However, this method leaves room for quality control issues and human error, limits number of network runs and data points, and can be costly to employ personnel (Turner, Eisele, Benz, \& Holdener, 1998).

\subsubsection{Remote Sensor \& Radar}

Intelligent transportation systems (ITS) probe vehicle techniques use passive technologies in personal, commercial, and transit vehicles to collect travel times throughout a network. Data typically reports back to a transportation management center (TMC) in real-time, allowing for ITS applications such as traveler information, real time traffic management, toll collection, bus tracking updates on transit information signs, and 
route guidance. Advantages include easy and relatively low cost data collection, a continuous data stream, automated collection, data already in electronic format, and no disruption to the typical flow of traffic. Disadvantages can include high initial costs, infrastructure constraints (antenna and coverage issues), requirements of skilled software personnel, privacy concerns, and unnecessary complications when in need of only small scale data collection (Turner et al., 1998).

\subsubsection{License Plate Match}

License plate matching consists of capturing license plate characters at several points along a network and computing difference in arrival times to yield average speed and travel time along a corridor. Manual license plate match includes personnel recording license plate characters using voice recorders and later transcribing and matching on a computer, typing characters directly onto a computer and later matching, and setting video cameras and later reviewing and transcribing license plates. License plate matching can also be done using video and character recognition software to automatically transcribe license plates for computer matching. This is often used for freeway/motorway section speed control and enforcement purposes in Europe, and in many U.S. tolling applications for toll payment and/or enforcement. Travel time advantages include potential large samples, continuous travel time data during the study period and shortterm analysis, the potential for origin-destination information, and relatively portable data collection equipment. Disadvantages include location limitation in terms of observer safety or video camera positioning, limited study area coverage in one day, highly manual and error-prone methods, inaccurate license plate reading via software or 
manual, skilled personnel requirements for data and observation (Turner et al., 1998), and privacy concerns.

\subsection{Bluetooth Functionality \& BlueMAC Devices}

\subsubsection{Overview of Bluetooth and MAC Addresses}

Bluetooth utilizes radio waves over short-range networks known as piconets to send and receive data. Bluetooth software and products are relatively low cost, utilize less power, and are easy to use. This ease of use led to their use in transmitting data among carry-in and embedded vehicle systems including in-dash navigation and entertainment systems, laptops, phones, tablets, speakers, smartwatches, and headphones (Bluetooth, 2015). An example scenario of detection is shown in Figure 1 (Libelium, 2012).

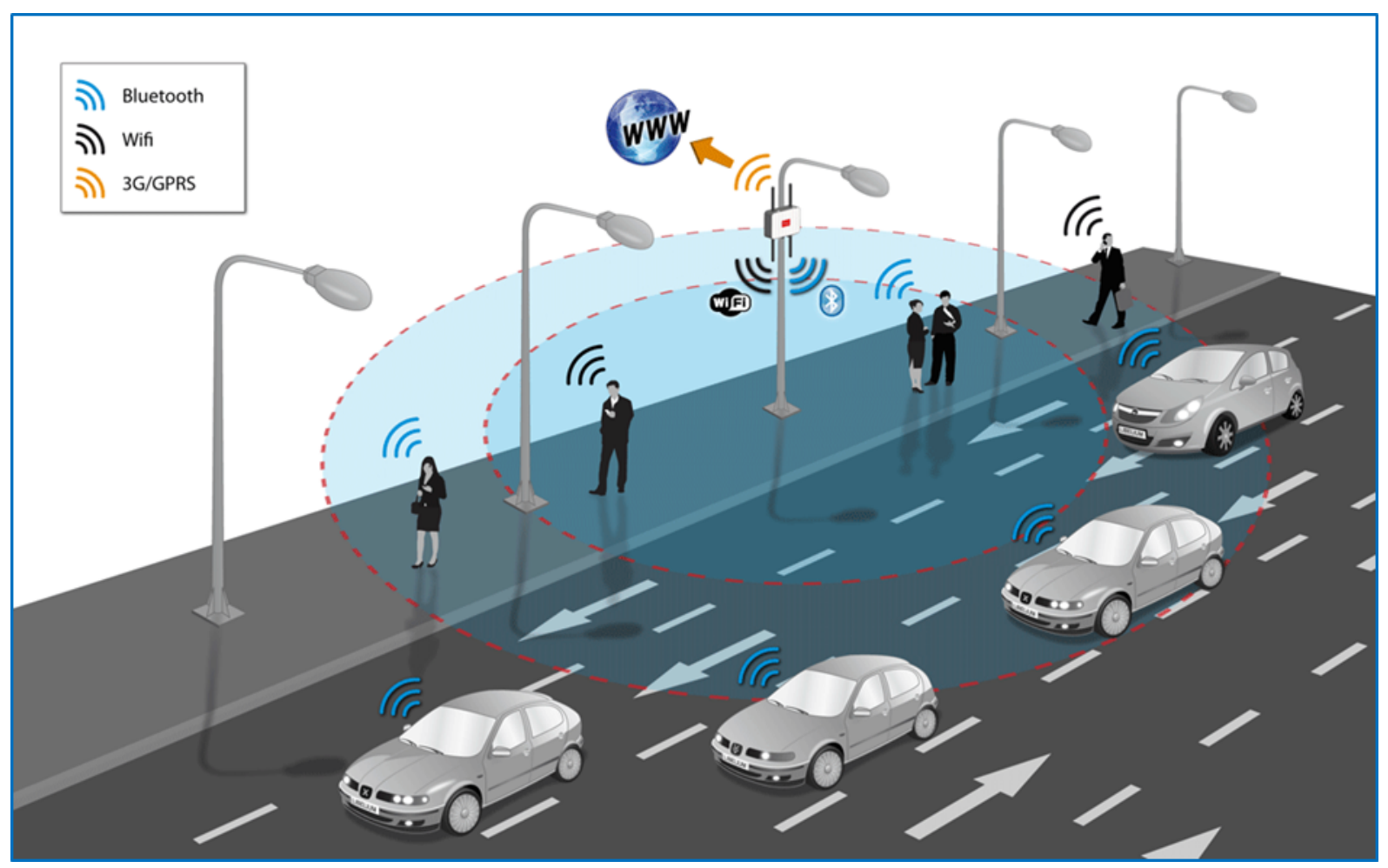

Figure 1: Bluetooth Sensitivity

BlueMAC is a brand of Bluetooth data collection technology, which utilize Bluetooth to match unique media access control (MAC) addresses between devices, 
allowing for the calculation of travel time and speed between match points. A diagram depicting the travel time calculation is shown in Figure 2 (Libelium, 2012).

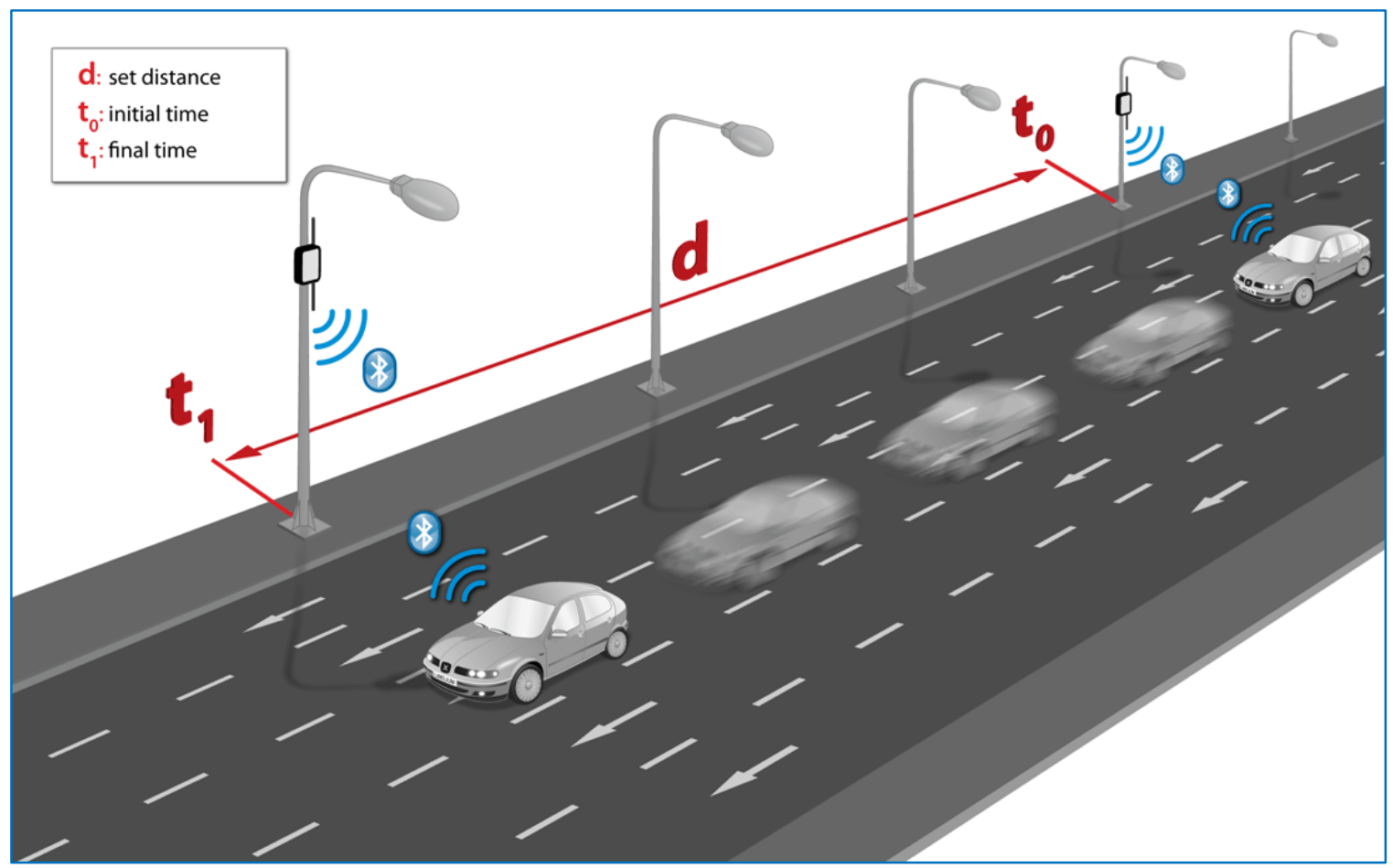

Figure 2: Bluetooth Travel Time Depiction

\subsubsection{Antenna and Range}

Antenna polarization and gains determine the accuracy and capture rate for Bluetooth data collection on roadways and trails. Antenna polarization includes directional and omni-directional. Omni-directional antennae send and receive data from any direction while directional only sends and receives data from certain angles in one direction (Abedi, Bhaskar, Chung, \& Miska, 2015). Antenna strength is measured in decibels isotropic, or $\mathrm{dBi}$, which correlates to the antenna's ability to direct or concentrate radio frequency energy in a particular direction. Omni-directional antennas with gains from 9 to $12 \mathrm{dBi}$ are best for road traffic data collection (Porter, Kim, Magana, Poocharoen, \& Arriaga, 2013). While larger antennas provide more gains and more data, they also produce more anomalies and require longer data processing times. Smaller gain 
antennas have fewer anomalies but produce a smaller sample size. Smaller ranges can be more beneficial to smaller projects with higher pedestrian and cyclist movements (Abedi et al., 2015).

\subsubsection{Data Capture and Detection Rate}

Data capture and detection rates vary by facility, speed, average daily traffic (ADT), and user type. The location of the Bluetooth device greatly impacts detection rates. A study on detection found a Bluetooth-enabled phone located on an automobile's dashboard has a three to five times higher detection rate than a Bluetooth-enabled phone in a pocket or purse. In addition, slow-moving vehicles were detected slightly more frequently than fast-moving vehicles due to antenna lag (Stevanovic, Olarte, Galletebeitia, Galletebeitia, \& Kaisar, 2014). A 2.5-mile arterial study with 40,000 ADT on Tualatin-Sherwood Road in Oregon found 3-4\% of ADT to be detected (Quayle \& Koonce, 2010). With higher amounts of access points, such as driveways and side streets, and longer spacing between devices, it's likely many of the daily trips do not pass both Bluetooth devices. Additional studies suggest 3-5\% (Asudegi, 2009) to 5-10\% of ADT can be detected using Bluetooth and MAC matching (Box, 2011).

\subsubsection{Known Sources of Error}

Sources of error depend on the implementation and facility type associated with the study. Arterials present several challenges to Bluetooth data collection, particularly when compared with freeways. The data collectors should be placed at intersections, where major route decisions become apparent. Appropriate routing between data collectors should be noted, as there are often several possible routes on local networks 
(Wasson, Sturdevant, \& Bullock, 2008). Data processing should account for unusual travel times caused by travel and route choices, such as the following situations:

- A vehicle exits the corridor to access a business, residence, or other destination, then re-enters the corridor later.

- A vehicle chooses a non-direct or unexpected route, where the most direct route is assumed to be taken.

- A vehicle is detected at one device, undetected at the next device, and then potentially detected at a later time or in the opposite direction.

These situations result in apparently increased travel times. In addition, pedestrian, cyclist, and transit movements along these routes are not distinguished from automobile trips. Vehicles with multiple devices, including carpools and transit, should be processed as well (Quayle \& Koonce, 2010). Even with errors, MAC readers can report travel times not significantly different with 95\% confidence from Global Positioning System (GPS) devices 83\% of the time (Stevanovic et al., 2014).

\subsubsection{Comparison to Other Methods}

"Ground truth" data can be collected using the more costly test vehicle or "floating car" data collection methods. While Bluetooth obtains multiple reads from one vehicle, in comparison with GPS which obtains only one read, the Bluetooth reads have been found to be consistent with the ground truth (Koprowski, 2012). In addition, Bluetooth sensors were found to be consistent with ground truth and on par with TRANSMIT data, which utilizes toll collection tags and fixed sensors. Bluetooth was found to outperform INRIX data sets at several study locations (Liu, Chien, \& Kim, 2012). 


\subsubsection{Privacy Concerns}

Privacy serves as a high concern to the public throughout any traffic data collection procedure. While GPS and cellular phone tracking for the purposes of travel time surveys can contain personally identifiable information (PII), MAC addresses hold no personal information while providing unique codes to match data and provide accurate travel times.

\subsection{Transportation Engineering Application of Bluetooth Data Collection}

\subsubsection{Multimodal Considerations}

Bluetooth data collection can assist with improving transit, bicycle, and pedestrian facilities and services. Using Bluetooth to identify commute patterns and origindestination data can assess potential ridership of a new transit service. Travel times can improve transit reliability by better estimating travel time, thus attracting more users (Kieu, Bhaskar, \& Chung, 2012). In addition, public transportation use can be further studied and estimated to increase ridership and decrease congestion (Weinzerl and Hagemann, 2007). To obtain data on pedestrian and bicycle trips, Bluetooth devices can be placed along multi-use paths or assess the slower moving data on a traditional roadway. Studies should note effects of temperature and weather, purposes of activity (leisure, travel, exercise), and interaction with vehicles and other modes. Pedestrian activity studies should also note buffer zones between building edges and other people as well as road crossing widths and lengths (Abedi et al., 2015). National Cooperative Highway Research Program (NCHRP) Report 797 also notes pedestrians and cyclists tend to make shorter trips, which can be harder to detect (Ryus et al., 2014). 


\subsubsection{Intelligent Transportation Systems Evaluations}

Bluetooth travel times can improve pedestrian, bicycle, transit, and automobile activities through ITS. Improved bus travel time data could better facilitate corridor improvements, preparing signals for bus preemption or prioritization. Signal timing could account for heavier incoming vehicles based on their expected travel time, increasing throughput of the system (Kieu et al., 2012). Before and after studies of signal timing changes gauges effectiveness and potential need for further improvement (Quayle \& Koonce, 2010). Pedestrian and cyclist activities have provided better information for before and after studies on corridors, allowing for anticipated demand on comparable projects (Ryus et al., 2014).

\subsubsection{Model Validation}

Bluetooth travel times can validate volume, distance, and origin-destination data to better predict future conditions. Quantifying volumes and modal interaction can better assess risk exposure for different modes (Ryus et al., 2014). In addition, the distance range for pedestrians and cyclists to reach either their destinations or a transit stop can also be verified (Kuzmyak, Walters, Bradley, \& Kockleman, 2014). Bluetooth travel times can validate simulations as well (Zhang, Hamedi, \& Haghani, 2015). Origindestination data has been used to gauge network-wide activity and provide appropriate facilities (Wasson et al., 2014). In one particular study, a Bluetooth collection device ran as a floating probe within a commute vehicle for a month on the same route recognized $30 \%$ of devices within its range at the end of the month. Commute pattern data gives

further information on platooning and transit ridership estimates (Filgueiras et al., 2914). 


\subsubsection{Mass Movement Circumstances}

Bluetooth travel times and travel patterns have also been utilized in studying evacuation procedures, work zone effects, and tourism patterns. Evacuation procedures can be improved by recognizing pedestrian bottlenecks and movements, and providing signage or guidance to diffuse or direct crowds. Work zones produce changes to travel patterns, potentially increasing collision risk and endangering construction workers' safety. Understanding movements in these hazardous conditions can improve safety and efficiency (Abedi et al., 2015). Tourism patterns have also been studied in conjunction with Bluetooth and GPS travel times and patterns. These small-scale studies highlighted popular locations to increase pedestrian facilities and transit service in those areas (Versichele et al., 2014).

\subsubsection{Data Processing Best Practices}

Due to the presence of multiple transportation modes, driveways and side streets where vehicles can turn off, and multiple devices in one vehicle, data cleaning and processing is necessary to assess data sets before analysis can be conducted. Prior studies have utilized oblique cumulative count curves to assess flow collected by detectors (Bertini, 2006), examined data sets point-by-point to find unrealistic travel times compared to trips made in the same time range (Schneider, Turner, \& Wikander, 2010), and removed speeds below the first quartile or above the third quartile in a data set (Li, Chai, \& Tang, 2013).

While the point-by-point method can be effective on smaller studies, the level of subjectivity and data processing for this multi-month study would be a dubious and 
time-intensive method. In addition, the somewhat arbitrary removal of speeds below the first quartile may be ineffective on arterial roadways (Box, 2011).

Maximum error can be determined from the following equation:

$$
E=Z_{\alpha / 2} \times \frac{s}{\sqrt{n}}
$$

Where $n$ is the minimum sample size, $Z_{\alpha / 2}$ is the standard normal curve area equal to $\alpha / 2$ for a confidence level of $1-\alpha . s$ is the standard deviation of the sample, and $E$ is the maximum error of the estimation (Tantiyanugulchai \& Bertini, 2003). An error of \pm 2 mph to \pm 4 mph may be acceptable (Institute of Transportation Engineers, 2000).

\subsubsection{Travel Time Reliability and Performance Metrics}

After calculation of the mean travel time and standard deviation of travel time with a reliable data set, further reliability measures can be calculated. Several straightforward metrics have been proposed, studied and used in various applications. In particular, the Freeway Management and Operations Handbook defines equations for the planning time index, buffer time, buffer index, and coefficient of variation (Neudorff, Randall, Reiss, \& Gordon, 2006) which are commonly used reliability measures in the transportation arena. Equations for these values are as follows:

The coefficient of variation is a standardized measure of dispersion of a probability distribution or a frequency distribution:

$$
\text { Coefficient of Variation }=\frac{\text { Standard Deviation of Travel Time }(\mathrm{min})}{\text { Average Travel Time }(\mathrm{min})}
$$

The buffer index represents the extra time (or time cushion) that travelers must add to their average travel time when planning trips to ensure on-time arrival. For example, a buffer index of 40 percent means that for a trip that usually takes 20 minutes a traveler should budget an additional 8 minutes to ensure on-time arrival most of the time: 


$$
\begin{aligned}
& \text { Buffer Index } \\
& =\frac{95 \text { th Percentile Travel Time ( } \mathrm{min})- \text { Average Travel Time }(\mathrm{min})}{\text { Average Travel Time (min) }}
\end{aligned}
$$

The 8 extra minutes is called the buffer time. Therefore the traveler should allow 28 minutes for the trip in order to ensure on-time arrival 95 percent of the time:

$$
\begin{aligned}
& \text { Buffer Time (min) } \\
& \qquad \begin{aligned}
& 95 \text { th Percentile Travel Time (min) } \\
& - \text { Average Travel Time (min) }
\end{aligned}
\end{aligned}
$$

The planning time index represents how much total time a traveler should allow to ensure on-time arrival. For example, a planning time index of 1.60 means that for a trip that takes 15 minutes in light traffic, a traveler should allow a total of 24 minutes to ensure on-time arrival 95 percent of the time.

$$
\text { Planning Time Index }=\frac{95 \text { th Percentile Travel Time }(\mathrm{min})}{\text { Free Flow Travel Time }(\mathrm{min})}
$$

Prior research has analyzed congestion and percent congested travel as a performance metric (Cambridge Systematics, 2004). Congestion occurs when a transportation facility experiences higher levels of delay or inconvenience than is deemed acceptable (Meyer, 1998). Delay is defined as the difference between actual travel time and free flow travel time. The amount of delay considered acceptable varies between facility classifications (freeway vs. arterial) and municipalities. In this thesis, the term “congestion" qualitatively describes segments experiencing high traffic densities as well as substantial delays during the designated time period. 


\subsection{Modeling Travel Time}

\subsubsection{Mean Travel Time}

Travel times along a corridor that includes traffic signals can be impacted by intersection and queue delays, with degree of impact related to corridor characteristics. For example, the Highway Capacity Manual (HCM) calculates intersection delay using a ratio of effective green time to cycle length, degree of saturation, and lane group capacity (Transportation Research Board, 2010). Previous studies have identified vehicle-miles traveled (VMT) per lane-mile, driveway density, driveway density per through volume, signal density, signal coordination, and weighted average green time to cycle time for through direction as factors to a travel time estimation model. Light congestion is found to correlate strongly with VMT per lane-mile and weighted average green time, while moderate congestion shows a strong relationship with VMT per lane-mile, driveway density weighted by link through volume, weighted average green time, and signal coordination (Eisele, Zhang, Park, Zhang, \& Stensrud, 2011). Stepwise regression is often used to determine statistically significant variables in a model (NCSS, n.d.).

\subsubsection{Travel Time Variability}

To estimate travel time distributions, portions of the distribution can be attributed to normal, Weibull, and log-normal patterns. Normal distributions reflect travel times under most traffic conditions, Weibull distributions reflect congested traffic, and lognormal distributions reflect free-flow. Previous studies have found variances in what portions can be attributed to each pattern (Li, Chai, \& Tang, 2013).

Variability can be estimated with reliability models. Gamma density functions, which skew to the right, are often an adequate fit for travel time distributions on arterials. 
Gamma density function parameters $\kappa$ and $\lambda$ are estimated with regression based on known data. The theoretical $\kappa$ is then found for each segment using the following equation:

$$
\kappa=\lambda * \mu
$$

Average travel times, $\mu$, can be estimated with several probe vehicles if not known. Precise travel times are not necessary, as the model was found to not be highly sensitive to travel time estimate error (Polus, 1979). The theoretical and actual $\kappa$ should be compared via cumulative distribution and a Kolmogorov-Smirnov (K-S) test (NIST Sematech, 2012). If statistically valid via $\mathrm{K}-\mathrm{S}$ test (O’Connor, 2012), reliability is then estimated with the following equation:

$$
R=\frac{\sqrt{\lambda}}{\sqrt{\mu}}
$$

This equation is validated to the true reliability, given by the inverse of standard deviation:

$$
R=\frac{1}{\sigma}
$$

Prior studies have found $\mathrm{R}^{2}$ for this method to be near 0.37 (Polus, 1979).

\subsection{Summary of Literature Review}

The low cost per-datum for Bluetooth makes it a viable option for vast and comprehensive data sets. With consideration to known sources of error and Bluetooth functionality, data sets can be processed to provide reliable travel time information, to compare multiple transportation modes, and to build travel time models. This literature review guides the subsequent research design and methodology, and provides insights and explanations to the results and conclusions. 


\section{RESEARCH DESIGN}

\subsection{Study Area}

To better understand the study area and data collection, the following figures and sections summarize existing conditions and future plans for the roadways and surrounding land uses.

Figure 3 shows the study roadway, where the thickness of Los Osos Valley Road indicates the number of lanes; the thinnest section has one lane in each direction, the medium section has two lanes in each direction, and the thickest section has three lanes in each direction. Intersecting roadways are labeled, signalized intersections are identified, and extents of construction that was underway during data collection are shown. Figure 4 shows bicycle and pedestrian facilities. Figure 5 shows transit routing (City of San Luis Obispo, 2013). Figure 6 shows existing land uses and future development areas.

BlueMAC devices were placed along Los Osos Valley Road at the intersections of Foothill Boulevard, Laguna, Lane, Madonna Road, Calle Joaquin, and South Higuera Street. Figure 7 shows BlueMAC device locations and distances between BlueMAC devices. Devices were placed at these locations due to the heavy amounts of vehicles entering and exiting the corridor at these intersections. Devices were installed on traffic signal poles by City of San Luis Obispo staff. Figure 8 shows the BlueMAC device at Madonna Road. 


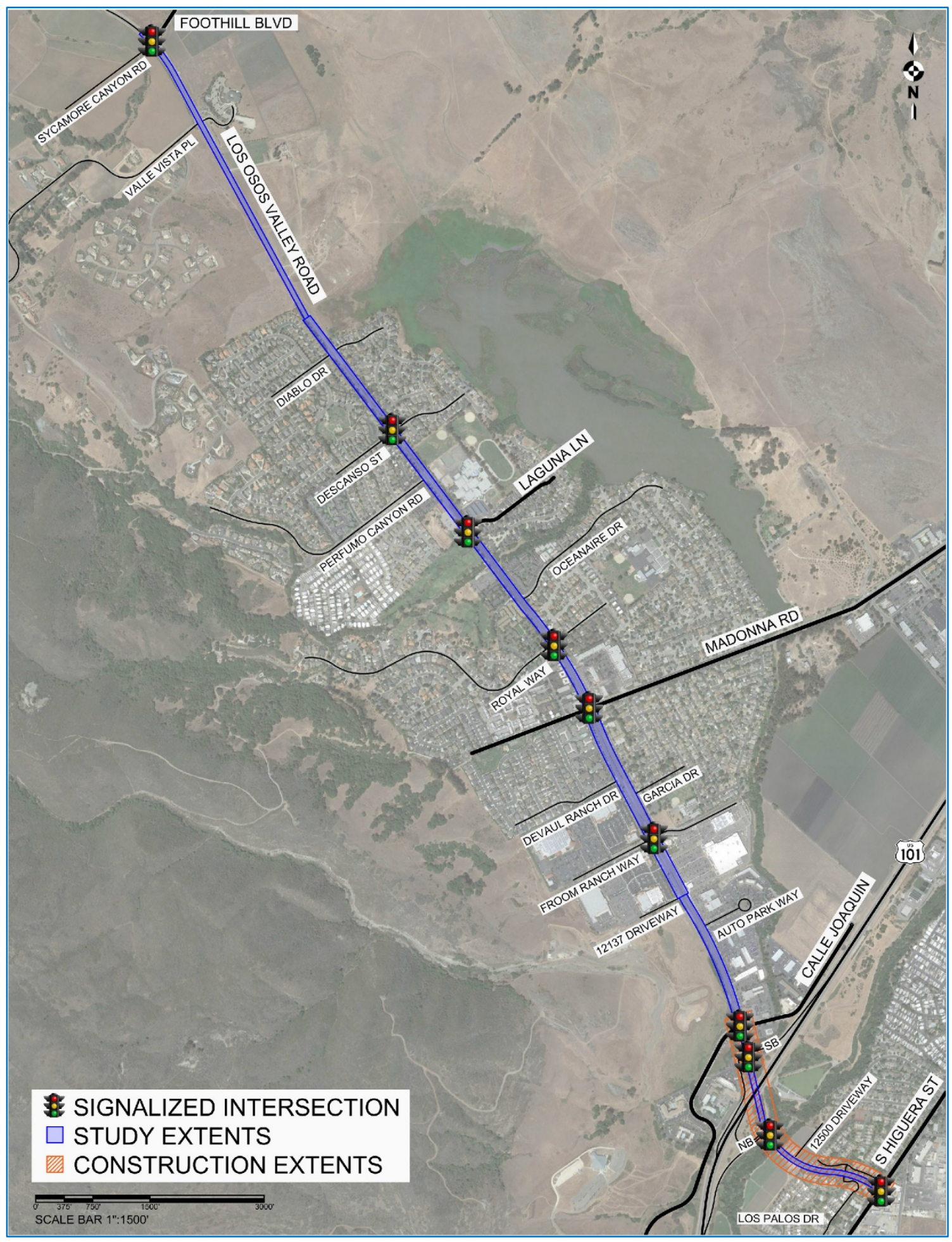

Figure 3: Los Osos Valley Road Overview 


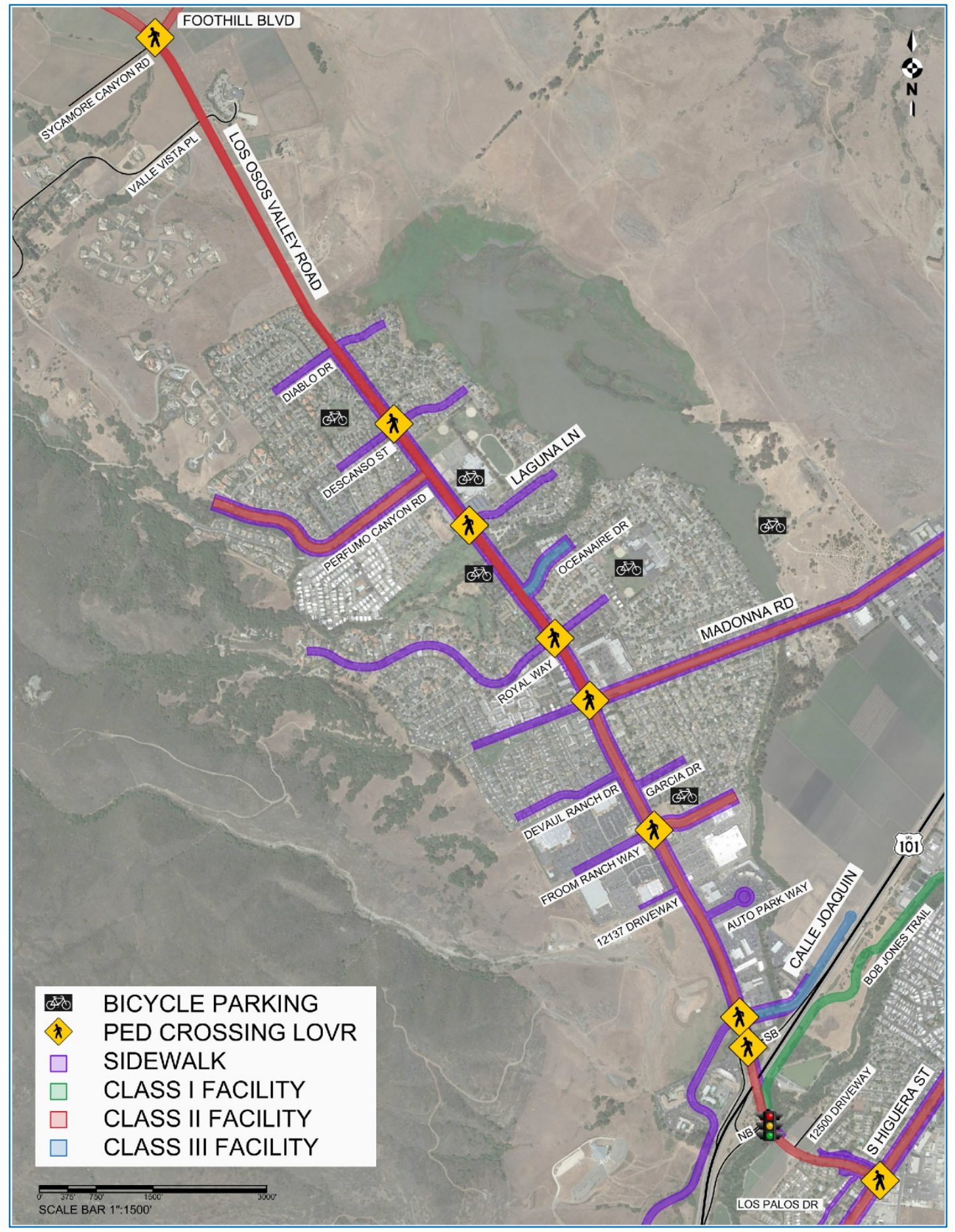

Figure 4: Bicycle and Pedestrian Facilities on Los Osos Valley Road 


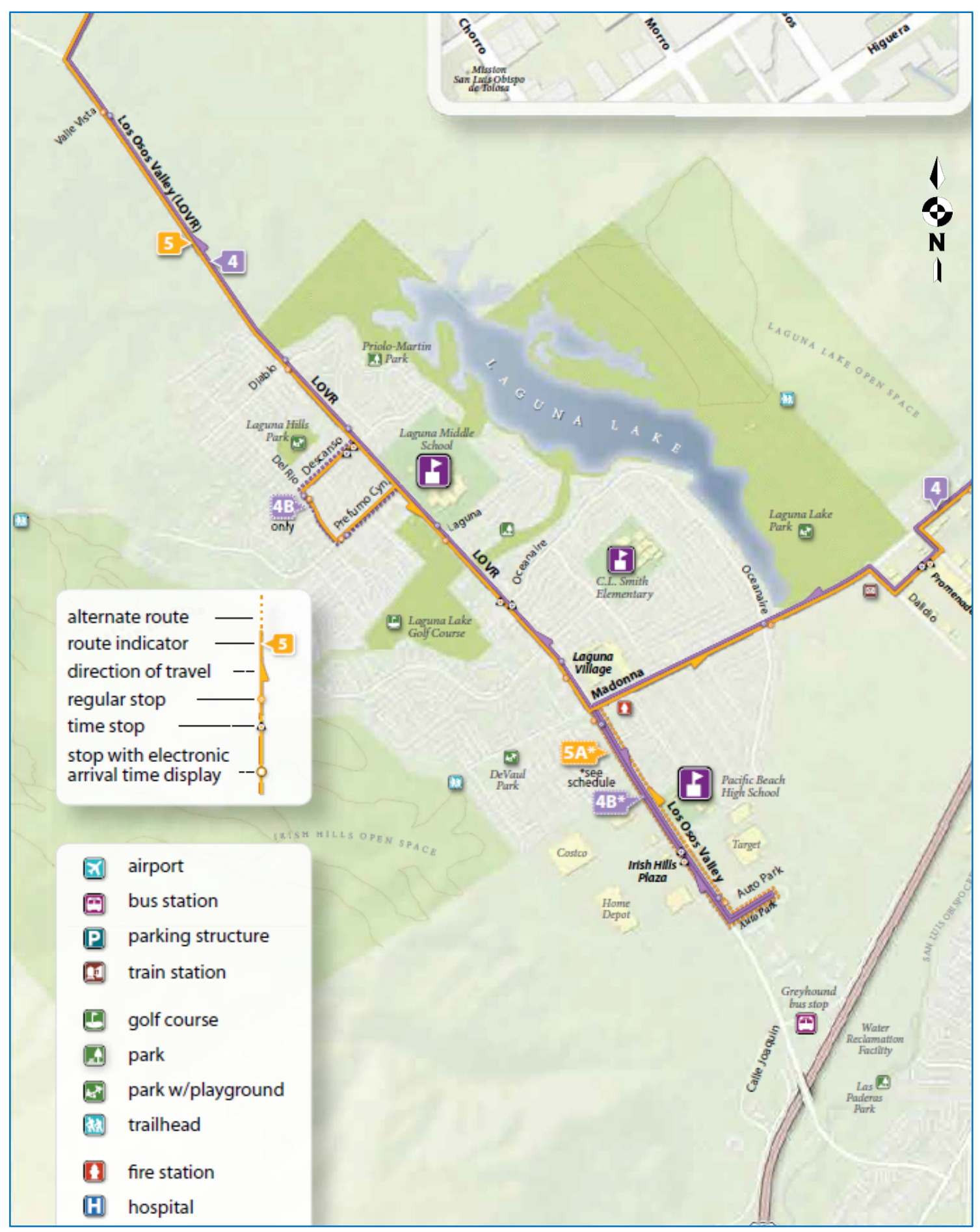

Figure 5: SLO Transit on Los Osos Valley Road 


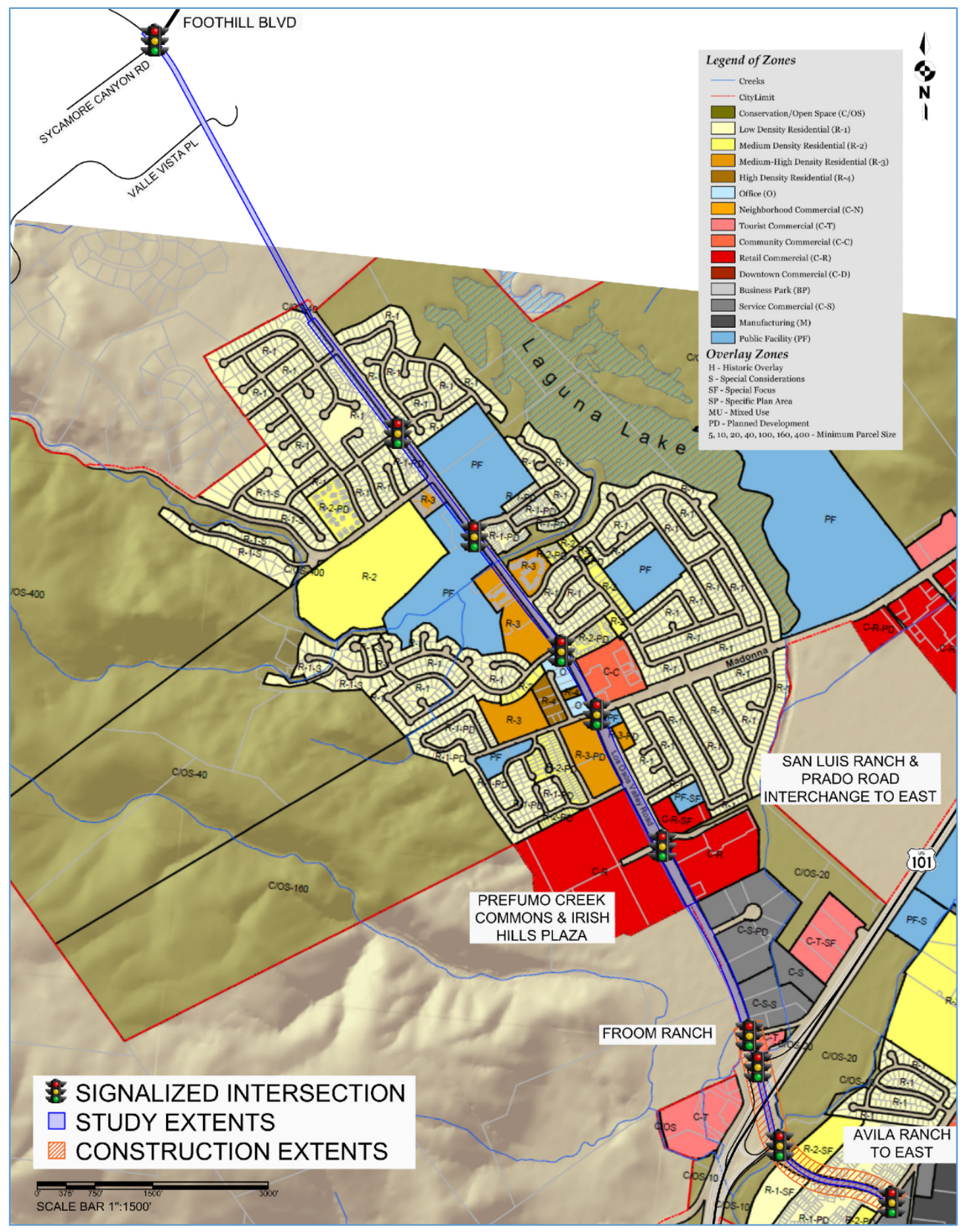

Figure 6: Existing and Future Land Uses 


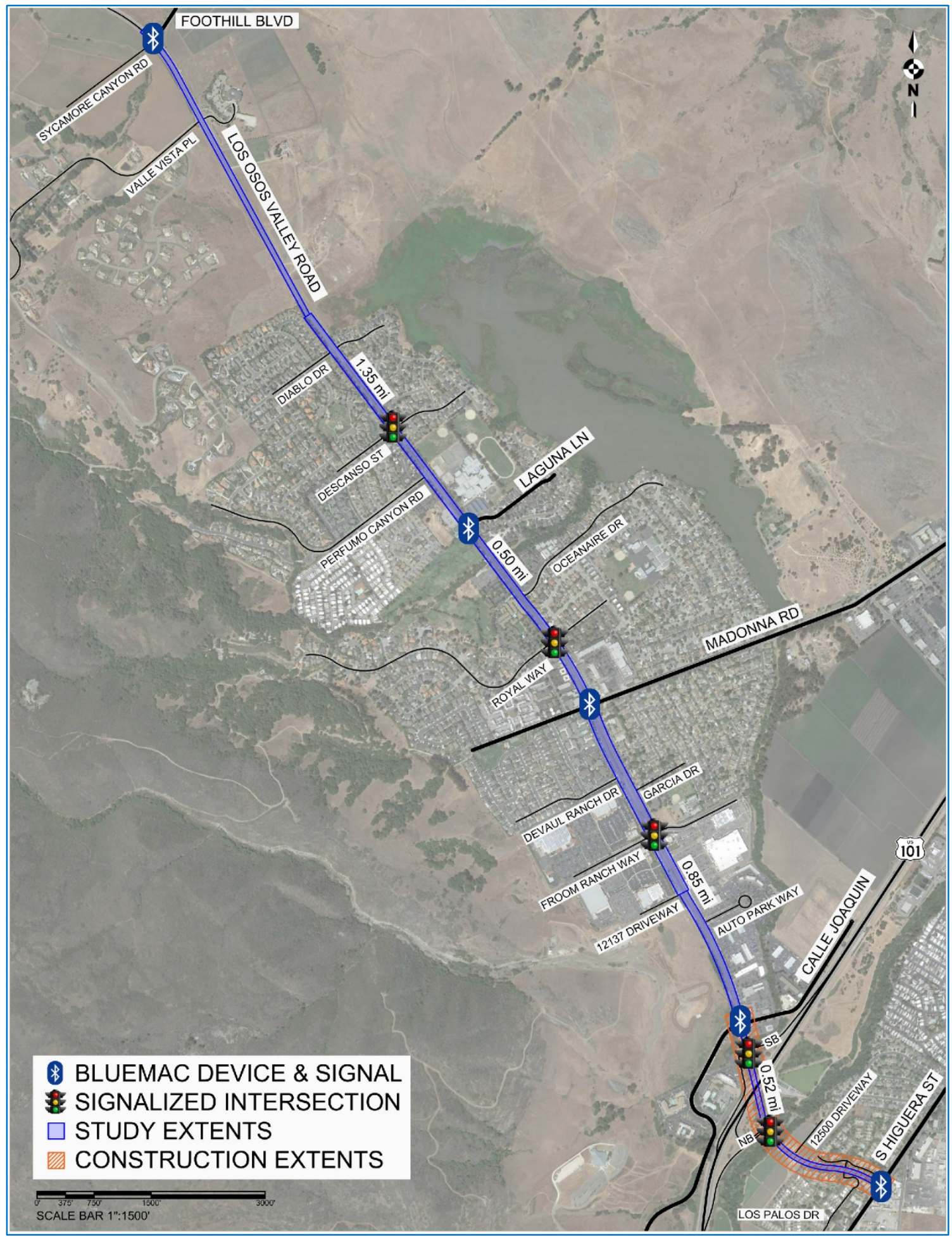

Figure 7: BlueMAC Device Locations 


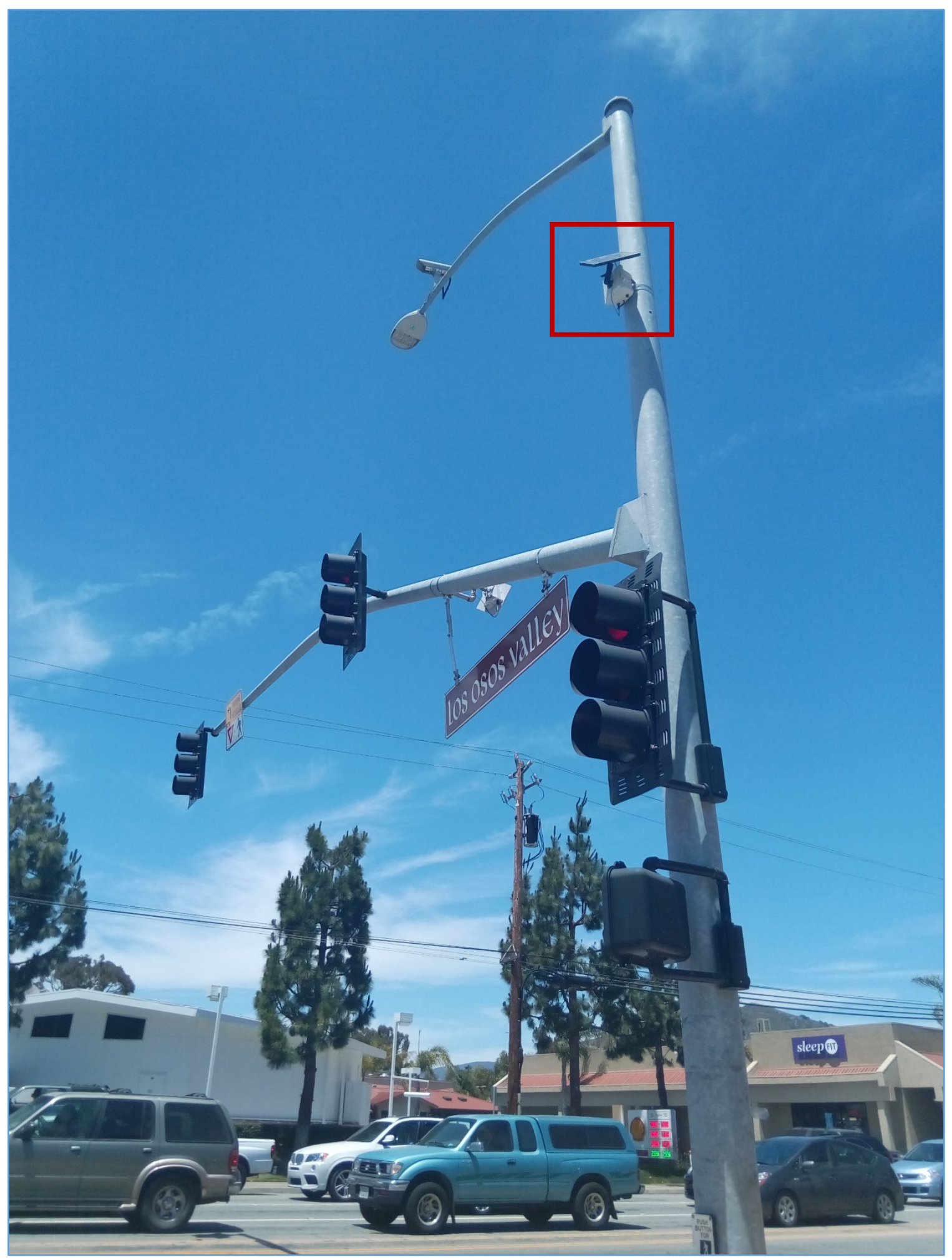

Figure 8: BlueMAC Device at Madonna Road 


\subsubsection{Study Segments}

Los Osos Valley Road ranges from two to six lanes in the study area, as indicated by the line thickness in Figure 3. The City of San Luis Obispo classifies Los Osos Valley Road as an arterial from Foothill Boulevard to Madonna Road and Calle Joaquin to South Higuera Street and as a parkway arterial from Madonna Road to Calle Joaquin. Los Osos Valley Road also serves as a designated Surface Transportation Assistance Act (STAA) truck route (City of San Luis Obispo, 2015).

Sidewalks are provided along most of the corridor, with no sidewalks provided from Diablo Drive to Foothill Boulevard, the west side of the roadway from the Froom Ranch Way shopping center to Los Palos Drive, or the east side of the roadway near the 12500 Los Osos Valley Road driveway. Sidewalks were closed near the Los Osos Valley Road and US 101 interchange during construction that was underway from October 2014 through March, 2016. The construction project involved widening Los Osos Valley Road in this section from two to four lanes, with the addition of a new bridge across US 101 and the associated modifications necessary for the freeway ramp terminals. Striped pedestrian crosswalks and pedestrian push buttons are provided along the roadway. The entirety of Los Osos Valley Road provides Class II bicycle facilities, which are standard painted bike lanes adjacent to the traveled lane. A portion of the Bob Jones Trail, a Class I bicycle and pedestrian trail connecting the City of San Luis Obispo to Avila Beach to the south, connects to Los Osos Valley Road near the US 101 Northbound ramps. Bicycle parking and changing locations at public facilities are provided at several points along the roadway. Bicycle lanes were closed near the US 101 interchange during construction, with temporary "Share the Road" signs provided instead (City of San Luis Obispo, 2013). 
San Luis Obispo Transit Routes 4 and 5 enter and exit the corridor on Foothill Boulevard and Madonna Road, turning around on the Auto Park Way spur, shown in Figure 5. Stops are provided at Los Osos Valley Road at Auto Park Way, Irish Hills, Madonna Road, Laguna Village, Oceanaire, Laguna Lane, Descanso Street, Diablo Drive, and Valley Vista. Both routes run on half-hour headways from 6:30 AM for both routes until 6:30 PM for Route 5 and 10:30 PM for Route 4 on weekdays and 8 AM to 6 PM on weekends and holidays (City of San Luis Obispo, 2013).

The aforementioned Los Osos Valley Road and US 101 interchange construction occurred between the BlueMAC detectors at Higuera Street and Calle Joaquin. One lane was required to be kept open in each direction. Upon completion in March 2016, the interchange provided two lanes in each direction.

Foothill Boulevard is two lanes in the study area. The City of San Luis Obispo classifies Foothill Boulevard as a Regional Route near Los Osos Valley Road. Foothill Boulevard intersects Los Osos Valley Road as a four-legged, signalized intersection with a channelized right-turn lane. Opposite the Foothill Boulevard approach is Sycamore Canyon Road, an unpaved roadway with minimal traffic entering or exiting (City of San Luis Obispo, 2015).

Sidewalks are not provided on this portion of Foothill Boulevard, though striped crosswalks with pedestrian push buttons are available on the south and east side of the intersection. The entirety of Foothill Boulevard provides Class II bicycle facilities. The Los Osos Valley Road bicycle lanes are striped green near the intersection, and the bicycle lane north of the intersection is identified as the Red Davis Bikeway (City of San 
Luis Obispo, 2013). SLO Transit Routes 4 and 5 enter and exit the Los Osos Valley Road corridor using Foothill Boulevard.

Laguna Lane is a two lane street in the study area. The City of San Luis Obispo classifies Laguna Lane as a local street. Laguna Lane meets Los Osos Valley Road as a signalized $\mathrm{t}$-intersection with two southbound left turn lanes and one southbound right turn lane (City of San Luis Obispo, 2015).

Sidewalks are provided near the intersection, as well as striped crosswalks on the east and north side of the intersection and pedestrian push buttons. A multiuse path is provided along Los Osos Valley Road from Laguna Lane to Oceanaire Drive. No bicycle facilities or transit stops are provided along Laguna Lane (City of San Luis Obispo, 2013).

Madonna Road is classified as a four lane arterial in the study area. Madonna Road meets with Los Osos Valley Road as a four-legged signalized intersection, providing a shared eastbound through and right lane, an eastbound left turn lane, two westbound right turn lanes, one shared westbound through and right lane, and a westbound left turn lane. Madonna Road also serves as a designated STAA truck route (City of San Luis Obispo, 2015).

Sidewalks are provided near the intersection, as well as pedestrian push buttons and striped crosswalks on all sides. The entirety of Madonna Road provides Class II bicycle facilities. Bicycle parking and changing locations at public facilities are provided at several points along the roadway (City of San Luis Obispo, 2013). SLO Transit Routes 4 and 5 enter and exit the Los Osos Valley Road corridor using Madonna Road. 
Calle Joaquin is classified as a two lane local road in the study area. Calle Joaquin meets with Los Osos Valley Road as a four-legged signalized intersection, providing one eastbound left turn lane, one eastbound through lane, one channelized eastbound right turn lane, one westbound left turn lane, and one shared westbound through and right lane. Though not designated as an STAA truck route, Calle Joaquin served as a temporary off-ramp during the US 101 interchange construction and carried trucks to the route on Los Osos Valley Road (City of San Luis Obispo, 2015).

Sidewalks are provided near the intersection, as well as pedestrian push buttons and striped crosswalks on all sides. Calle Joaquin provides Class III bicycle facilities (Bike Route, shared use with motor vehicle traffic), though the higher speeds and higher traffic volumes during interchange construction may have shifted bicycle patterns on the roadway (City of San Luis Obispo, 2013). No transit stops are provided along Calle Joaquin.

South Higuera Street is two lanes south and four lanes north of the intersection with Los Osos Valley Road and is classified as an arterial. South Higuera Street meets with Los Osos Valley Road as a signalized t-intersection, with one northbound left turn lane, one northbound through lane, one southbound through lane, and one southbound right turn lane. Higuera Street also serves as a designated STAA truck route (City of San Luis Obispo, 2015).

Sidewalks are provided near the intersection, as well as pedestrian push buttons and striped crosswalks on the west and south side. The entirety of South Higuera Street provides Class II bicycle facilities. Bicycle parking and changing locations at public facilities are provided at several points along the roadway (City of San Luis Obispo, 
2013). Regional Transit Authority Route 10 runs north and south on South Higuera Street.

\subsubsection{Surrounding Land Uses \& Future Development}

The City of San Luis Obispo Zoning Map shows high amounts of residential and commercial land uses along the Los Osos Valley Road corridor. Housing density ranges from low to high and commercial uses from neighborhood to big-box retail. Several office developments, public parks, and open space are also located along the roadway.

Los Osos Valley Road is poised for future growth. Recent developments include the Prefumo Creek Commons and Irish Hills Plaza, which have increased traffic flows in the area. Completion of the US Highway 101/ Los Osos Valley Road interchange widening project in March 2016 provides two lanes in each direction and improves ramp intersection operations.

Potential future development and network changes include San Luis Ranch, the Prado Road Interchange, Froom Ranch, and Avila Ranch. San Luis Ranch, Froom Ranch, and Avila Ranch are proposed developments with varying levels of commercial and residential land uses. San Luis Ranch, adjacent to Madonna Road, would potentially occur alongside a future US 101 interchange with Prado Road, and provide alternative routes in the Los Osos Valley Road region of the City. Froom Ranch, proposed to the north of Calle Joaquin and west of Los Osos Valley Road, may increase traffic flows in the area or alter access along Los Osos Valley Road. Avila Ranch, adjacent to South Higuera Street, may increase traffic flows near the southern end of the study area. 


\subsection{Data Collection}

\subsubsection{BlueMAC Sensitivity}

According to the BlueMAC manufacturer, DigiWest, the effective range of the BlueMAC device is estimated by the following calculation:

$$
\begin{gathered}
\text { Responding device Tx power }(\mathrm{dBm})+\text { antenna gain }(\mathrm{dBi}) \text {-free space loss }(\mathrm{dB})-\text { fade } \\
\text { margin }(\mathrm{dB})+\text { BlueMAC antenna gain }(\mathrm{dBi})-\text { cable loss }(\mathrm{dB})+\text { device Rx sensitivity } \\
(\mathrm{dBm})>0
\end{gathered}
$$

Antenna gain and cable loss for the detected devices in this study can be assumed negligible, as virtually all devices have embedded chip antennas and no cables. Thus, the equation becomes:

$$
\begin{aligned}
& \text { Responding device Tx power }(\mathrm{dBm}) \text { - free space loss }(\mathrm{dB}) \text {-fade margin }(\mathrm{dB})+ \\
& \text { BlueMAC antenna gain }(\mathrm{dBi})-\text { cable loss }(\mathrm{dB})+\text { device Rx sensitivity }(\mathrm{dBm})>0
\end{aligned}
$$

The BlueMAC devices have $20 \mathrm{dBm}$ power, equivalent to a Tx Power of $19 \mathrm{dBm}$. A fade margin is applied to account for physical obstructions or network noise, with 11 $\mathrm{dB}$ being industry-standard for reliability (Cameron, 2013). The BlueMAC devices use a standard antenna, which provides a $+2.14 \mathrm{dBi}$ gain, and typical cable loss is $1.5 \mathrm{~dB}$ (Cameron, 2013). Device sensitivity averages $83 \mathrm{dBm}$ across the study period. Lastly, the free space loss is calculated in terms of distance from the BlueMAC device. The BlueMAC manufacturer calculates free space loss using the following formula:

Free Space Loss $=20 \times \log 10($ Frequency in MHz) $+20 \times \log 10$ (Distance in Miles) + 36.6

Bluetooth runs on a $2.4 \mathrm{GHz}$, or $2400 \mathrm{MHz}$, frequency. The furthest point in any study intersection from a BlueMAC device is 160 feet. Using 175 feet, or 0.033 miles, to be conservative, the free space loss would be $74.6 \mathrm{~dB}$. 
The resulting equation is as follows:

$$
\begin{gathered}
19-74.6-11+2.14-1.5+83>0 \\
28.0>0
\end{gathered}
$$

The BlueMAC devices have more than enough signal strength to reliably detect Bluetooth devices at the intersections, creating a clear picture of the corridor.

\subsubsection{BlueMAC Data Collection}

The BlueMAC devices were stationed along Los Osos Valley Road at intersections with Foothill Boulevard, Laguna Lane, Madonna Road, Calle Joaquin, and South Higuera Street. Figure 7 shows the detector locations, distances between BlueMAC devices, and mid-study segment signal locations. BlueMAC devices were set to collect continuous data in January and February of 2016, for 60 days' worth of collection. An example of the data between BlueMAC devices at Madonna Road and Calle Joaquin is

\begin{tabular}{|c|c|c|c|c|}
\hline Start Time & End Time & MAC & Travel Time $(\mathrm{s})$ & Speed(mph) \\
\hline 1/1/2016 0:09 & 1/1/2016 0:10 & 407B81 & 62 & 30.3 \\
\hline 1/1/2016 0:19 & 1/1/2016 0:20 & B7CF8C & 77 & 24.4 \\
\hline $1 / 1 / 20160: 28$ & $1 / 1 / 20160: 30$ & $59906 C$ & 109 & 17.2 \\
\hline 1/1/2016 0:44 & $1 / 1 / 20160: 45$ & F3E489 & 87 & 21.6 \\
\hline 1/1/2016 0:48 & $1 / 1 / 20160: 49$ & 68EAA8 & 99 & 19 \\
\hline $1 / 1 / 20160: 56$ & $1 / 1 / 20160: 58$ & BE8A5B & 67 & 28 \\
\hline 1/1/2016 1:17 & 1/1/2016 1:18 & $6 C 6175$ & 80 & 23.5 \\
\hline
\end{tabular}
shown in Figure 9.

Figure 9: BlueMAC Raw Data Example

Over 100,000 unique trips were detected. The number of intersections at which Bluetooth devices were detected is shown in Figure 10. 


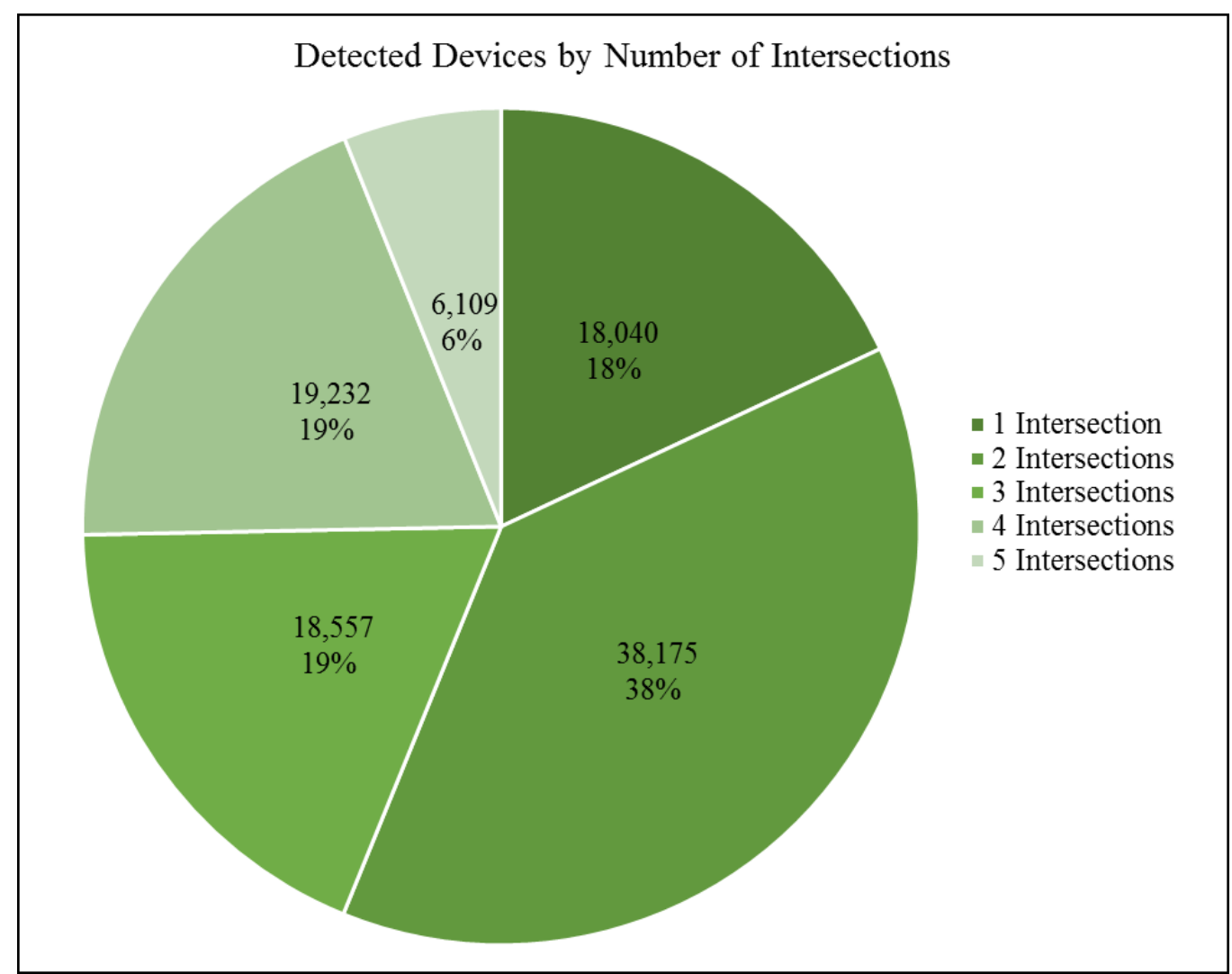

Figure 10: Devices Detected by Number of Intersections

A total of 13 days of data collection, $22 \%$ of the study period, had missing segments of data. BlueMAC device at South Higuera Street did not collect data from January 18 at 1:00 AM to January 21 at 9:00 AM due to low battery voltage. BlueMAC device at Calle Joaquin did not collect data from January 19 at 8:00 PM to January 21 at 11:00 AM due to low battery voltage. BlueMAC device at Laguna Lane was unavailable from February 22 at 11:00 AM through the end of February (end of study) for unknown reasons. Despite these small gaps, a robust sample size was available for analysis.

Detection rates for each study segment, direction, and peak period are shown in Table 1 and Figure 11. Data points reflect AM, MID, and PM peak hour volumes versus the average detected devices during that weekday peak hour, averaged over the January 2016 to February 2016 study period and eliminating holidays. Note that these data are for 
Bluetooth devices detected at two BlueMAC locations versus the City of San Luis Obispo's 2014 segment counts, and thus ignore vehicles entering or exiting midsegment. The overall detection rate is $5.7 \%$.

\begin{tabular}{|c|c|c|c|c|}
\hline \multirow{2}{*}{ Segment } & \multirow{2}{*}{ Direction } & \multicolumn{3}{|c|}{ Hourly Detected Devices/Hourly Traffic Count } \\
\hline & & $\mathrm{AM}$ & MID & PM \\
\hline \multirow{2}{*}{ Calle Joaquin-Higuera } & Northbound & $26 / 482$ & $45 / 822$ & $47 / 1042$ \\
\hline & Southbound & $47 / 930$ & $39 / 786$ & $37 / 767$ \\
\hline \multirow{2}{*}{ Madonna-Calle Joaquin } & Northbound & $32 / 659$ & $41 / 1041$ & $52 / 1353$ \\
\hline & Southbound & $45 / 839$ & $44 / 956$ & $39 / 1022$ \\
\hline \multirow{2}{*}{ Laguna-Madonna } & Northbound & $47 / 721$ & $50 / 776$ & $74 / 1218$ \\
\hline & Southbound & $73 / 1099$ & $54 / 794$ & $58 / 876$ \\
\hline \multirow{2}{*}{ Foothill-Laguna } & Northbound & $44 / 615$ & $50 / 655$ & $67 / 949$ \\
\hline & Southbound & $59 / 786$ & $53 / 646$ & $57 / 735$ \\
\hline \multicolumn{2}{|l|}{ Detection } & \multicolumn{3}{|c|}{$5.7 \%$} \\
\hline
\end{tabular}

Table 1: Detection Rates by Segment, Direction, and Peak Period 


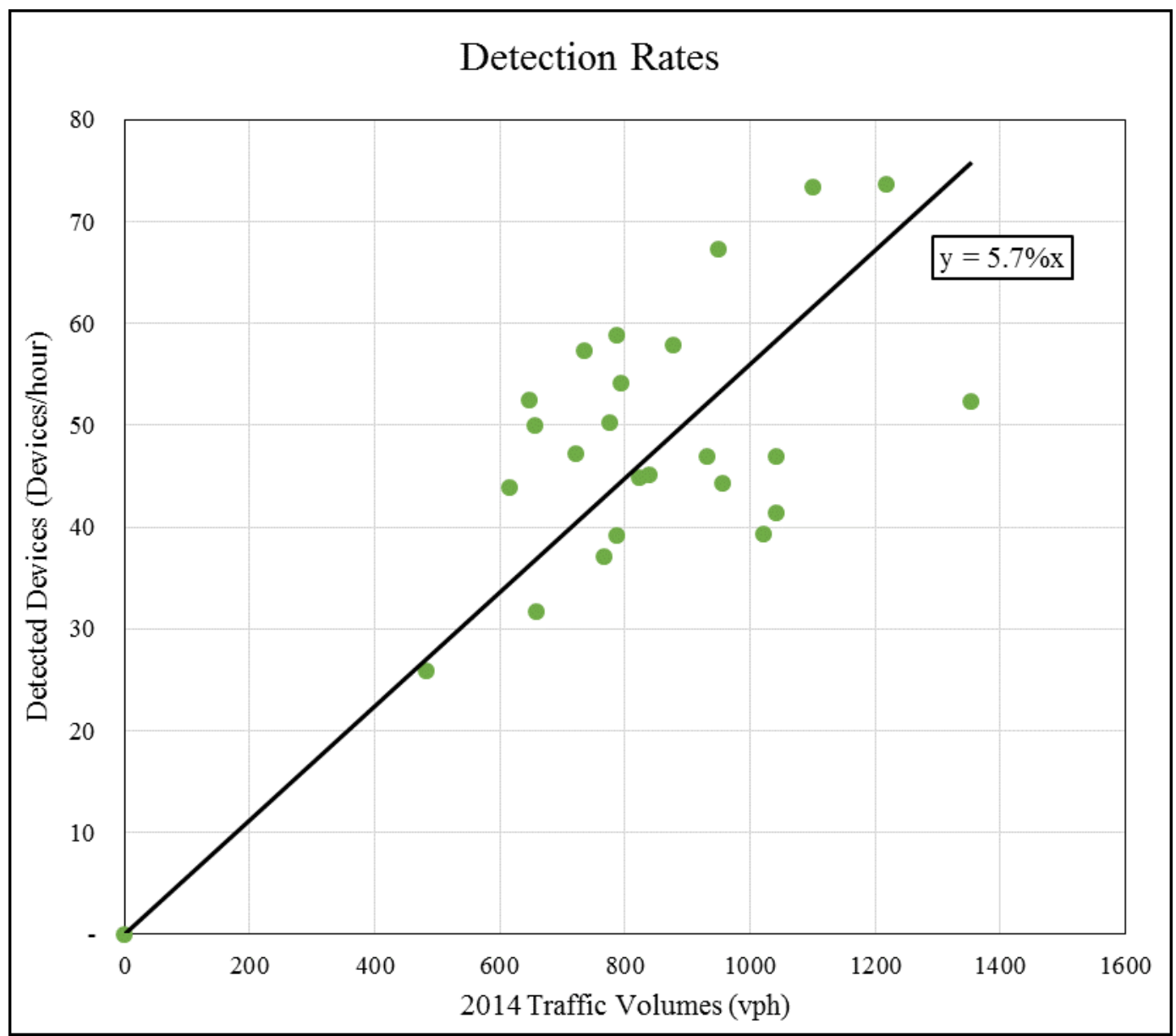

Figure 11: BlueMAC Detection Rates

Several sources of error for computing travel time would include occasions when vehicles turn off of the roadway into a driveway or side street or the presence of multiple devices in the same vehicle. This includes vehicles that stopped mid-segment at businesses, residences, or other destinations before continuing along Los Osos Valley Road. Multiple Bluetooth devices may be detected from the same personal or transit vehicle along the route. For example, a driver may have a Bluetooth-enabled smart phone, tablet, laptop, headset and in-dash entertainment or navigation unit. As the corridor serves multimodal trips, several detected trips may be bicyclists or pedestrians. However, the detectors are unable to distinguish between trip modes and thus could not draw conclusive results regarding pedestrian or bicycle travel with Bluetooth data. Along 
the corridor, several parking lots and gas stations within the detector range and could have skewed travel time data. For example, Figure 12 shows the BlueMAC location and standard 300-foot probable detection radius at the intersection of Madonna Road and Los Osos Valley Road. A vehicle at the gas station on the northern edge of the intersection may be continuously detected as being stopped at the intersection, and thus skew travel time data.

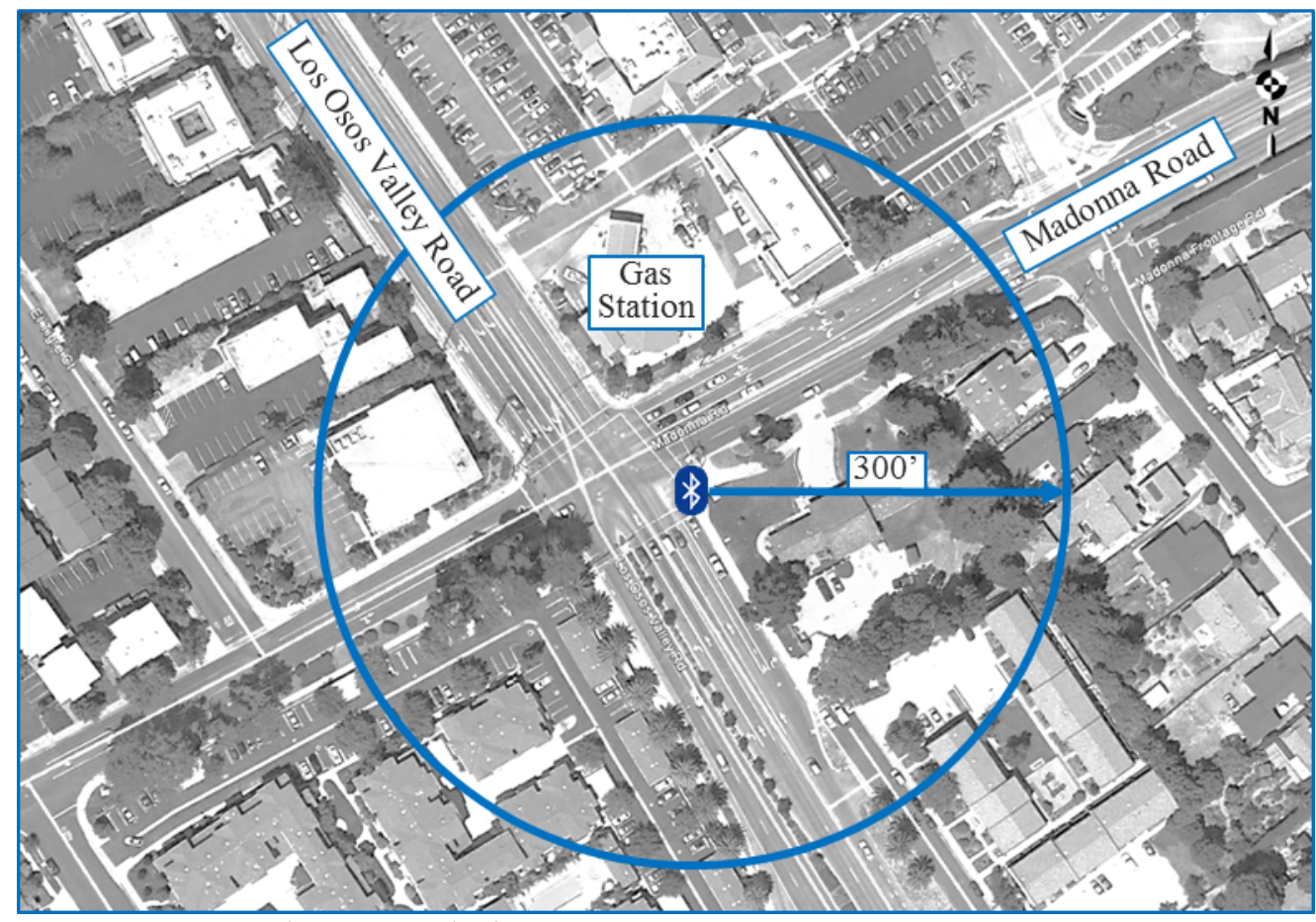

Figure 12: Madonna Road BlueMAC Detection Range

Aside from the ongoing construction at the US 101/ Los Osos Valley Road interchange, no other construction projects were underway along the corridor. Neither incident nor crash data were available for the data collection time frame.

Of the 60 days during January and February 2016 data collection, 15 days had precipitation, with 10 days having more than 0.1 inches of rain. No severe weather conditions were reported during the study period (Weather History for KSBP, 2016). 


\subsubsection{GPS Probes}

Twelve probe runs were completed on the corridor during the weekday PM peak period in an automobile and two probe runs were completed during the off-peak period on a bicycle and tracked with the GPS tracking application "Geo Tracker." Geo Tracker recorded probe runs for comparison to BlueMAC-collected data. An example of the Geo Tracker data is shown in Figure 13.

\begin{tabular}{|l|r|r|r|r|r|r|r|}
\hline type & \multicolumn{1}{|c|}{ Day } & Time & Latitude & Longitude & Altitude $(\mathrm{m})$ & Speed $(\mathrm{km} / \mathrm{hr})$ & Distance $(\mathrm{km})$ \\
\hline $\mathrm{T}$ & $2 / 25 / 2016$ & $12: 28: 52 \mathrm{AM}$ & 35.24 & $(120.67)$ & 4.00 & & \\
\hline $\mathrm{T}$ & $2 / 25 / 2016$ & $12: 28: 54 \mathrm{AM}$ & 35.24 & $(120.67)$ & 4.00 & 31.40 & 0.02 \\
\hline $\mathrm{T}$ & $2 / 25 / 2016$ & $12: 28: 55 \mathrm{AM}$ & 35.24 & $(120.67)$ & 3.00 & 34.70 & 0.03 \\
\hline $\mathrm{T}$ & $2 / 25 / 2016$ & $12: 28: 57 \mathrm{AM}$ & 35.24 & $(120.67)$ & 3.00 & 35.10 & 0.05 \\
\hline $\mathrm{T}$ & $2 / 25 / 2016$ & $12: 28: 59 \mathrm{AM}$ & 35.24 & $(120.67)$ & 3.00 & 33.80 & 0.07 \\
\hline $\mathrm{T}$ & $2 / 25 / 2016$ & $12: 29: 01 \mathrm{AM}$ & 35.24 & $(120.67)$ & 4.00 & 30.00 & 0.08 \\
\hline $\mathrm{T}$ & $2 / 25 / 2016$ & $12: 29: 03 \mathrm{AM}$ & 35.24 & $(120.67)$ & 5.00 & 22.70 & 0.10 \\
\hline
\end{tabular}

Figure 13: Geo Tracker Raw Data Example

Automobile probe runs captured the entire corridor, from South Higuera Street to and from Foothill Boulevard. At 95\% confidence, the automobile probe runs yielded a maximum error of $3.07 \mathrm{mph}$, within acceptable range. Bicycle probe runs captured most of the corridor, from Madonna Road to and from Foothill Boulevard. The bicycle probe runs yielded a maximum error of $1.03 \mathrm{mph}$ at $95 \%$ confidence, though no acceptable range is established for bicycle data. GPS data were recorded at 1-2 second intervals.

\subsubsection{Transit Data}

San Luis Obispo Transit uses GPS to track their fleet and stores historical data to evaluate system performance. Historical GPS data of routes 4 and 5, which run along the Los Osos Valley Road corridor, were provided by the Transit app developers, Bishop's Peak Technology, for the range of February 20, 2016 to March 8, 2016. Collection 
software provides longitude and latitude, vehicle ID, route ID, time stamps, and minutes late from schedule. Transit data were recorded at 15 second intervals.

\subsection{Configuration Tests}

\subsubsection{Automobile}

Probe runs in an automobile were conducted along the corridor during the weekday PM peak hour on February 18 and February 24, 2016, with three northbound trips and three southbound trips across the entire corridor each day, for a total of twelve trips. In addition to the Geo Tracker application using GPS to collect travel times along the corridor, a Bluetooth device with a known MAC address in the probe automobile was enabled to compare GPS times to BlueMAC detection times. Table 2 summarizes the probe automobile runs.

\begin{tabular}{|c|c|c|c|c|c|c|}
\hline $\begin{array}{c}\text { Trial } \\
\text { Run }\end{array}$ & Direction & Date & $\begin{array}{c}\text { Start } \\
\text { Time }\end{array}$ & $\begin{array}{c}\text { Foothill-Higuera } \\
\text { Travel Time } \\
(\mathrm{mm}: \mathrm{ss})\end{array}$ & $\begin{array}{c}\text { Mean Speed } \\
(\mathrm{mph})\end{array}$ & $\begin{array}{c}\text { Number } \\
\text { of Stops }\end{array}$ \\
\hline \hline 1 & Southbound & $2 / 18 / 16$ & $4: 20$ PM & $7: 24$ & 25.9 & 4 \\
\hline 2 & Northbound & $2 / 18 / 16$ & $4: 30$ PM & $11: 20$ & 16.8 & 7 \\
\hline 3 & Southbound & $2 / 18 / 16$ & $4: 44$ PM & $8: 30$ & 22.6 & 4 \\
\hline 4 & Northbound & $2 / 18 / 16$ & $4: 54$ PM & $8: 20$ & 23.0 & 4 \\
\hline 5 & Southbound & $2 / 18 / 16$ & $5: 04$ PM & $7: 43$ & 24.9 & 3 \\
\hline 6 & Northbound & $2 / 18 / 16$ & $5: 14$ PM & $11: 49$ & 16.2 & 8 \\
\hline 7 & Southbound & $2 / 24 / 16$ & $3: 35$ PM & $7: 04$ & 27.2 & 2 \\
\hline 8 & Northbound & $2 / 24 / 16$ & $3: 44$ PM & $8: 06$ & 23.7 & 4 \\
\hline 9 & Southbound & $2 / 24 / 16$ & $4: 01$ PM & $8: 04$ & 23.8 & 4 \\
\hline 10 & Northbound & $2 / 24 / 16$ & $4: 11$ PM & $7: 39$ & 25.1 & 5 \\
\hline 11 & Southbound & $2 / 24 / 16$ & $4: 21$ PM & $6: 35$ & 29.2 & 2 \\
\hline 12 & Northbound & $2 / 24 / 16$ & $4: 30$ PM & $5: 11$ & 37.0 & 1 \\
\hline
\end{tabular}

Table 2: Probe Automobile Runs

The raw GPS reports were first processed to cut off data beyond the Foothill Boulevard and South Higuera Street intersections, giving the travel times for the study area extents and nothing more. This data can be visualized as trajectories in a time-space 
diagram, with time on the $x$-axis, with distance on the $y$-axis. The GPS data for Trial Run \#7 is shown in Figure 14.

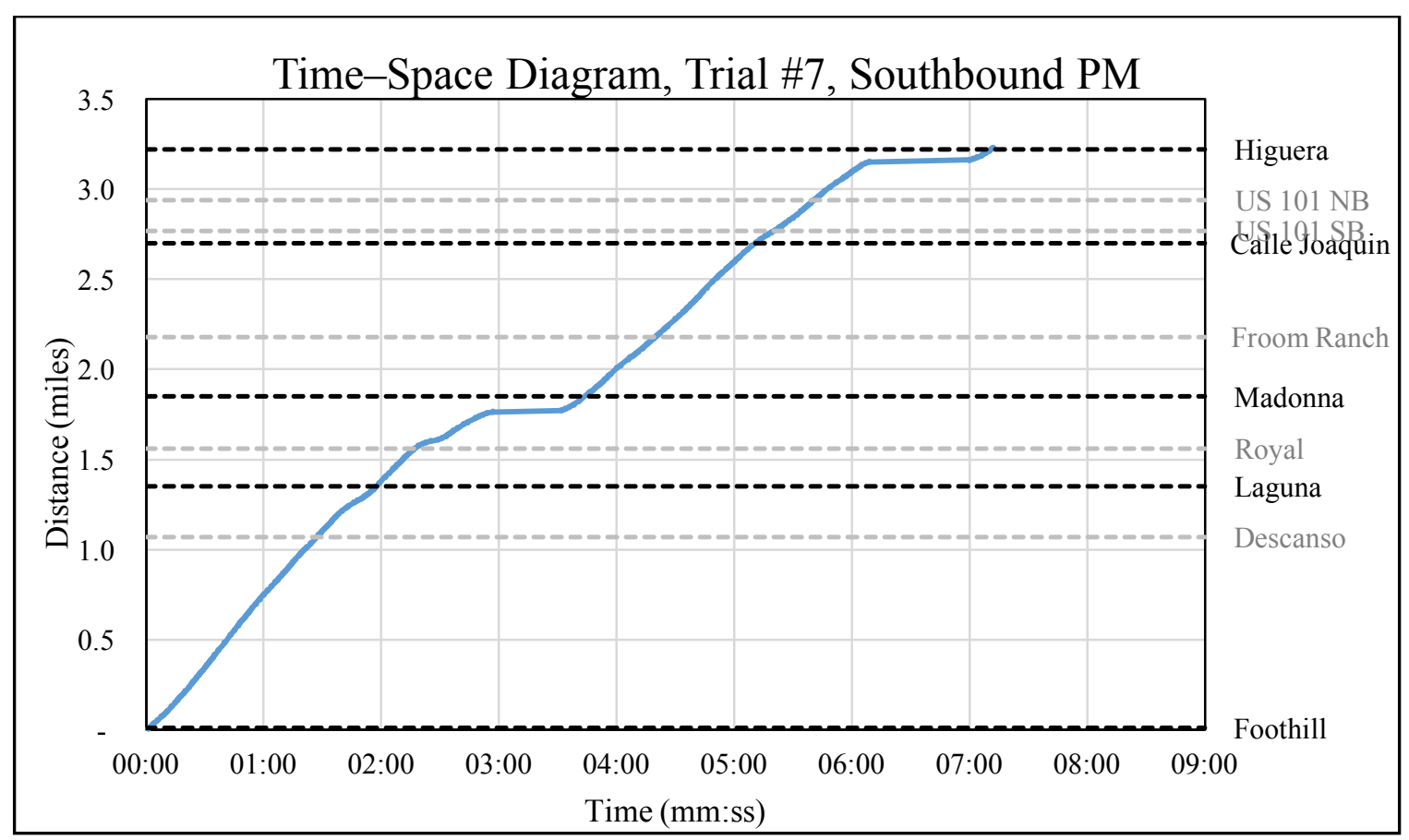

Figure 14: Automobile Run \#7 Time-Space Diagram

The slope of the line denotes the instantaneous speed (change in distance/change in time) of the automobile. Horizontal lines on the graph show where an automobile was stopped, such as at an intersection or in a queue. To validate BlueMAC accuracy, the automobile probes should be compared to the BlueMAC device data where possible.

For southbound, the personal Bluetooth device was not detected at the Foothill Boulevard nor the Laguna Lane detectors, meaning travel times were not calculated by BlueMAC for either Foothill Boulevard to Laguna Lane or Laguna Lane to Madonna Road. Trials 9 and 11 were only detected at Madonna Road, Calle Joaquin, and South Higuera. Figures 13 and 14 show these trial runs, with the BlueMAC-reported travel time overlaid. As the BlueMAC devices only detect the points of time an automobile passes each location, the automobile's movements in between devices are not known. Hence, 
one can only estimate devices' average speed across a segment, with no detail as to midsegment delay. This may be observed in Figures 15 and 16, with no mid-segment details for the BlueMAC data.

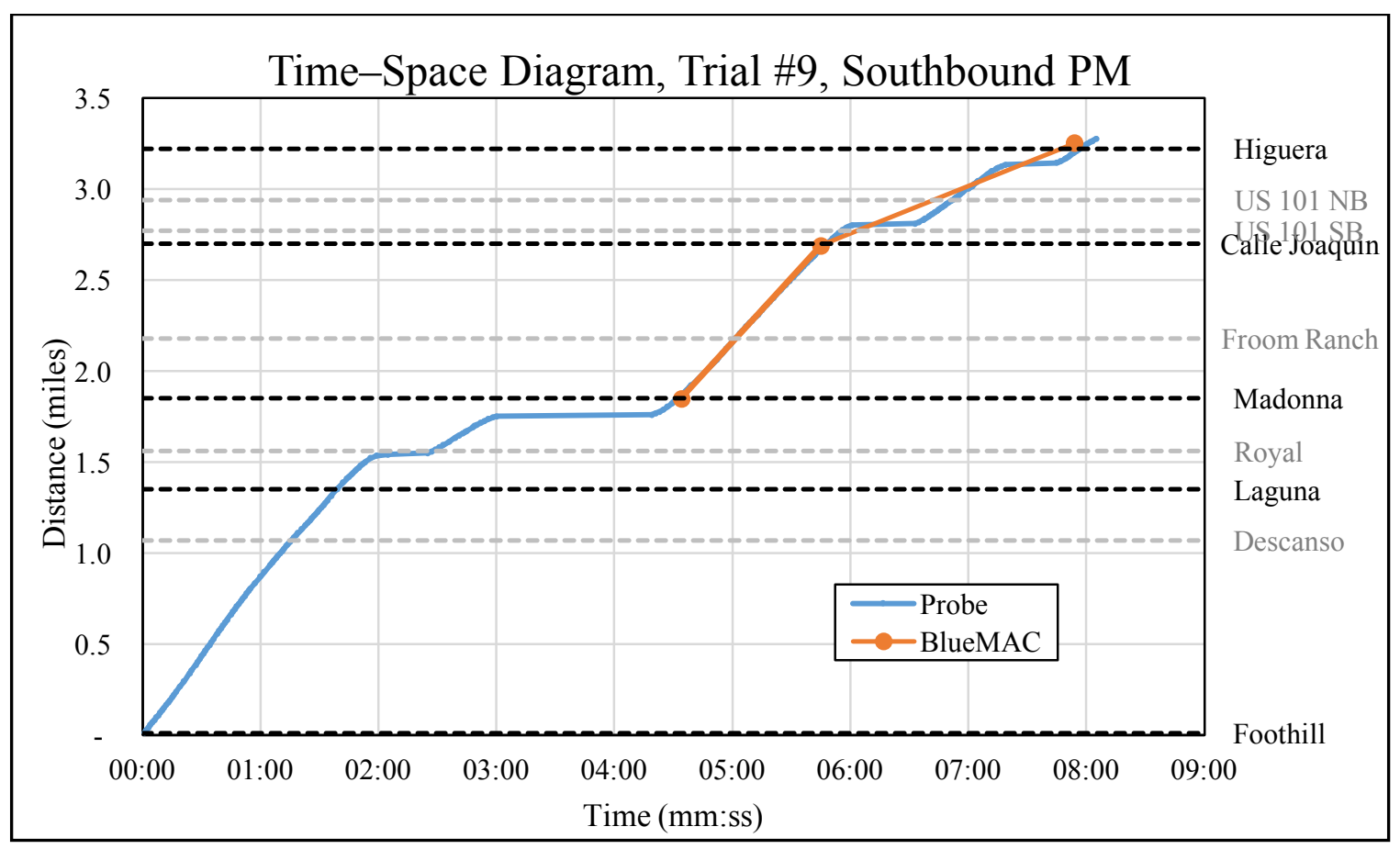

Figure 15: Automobile Run \#9 Time-Space Diagram

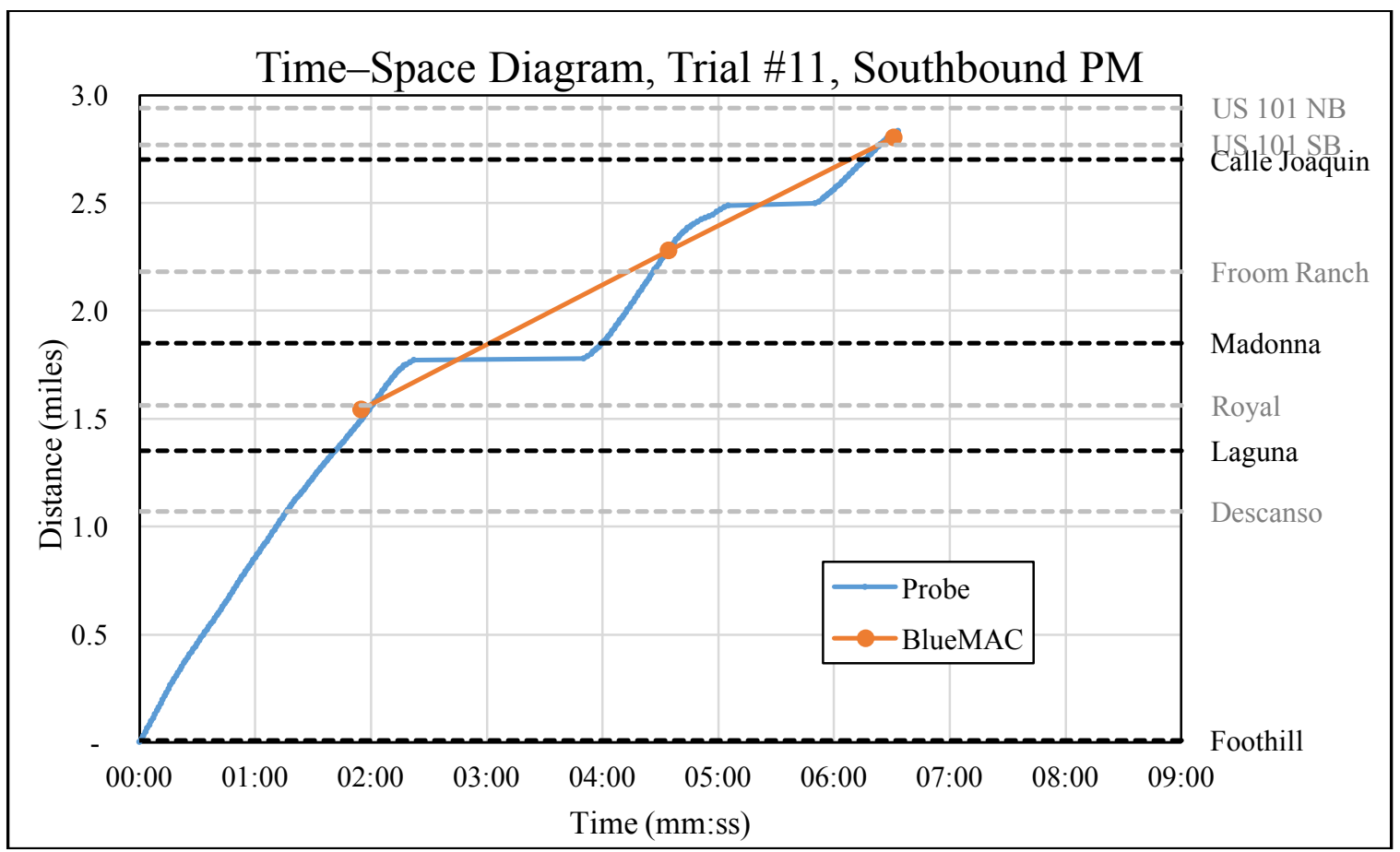

Figure 16: Automobile Run \#11 Time-Space Diagram 
For northbound, a similar detection issue occurred. The personal Bluetooth device was only detected at the South Higuera Street and Calle Joaquin detectors during Trial 10 and only detected at the South Higuera Street, Calle Joaquin, and Madonna Road detectors during Trial 12. Figures 17 and 18 show these trial runs, with BlueMACreported detection times and a connecting line overlaid.

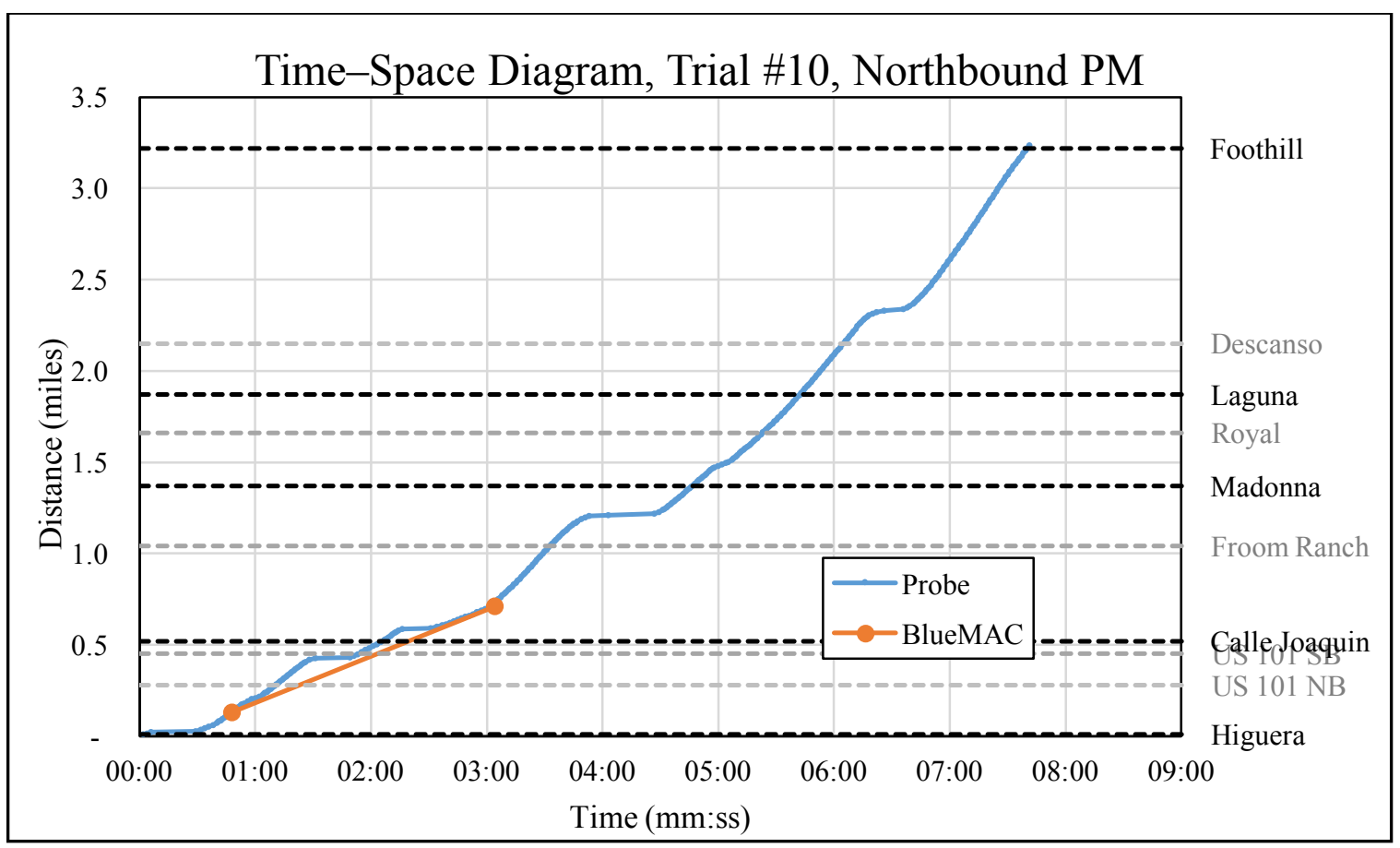

Figure 17: Automobile Run \#10 Time-Space Diagram 


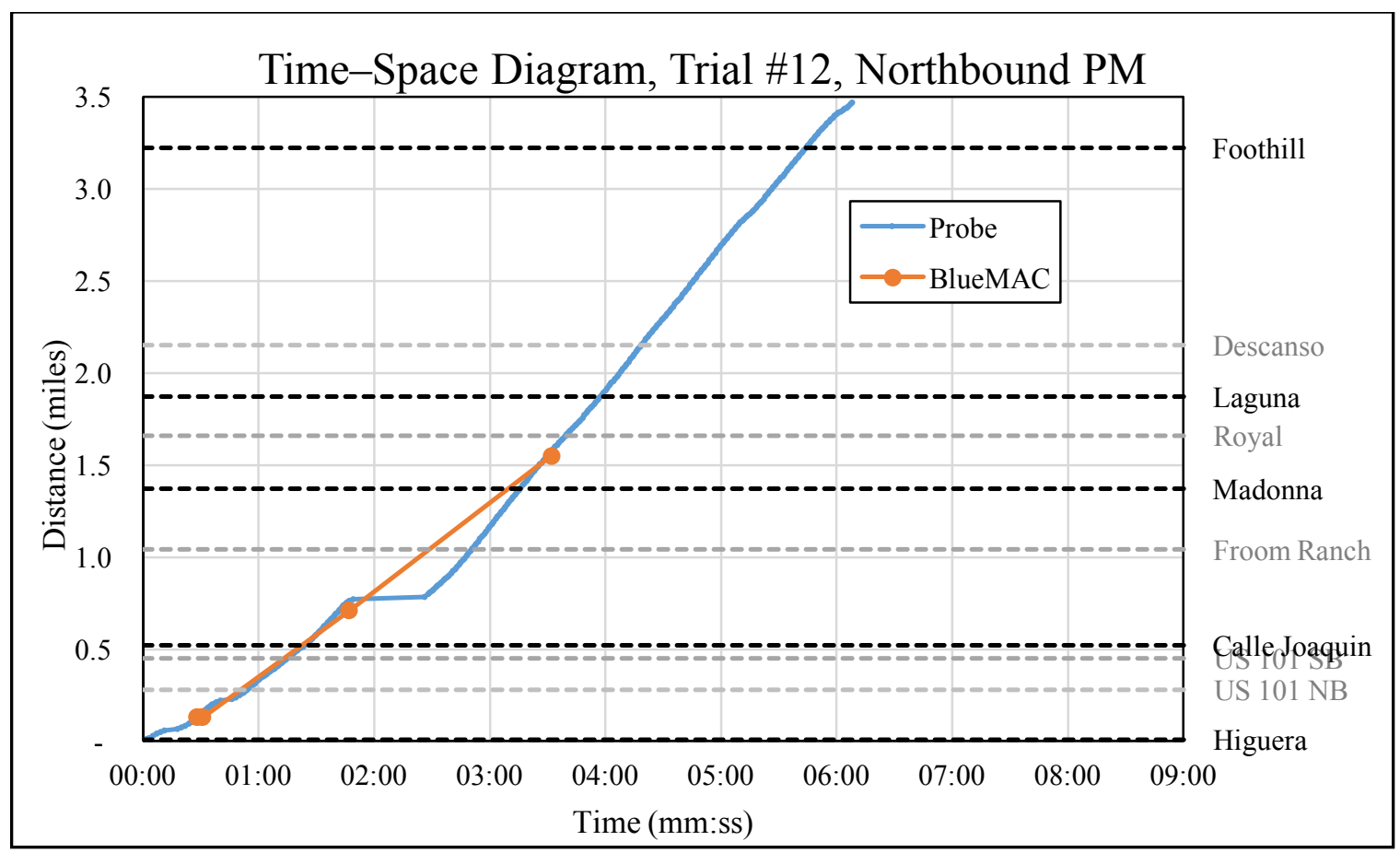

Figure 18: Automobile Run \#12 Time-Space Diagram

\subsubsection{Bicycle}

One northbound and one southbound bicycle trip were completed midday on Saturday, February 20 for the majority of the corridor. Due to bike lane closures on the US 101/Los Osos Valley Road interchange during construction, the bicycle trips were conducted from just north of Calle Joaquin to Foothill Boulevard. While a personal Bluetooth device with a known MAC address was enabled, the personal Bluetooth device's signal was weak and not captured by the BlueMAC devices. Hence, the trial bicycle travel time estimates could not be used to validate BlueMAC-collected bicycle travel times. Table 3 summarizes the probe bicycle runs, and Figures 19 and 20 show the time-space diagrams.

\begin{tabular}{|c|c|c|c|c|c|c|}
\hline $\begin{array}{c}\text { Trial } \\
\text { Run }\end{array}$ & Direction & Date & Start Time & $\begin{array}{c}\text { Foothill-Calle } \\
\text { Joaquin Travel } \\
\text { Time (mm:ss) }\end{array}$ & $\begin{array}{c}\text { Mean } \\
\text { Speed } \\
(\mathrm{mph})\end{array}$ & $\begin{array}{c}\text { Number } \\
\text { of Stops }\end{array}$ \\
\hline \hline 1 & Northbound & $2 / 20 / 16$ & $11: 52 \mathrm{AM}$ & $13: 43$ & 11.0 & 1 \\
\hline 2 & Southbound & $2 / 20 / 16$ & $12: 13 \mathrm{PM}$ & $12: 46$ & 11.8 & 1 \\
\hline
\end{tabular}

Table 3: Probe Bicycle Runs 
The bicycle runs were completed by a regular cyclist in good health, with minimal additional weight (one lightweight backpack) and a well-operating bicycle. The cyclist did not raise off the bicycle seat and was asked to maintain a non-exerting speed. Other cyclists on the roadway may travel at faster or slower speeds or take breaks.

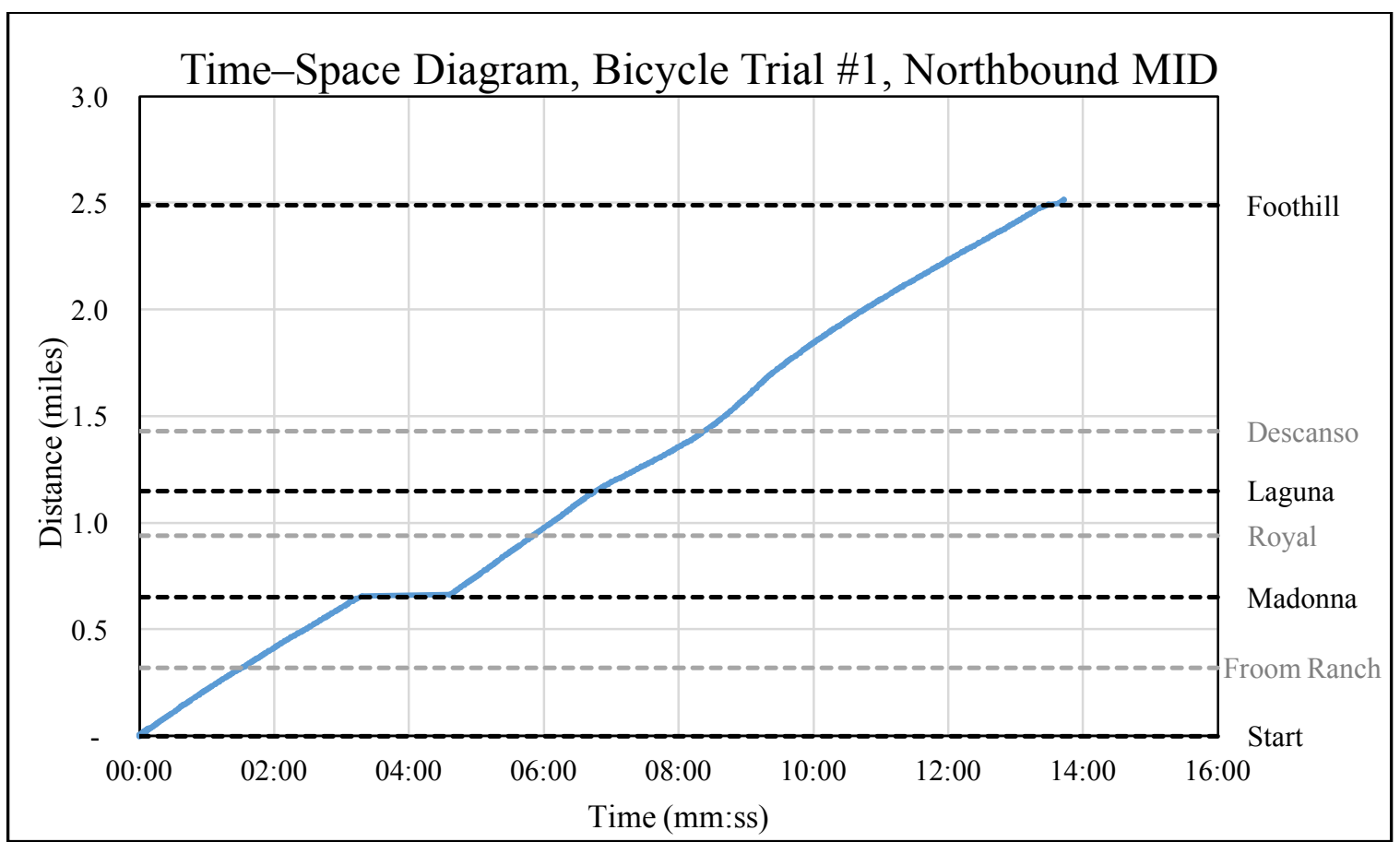

Figure 19: Bicycle Trial Run \#1 Time-Space Diagram 


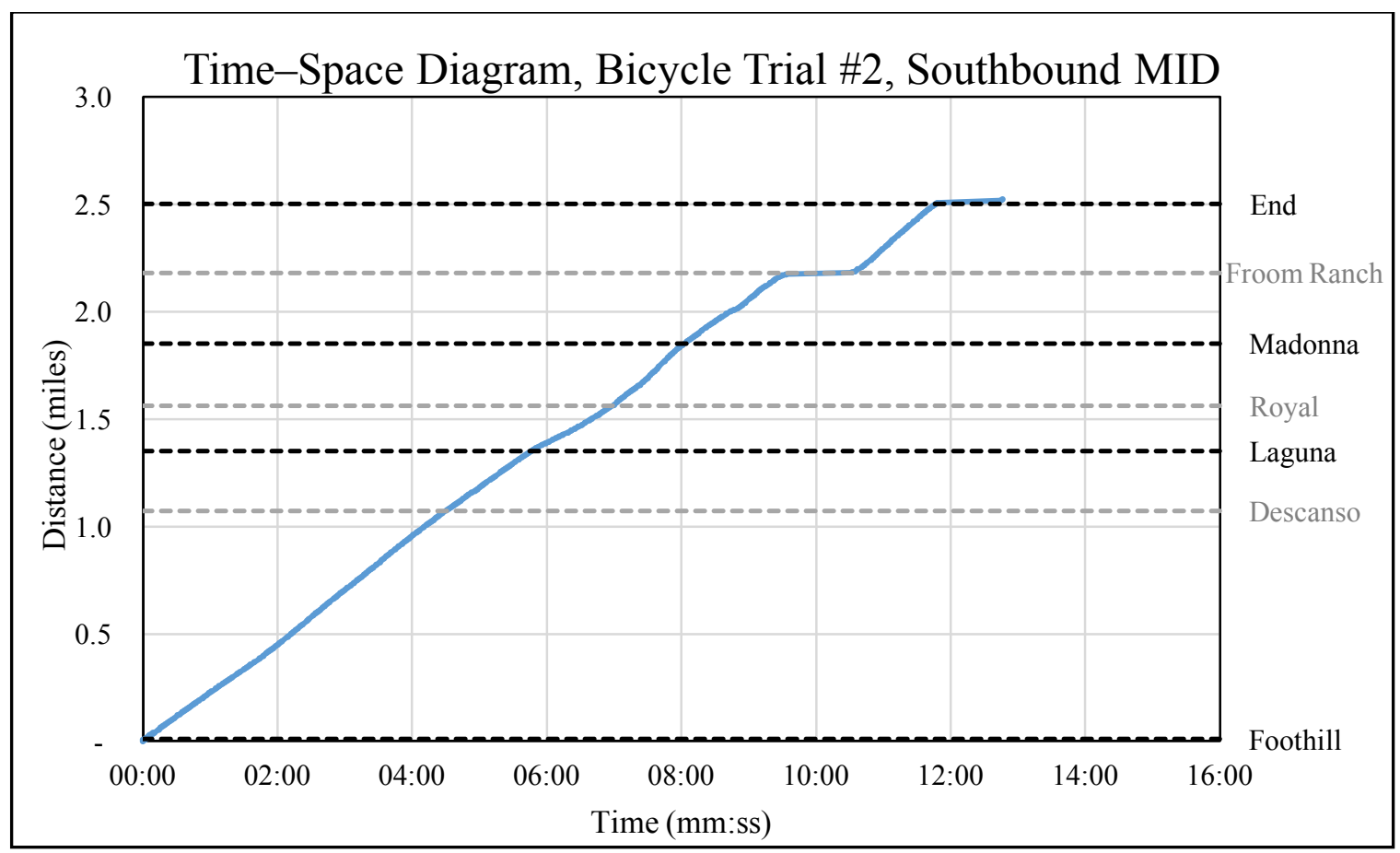

Figure 20: Bicycle Trial Run \#2 Time-Space Diagram

Aside from delays toward the southern end of Los Osos Valley Road, bicycle travel speed appears to be constant. 


\section{METHODOLOGY}

\subsection{Data Visualization}

Prior to the determination of delay and travel time estimation, the data must be assessed for validity and processed if the need arises.

\subsubsection{Raw Data}

Travel time data was collected from January 1, 2016 through February 19, 2016, for a total of 60 days. Figure 21 shows an example of raw travel time data for northbound Calle Joaquin (CP2) to Madonna (CP5).

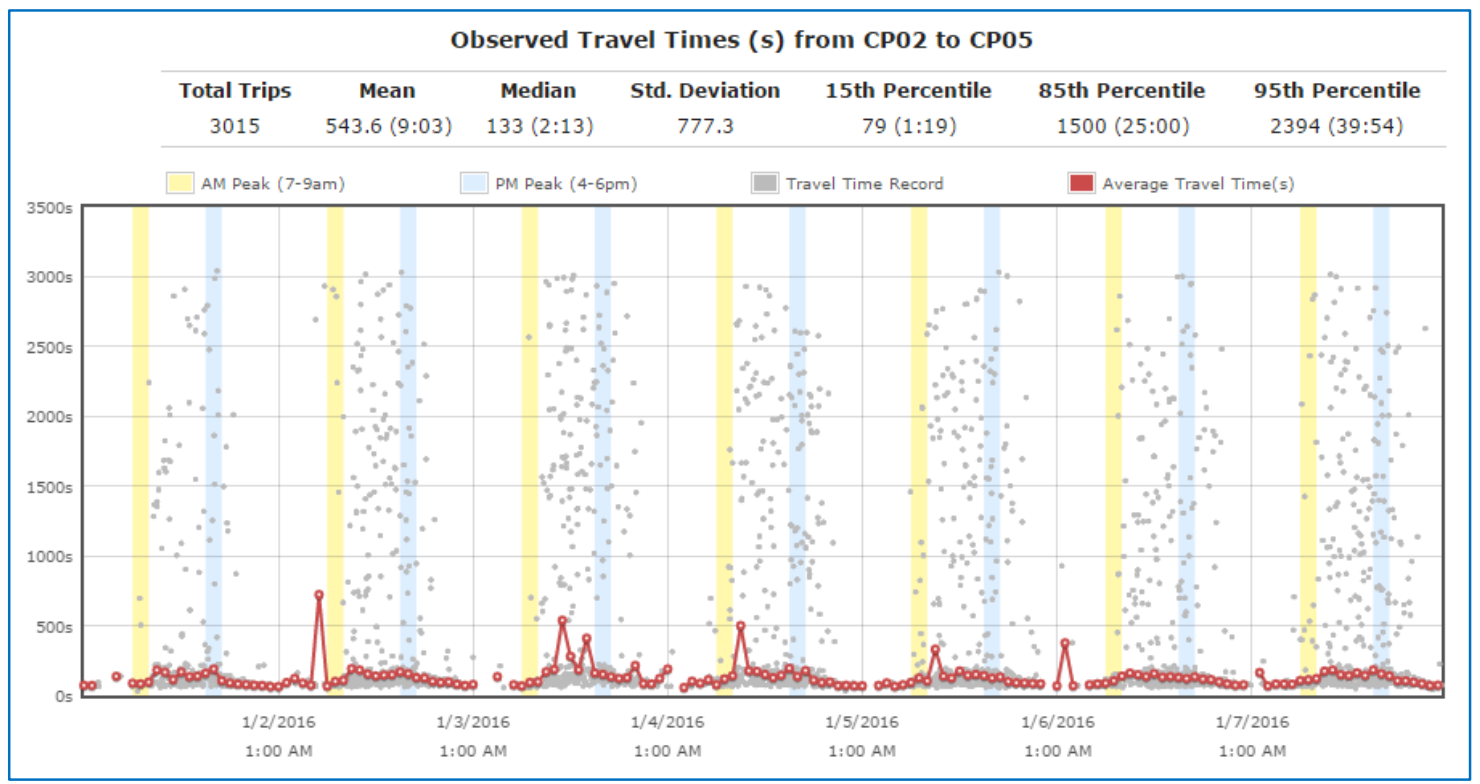

Figure 21: Raw Data Travel Time Example

Raw data findings are summarized in Table 4. 


\begin{tabular}{|c|c|c|c|c|c|c|c|c|}
\hline \multirow{2}{*}{ Segment } & \multirow{2}{*}{ Direction } & \multirow{2}{*}{$\begin{array}{l}\text { Length } \\
\text { (mi) }\end{array}$} & \multicolumn{2}{|c|}{ Travel Time (min) } & \multicolumn{2}{|c|}{ Speed (mph) } & \multirow{2}{*}{$\begin{array}{l}\text { Speed } \\
\text { Limit }\end{array}$} & \multirow[b]{2}{*}{$\mathrm{n}$} \\
\hline & & & $\overline{\bar{x}}$ & $\bar{s}$ & $\overline{\bar{x}}$ & $s$ & & \\
\hline \multirow{2}{*}{$\begin{array}{c}\text { Higuera-Calle } \\
\text { Joaquin }\end{array}$} & NB & 0.52 & 3.3 & 3.9 & 15.5 & 7.8 & 35 & 14,540 \\
\hline & SB & 0.52 & 2.4 & 3.0 & 18.7 & 7.2 & 35 & 14,692 \\
\hline \multirow{2}{*}{$\begin{array}{c}\text { Calle Joaquin- } \\
\text { Madonna } \\
\end{array}$} & $\mathrm{NB}$ & 0.85 & 8.4 & 12.3 & 22.1 & 15.0 & 45 & 24,162 \\
\hline & SB & 0.85 & 8.5 & 12.1 & 21.1 & 15.0 & 45 & 17,152 \\
\hline \multirow{2}{*}{$\begin{array}{l}\text { Madonna- } \\
\text { Laguna }\end{array}$} & NB & 0.50 & 2.2 & 3.7 & 24.3 & 11.5 & 45 & 23,412 \\
\hline & SB & 0.50 & 2.4 & 3.8 & 21.7 & 10.4 & 45 & 19,242 \\
\hline \multirow{2}{*}{$\begin{array}{l}\text { Laguna- } \\
\text { Foothill }\end{array}$} & NB & 1.35 & 2.6 & $\overline{4.7}$ & 442.9 & 10.3 & $45-55$ & 22,584 \\
\hline & SB & 1.35 & 3.1 & 6.3 & 41.8 & 11.2 & $45-55$ & 17,673 \\
\hline
\end{tabular}

Table 4: Raw Data Statistics

Figures 22, 23, 24, and 25 show the travel time distributions by count and percentage frequencies for all study segments for the northbound and southbound directions, respectively. Segment lengths can be found in Table 4. Travel times were binned into $10-$ second intervals.

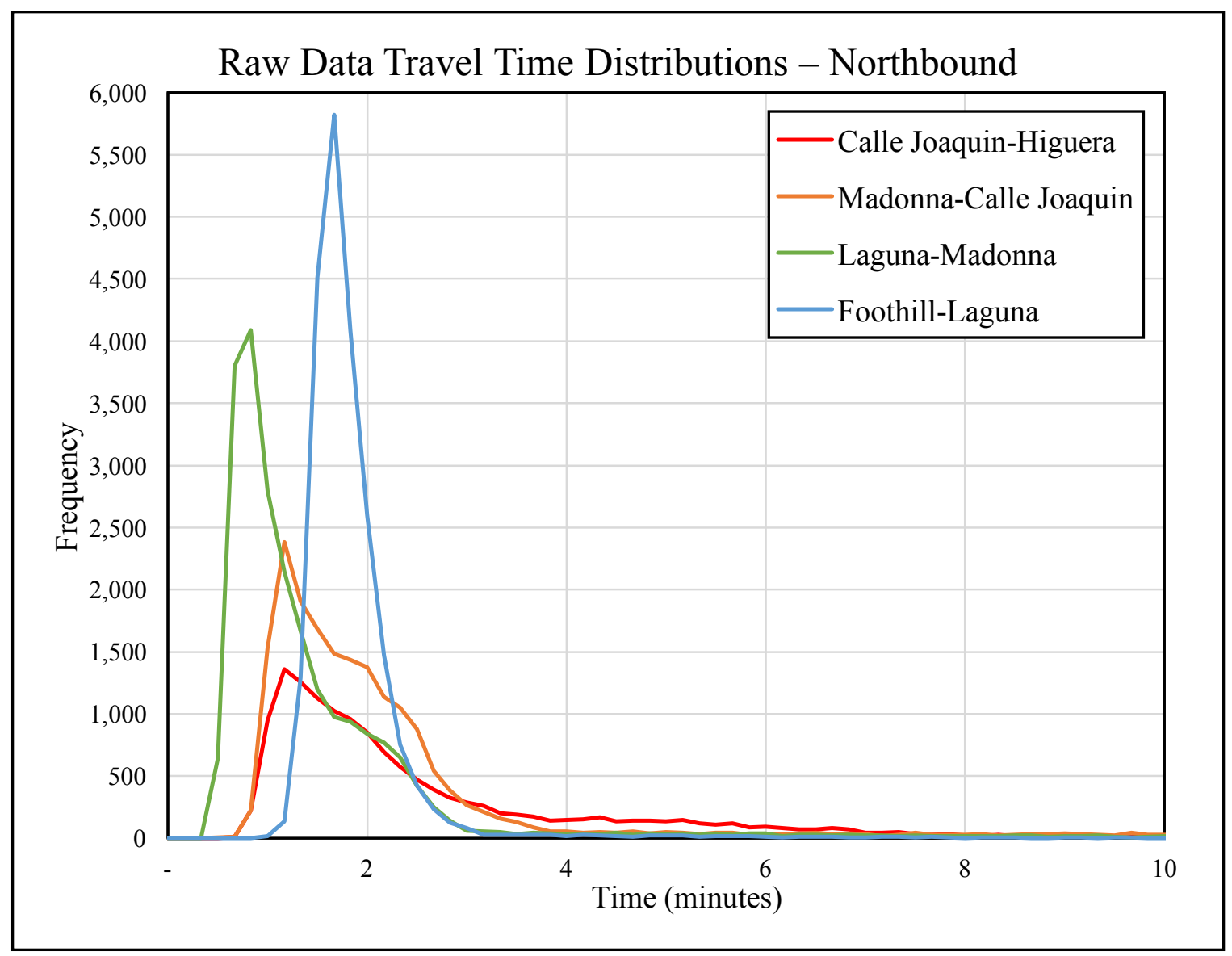

Figure 22: Raw Data Travel Time Count Distributions - Northbound 


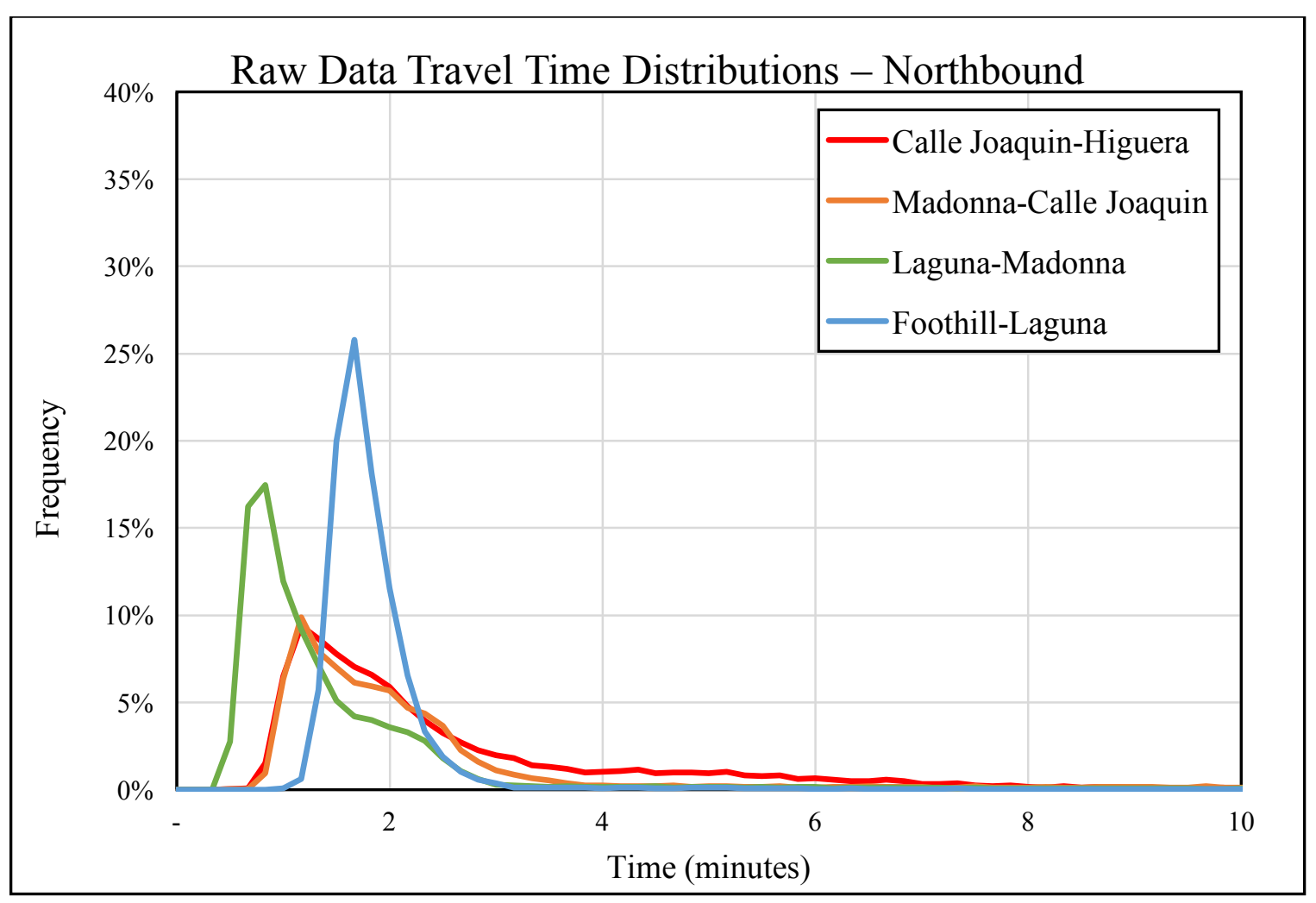

Figure 23: Raw Data Travel Time Percentage Distributions - Northbound

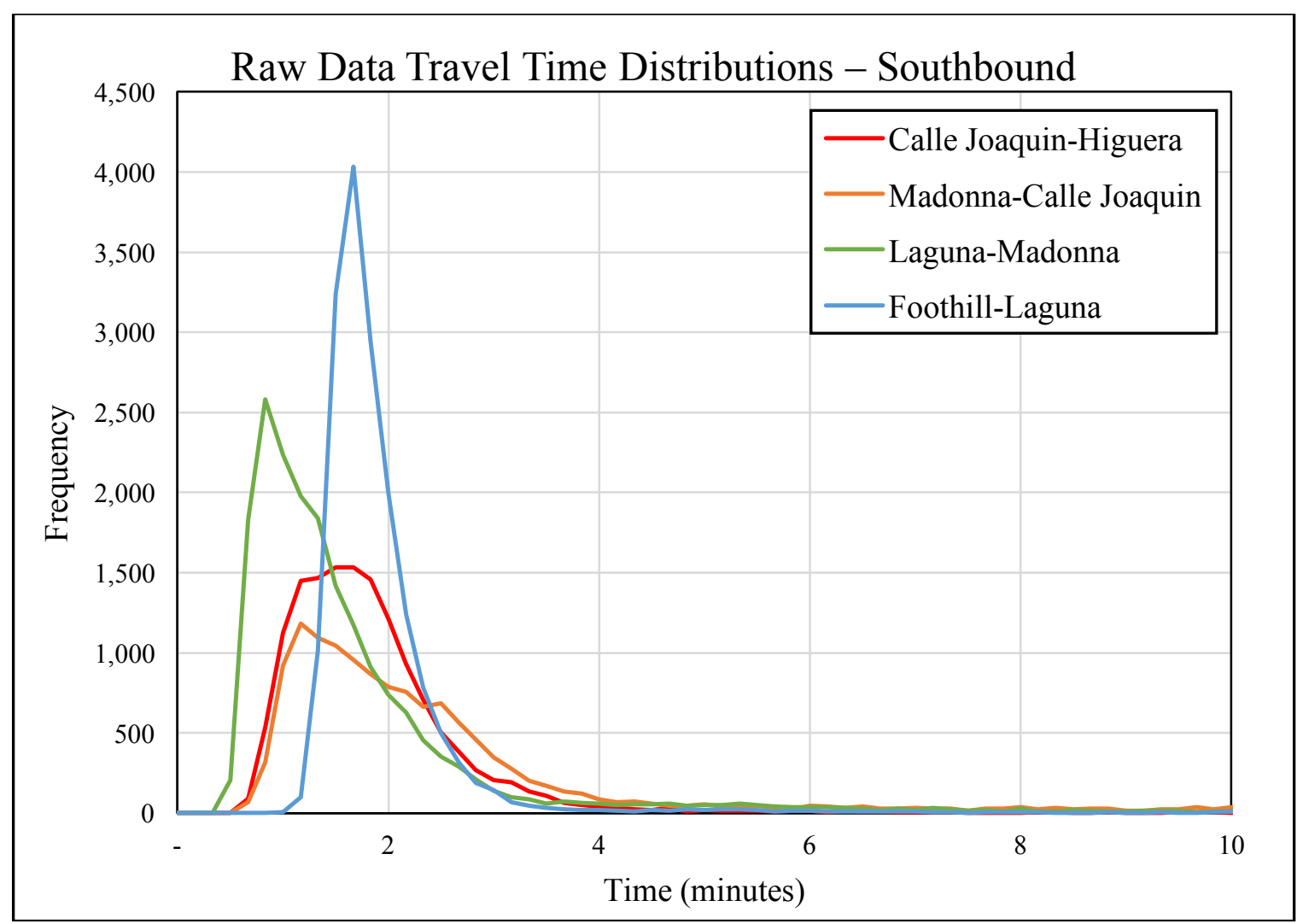

Figure 24: Raw Data Travel Time Count Distributions - Southbound 


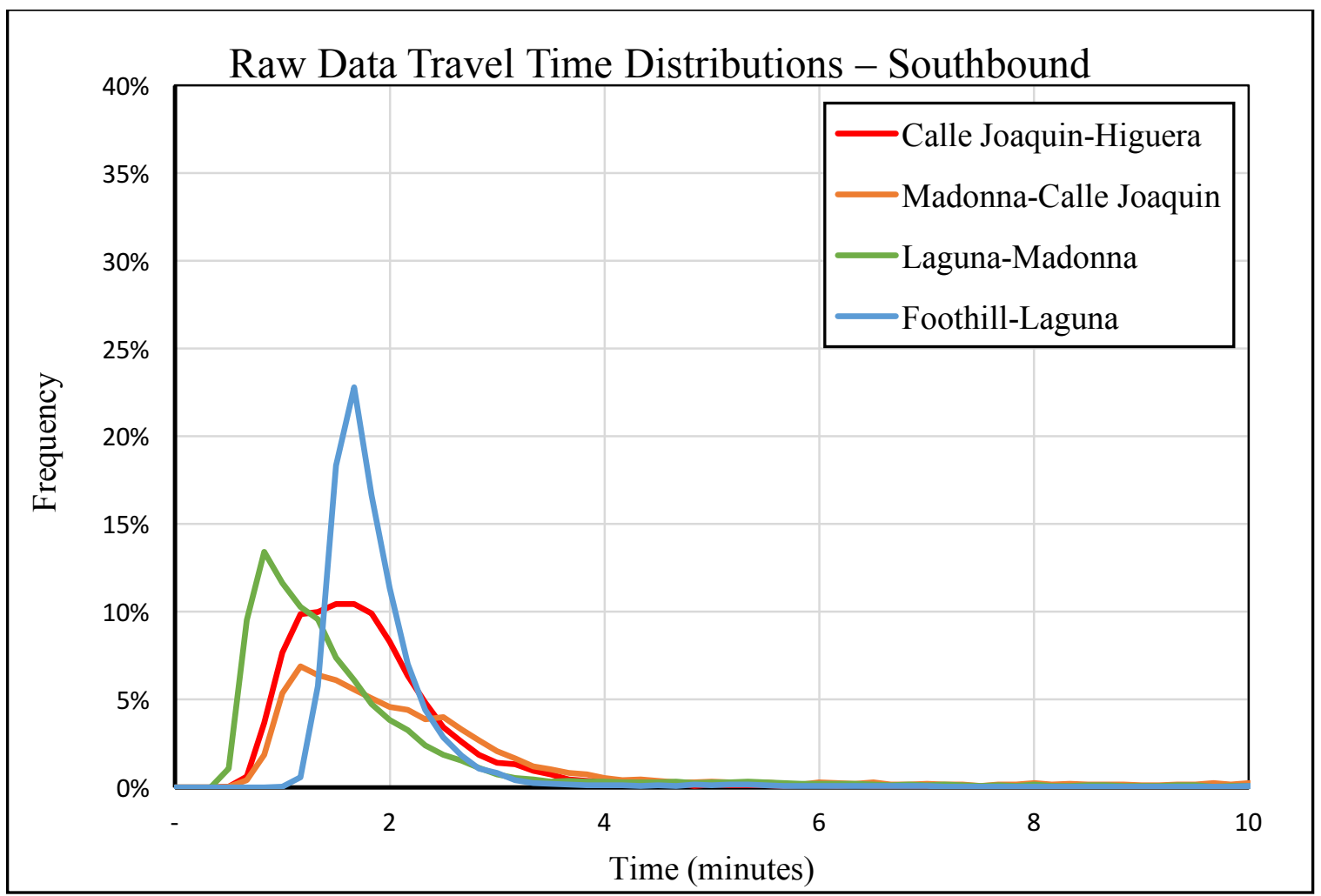

Figure 25: Raw Data Travel Time Percentage Distributions - Southbound

At first glance, the travel times follow an 'expected' distribution. However, consider these segments range from 0.5 miles to 1.35 miles, and a non-trivial amount of trips take more than four minutes. To further evaluate the data, narrowed examinations using time-space diagrams were conducted.

Examining the segment from Madonna Road to Calle Joaquin, which has a 45 mph speed limit and is 0.85 miles long, yields the time-space diagram depicted in Figures 26 and 27 for 4 PM to 5 PM on January 28, 2016 in the northbound and southbound directions, respectively. Unrealistic data have been identified in red. A free flow trip is shown starting at $4 \mathrm{PM}$, identified in green. The speed limit along this segment is $45 \mathrm{mph}$, with a speed survey showing the 85 th percentile speed to be $46 \mathrm{mph}$. Figure 28 shows raw Bluetooth data's mean, median, and 85 th percentile speeds on a cumulative density plot, as well as the pre-construction 85 th percentile speed. 


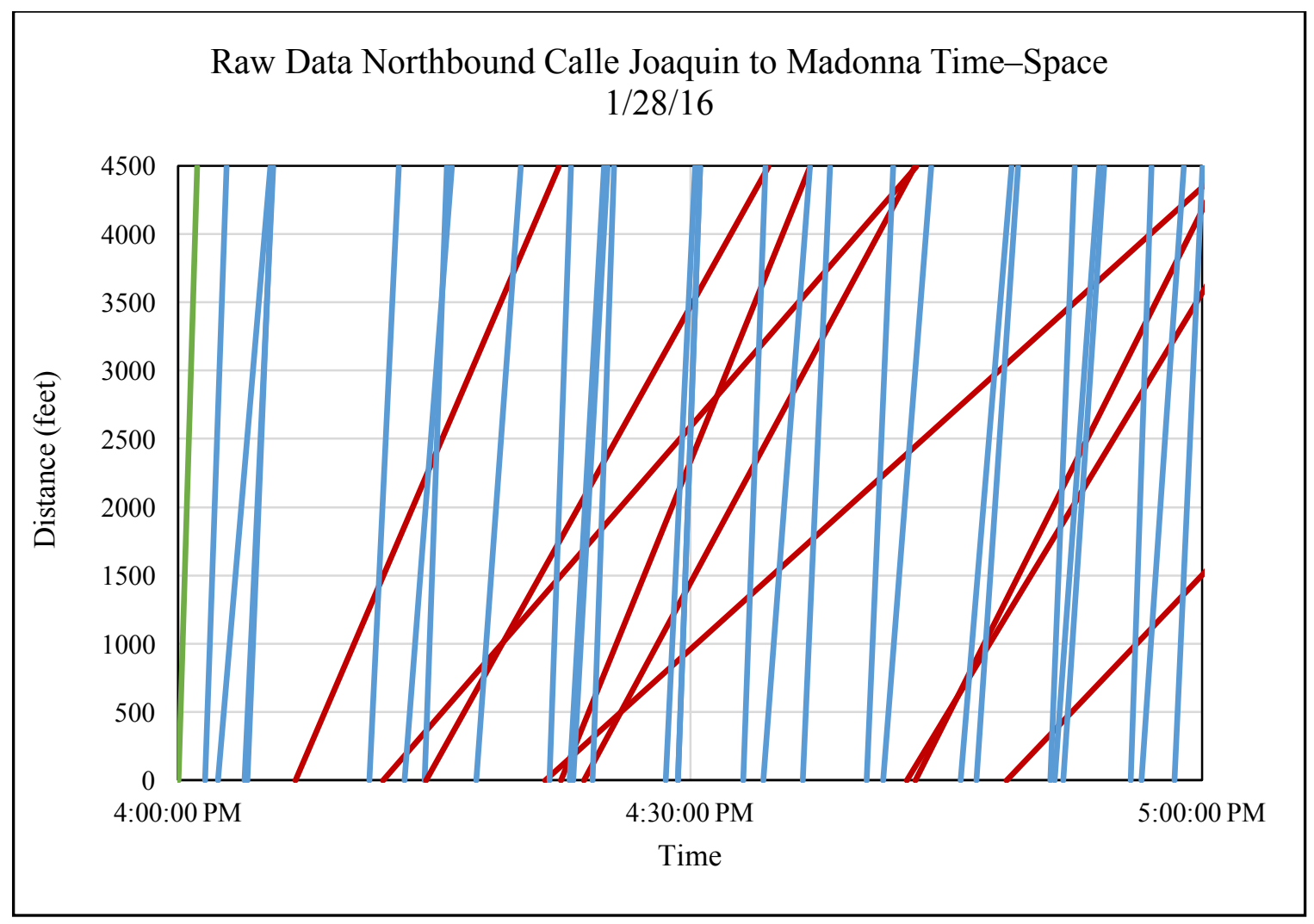

Figure 26: Raw Data Time-Space Diagram for Northbound Madonna to Calle Joaquin

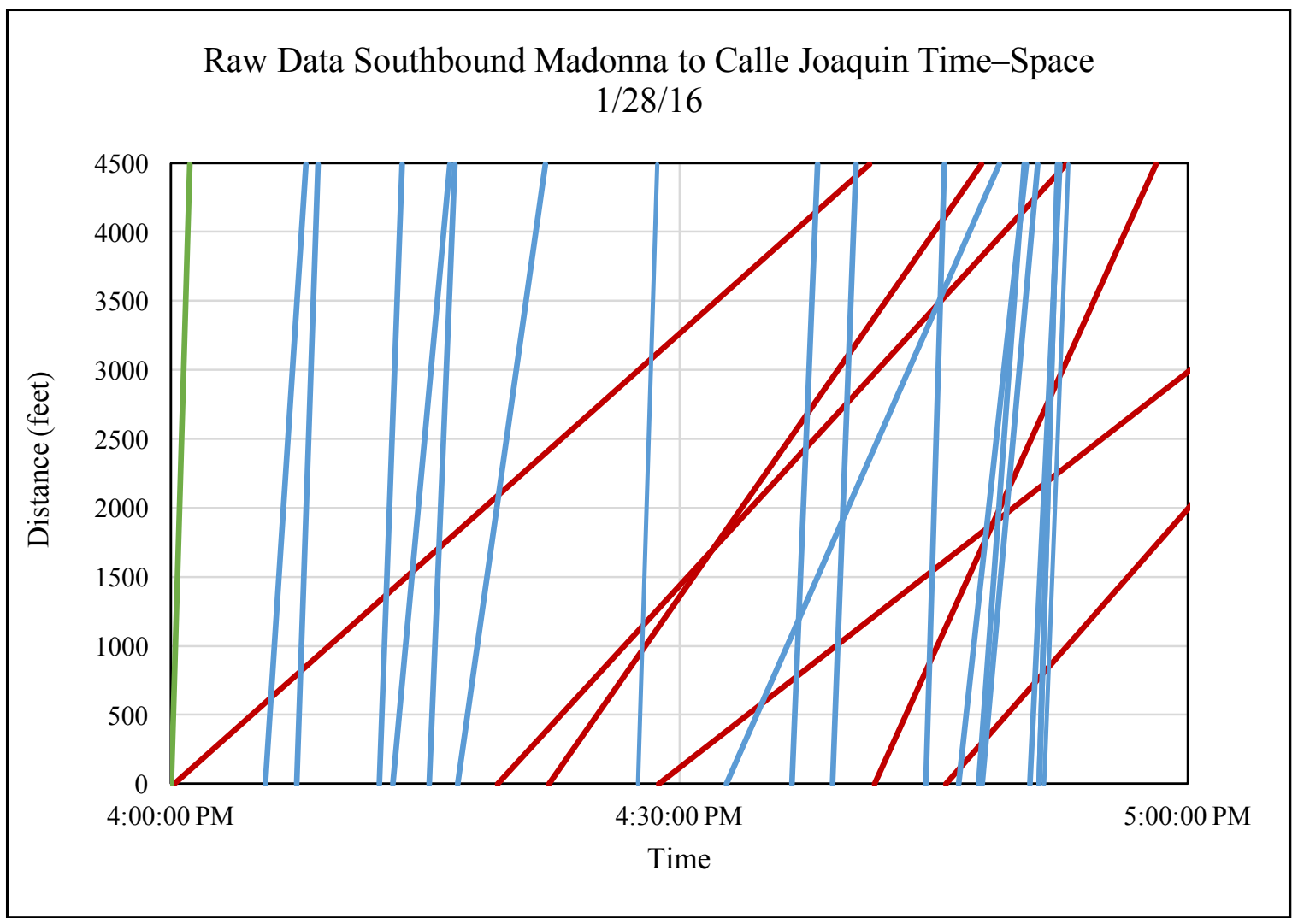

Figure 27: Raw Data Time-Space Diagram for Southbound Madonna to Calle Joaquin 


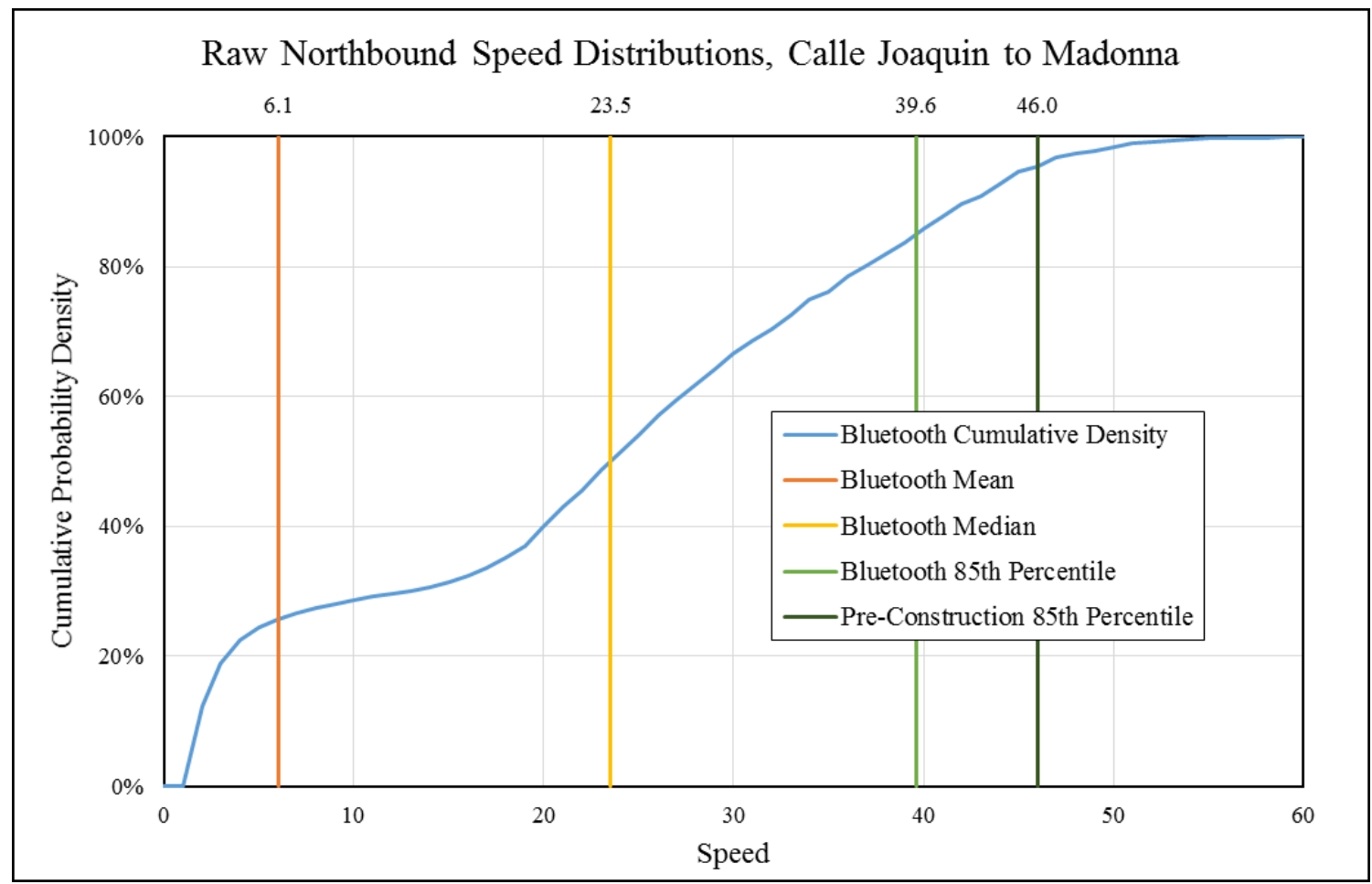

Figure 28: Raw Data Speed Distributions for Northbound Calle Joaquin to Madonna

The segment has a maximum northbound travel time of 3050 seconds, or about 51 minutes. Considering several other trips starting at the same time take 2-3 minutes to traverse the segment, this 51-minute trip is more likely to be an occasion where a vehicle turned off the roadway for some purpose and then returned to the roadway than a vehicle traveling at an average speed of $1 \mathrm{mph}$. Mid-segment land uses include grocery stores, hardware stores, auto dealerships, apartments, fast-food restaurants, big box retail, and many other destinations, increasing the likelihood that vehicles were turning into driveways or side streets.

Longer trips on the roadway are likely to be situations where vehicles turn off of the roadway, pedestrian, or bicycle trips. The data must be further processed to gain an accurate representation of travel times along Los Osos Valley Road. In order to evaluate processing methods, the error should be calculated using the following equation: 


$$
E=Z_{\alpha / 2} \times \frac{s}{\sqrt{n}}
$$

The sample size, $n$, and the standard deviation, $\sigma$, will be broken down by AM peak (7 AM - 9 AM), MID peak (11 AM - 1 PM), and PM peak (4 PM - 6 PM) for each segment. Confidence will be set to $95 \%$, resulting in an $\alpha$ of 0.05 and $Z_{\alpha / 2}$ of 1.96 (Tantiyanugulchai \& Bertini, 2003). The maximum error, $E$, should be $\pm 4 \mathrm{mph}$ or below (Institute of Transportation Engineers, 2000). To better compare between data processing methods, a "weighted error" is calculated by summing the product of each peak period's error and sample size, then dividing by the total sample size.

For raw data, the error estimates were as follows:

\begin{tabular}{|c|l|c|c|c|}
\hline \multirow{2}{*}{ Segment } & \multirow{2}{*}{ Direction } & \multicolumn{3}{|c|}{ Error (mph) } \\
\cline { 3 - 5 } & & AM & MID & PM \\
\hline \hline \multirow{2}{*}{ Calle Joaquin-Higuera } & Northbound & 0.46 & 0.31 & 0.26 \\
\cline { 2 - 5 } & Southbound & 0.26 & 0.31 & 0.35 \\
\hline \multirow{2}{*}{ Madonna-Calle Joaquin } & Northbound & 0.79 & 0.69 & 0.61 \\
\cline { 2 - 5 } & Southbound & 0.62 & 0.67 & 0.76 \\
\hline \multirow{2}{*}{ Laguna-Madonna } & Northbound & 0.50 & 0.58 & 0.42 \\
\cline { 2 - 5 } & Southbound & 0.37 & 0.44 & 0.42 \\
\hline \multirow{2}{*}{ Foothill-Laguna } & Northbound & 0.50 & 0.49 & 0.40 \\
\cline { 2 - 5 } & Southbound & 0.43 & 0.52 & 0.49 \\
\hline \hline \multicolumn{4}{|c|}{$0.48 \mathrm{mph}$} \\
\hline
\end{tabular}

Table 5: Raw Data Error Summary

These results are reasonable given the large sample size, resulting in a weighted error of $0.48 \mathrm{mph}$. However, Figures 24 and 25 highlight that some data points are unreasonable and should be removed from the analysis dataset. Several data filtering methodologies were identified in the literature review; filtering methodologies in this thesis are the Outlier-Filtered and Median Method, further described in the following sections. 


\subsubsection{Outlier-Filtered}

To better estimate travel time reliability, outliers should be removed from the data (Box, 2011). Inner fence outliers were calculated by identifying first and third quartiles. The first quartile (Q1) is the point at which $25 \%$ of the data are below this value and the third quartile (Q3) is the point at which $75 \%$ of the data are below this value. The interquartile range (IQR) is then calculated by subtracting the first quartile from the third quartile. Inner fence outliers are identified as the values below Q1-1.5*IQR or above $\mathrm{Q} 3+1.5 * \mathrm{IQR}$.

These values were eliminated from the data sets, and the results are shown in Table 6 and Figures 29, 30, 31, and 32. Raw data distributions are shown as screened dashed lines.

\begin{tabular}{|c|c|c|c|c|c|c|}
\hline Segment & Direction & $\overline{\mathrm{x}}$ & $s$ & $\mathrm{n}$ & $\begin{array}{c}\text { Number } \\
\text { Removed }\end{array}$ & $\begin{array}{c}\text { Percent } \\
\text { Removed }\end{array}$ \\
\hline \hline \multirow{2}{*}{$\begin{array}{c}\text { Higuera-Calle } \\
\text { Joaquin }\end{array}$} & $\mathrm{NB}$ & 2.4 & 1.3 & 13,135 & 1,405 & $9.7 \%$ \\
\cline { 2 - 7 } & $\mathrm{SB}$ & 1.8 & 0.6 & 13,805 & 887 & $6.0 \%$ \\
\hline \hline $\begin{array}{c}\text { Calle Joaquin- } \\
\text { Madonna }\end{array}$ & $\mathrm{NB}$ & 4.1 & 5.9 & 20,521 & 3,641 & $15.1 \%$ \\
\cline { 2 - 7 } & SB & 4.7 & 6.5 & 14,902 & 2,250 & $13.1 \%$ \\
\hline $\begin{array}{c}\text { Madonna- } \\
\text { Laguna }\end{array}$ & NB & 1.3 & 0.6 & 21,447 & 1,965 & $8.4 \%$ \\
\cline { 2 - 7 } & SB & 1.4 & 0.6 & 17,247 & 1,995 & $10.4 \%$ \\
\hline \hline $\begin{array}{c}\text { Laguna- } \\
\text { Foothill }\end{array}$ & NB & 1.8 & 0.3 & 21,073 & 1,511 & $6.7 \%$ \\
\cline { 2 - 7 } & SB & 1.9 & 0.3 & 16,275 & 1,398 & $7.9 \%$ \\
\hline
\end{tabular}

Table 6: Outlier-Filtered 1-Variable Statistics 


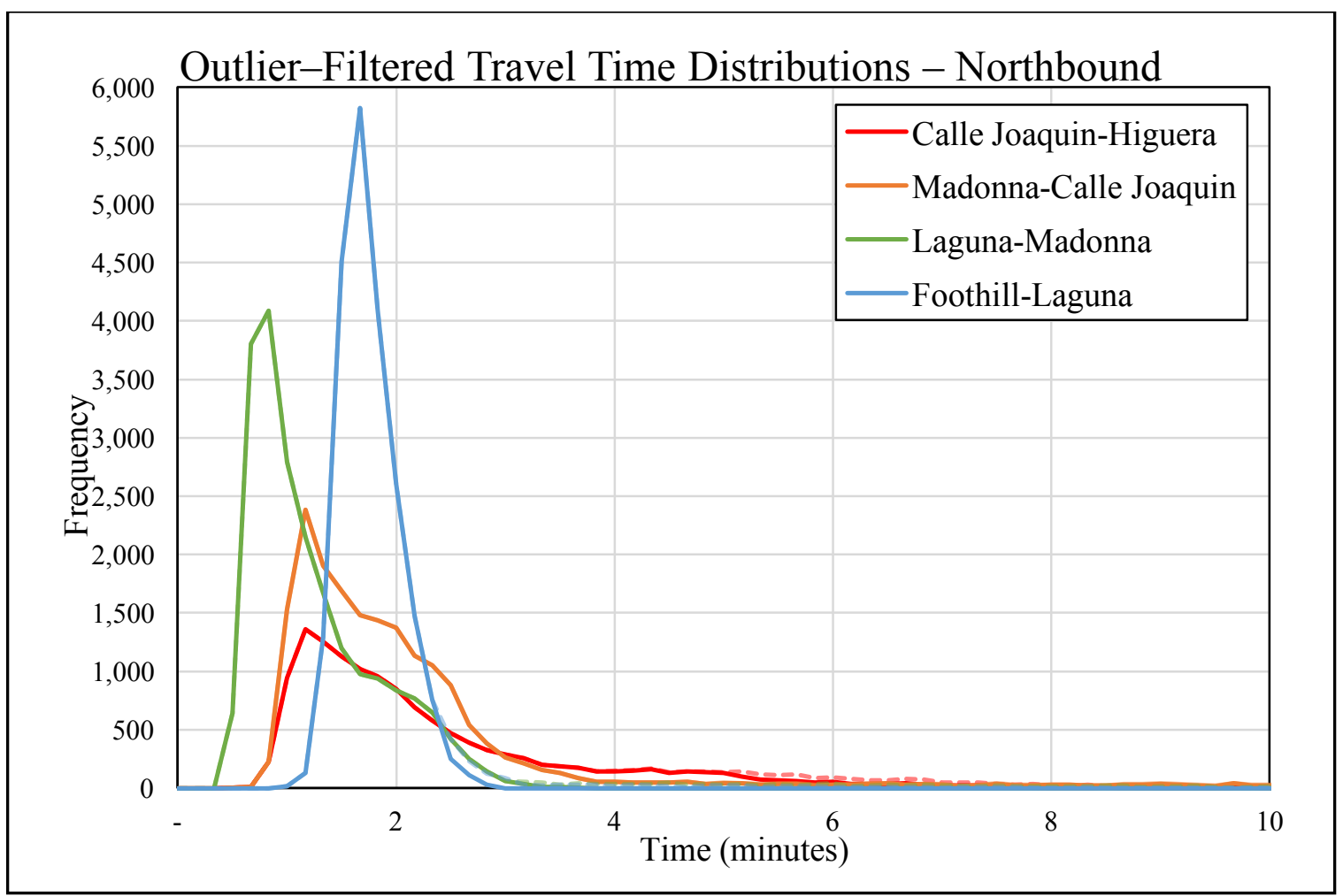

Figure 29: Outlier-Filtered Travel Time Count Distributions - Northbound

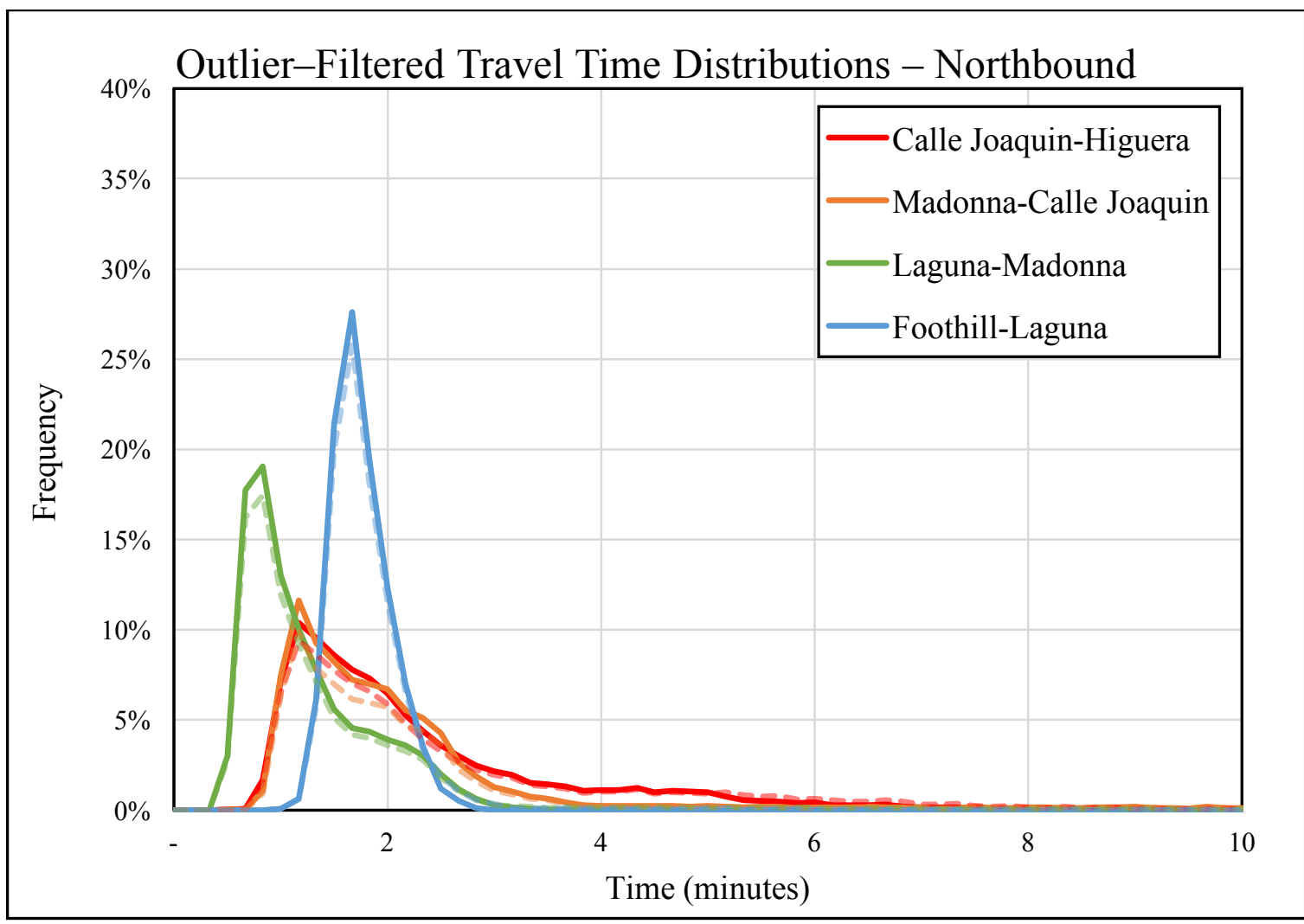

Figure 30: Outlier-Filtered Travel Time Percentage Distributions - Northbound 


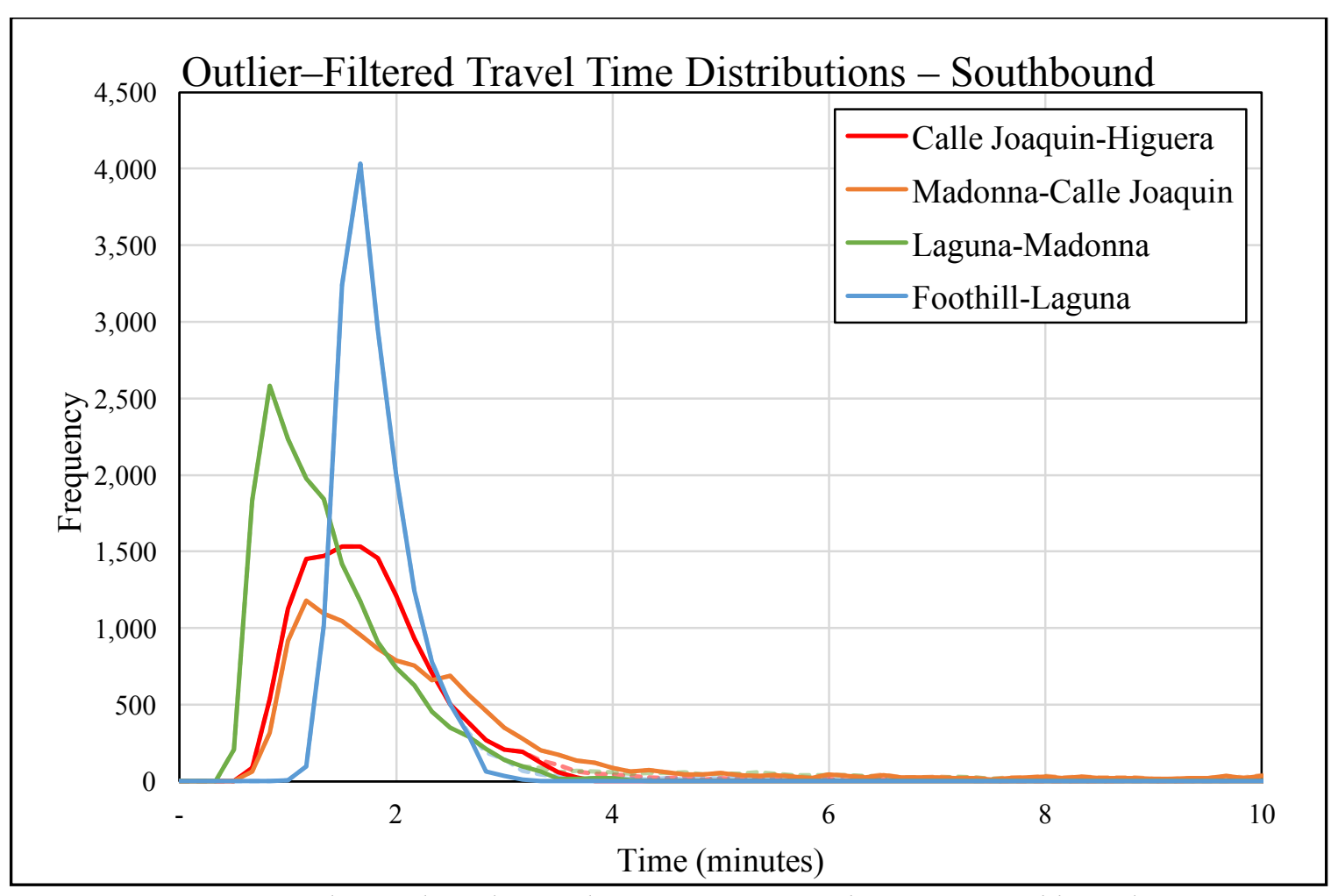

Figure 31: Outlier-Filtered Travel Time Count Distributions - Southbound

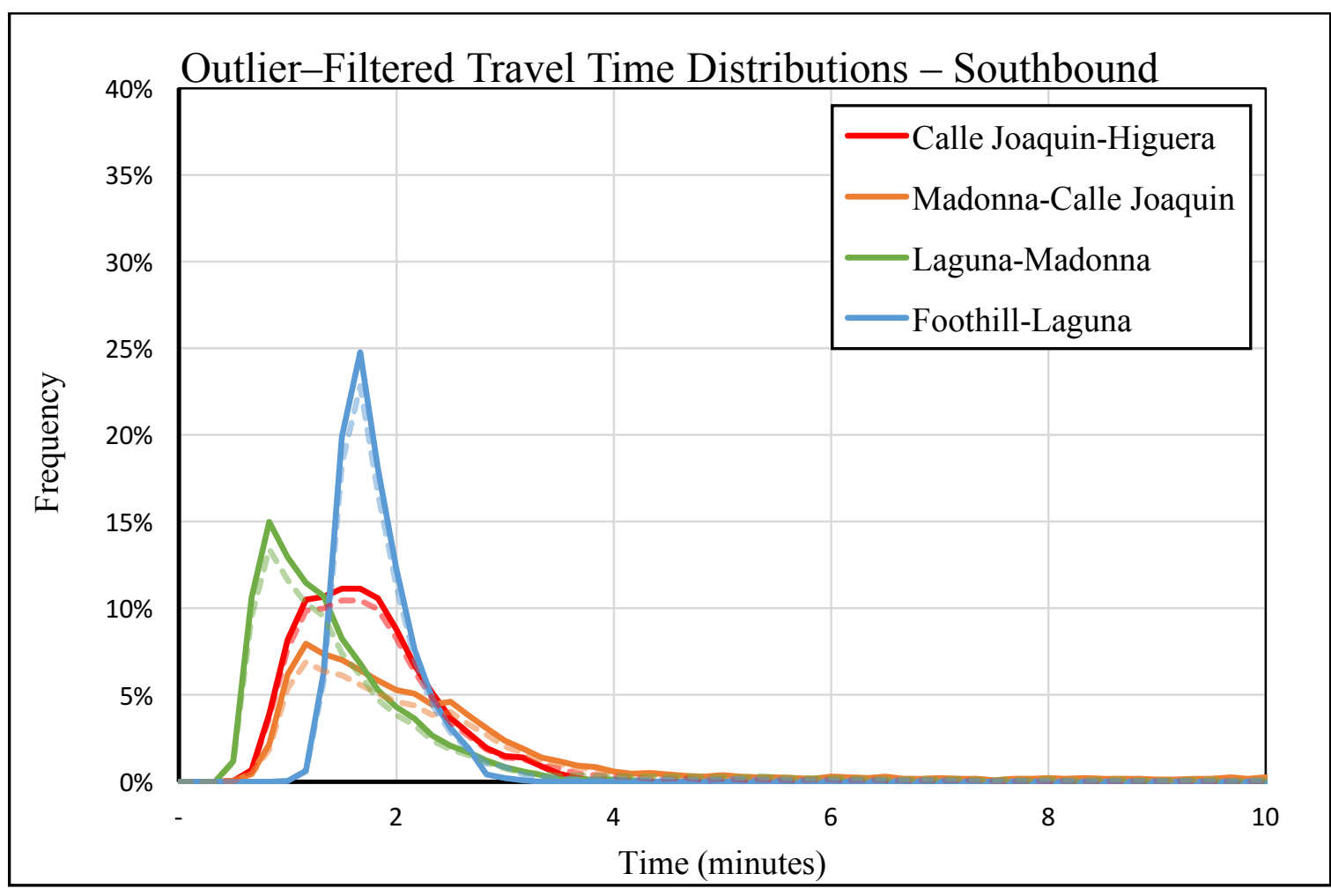

Figure 32: Outlier-Filtered Travel Time Percentage Distributions - Southbound 
While the number of unrealistic data points has decreased, several segments still have unreasonable travel times. In particular, the Madonna-Calle Joaquin segment had such large quantities of occasions when drivers turned off the segment and were reidentified later that the outlier filter did not eliminate the unreasonable data. Figures 33 and 34 show the time-space diagrams for the same range and segment as Figures 26 and 27.

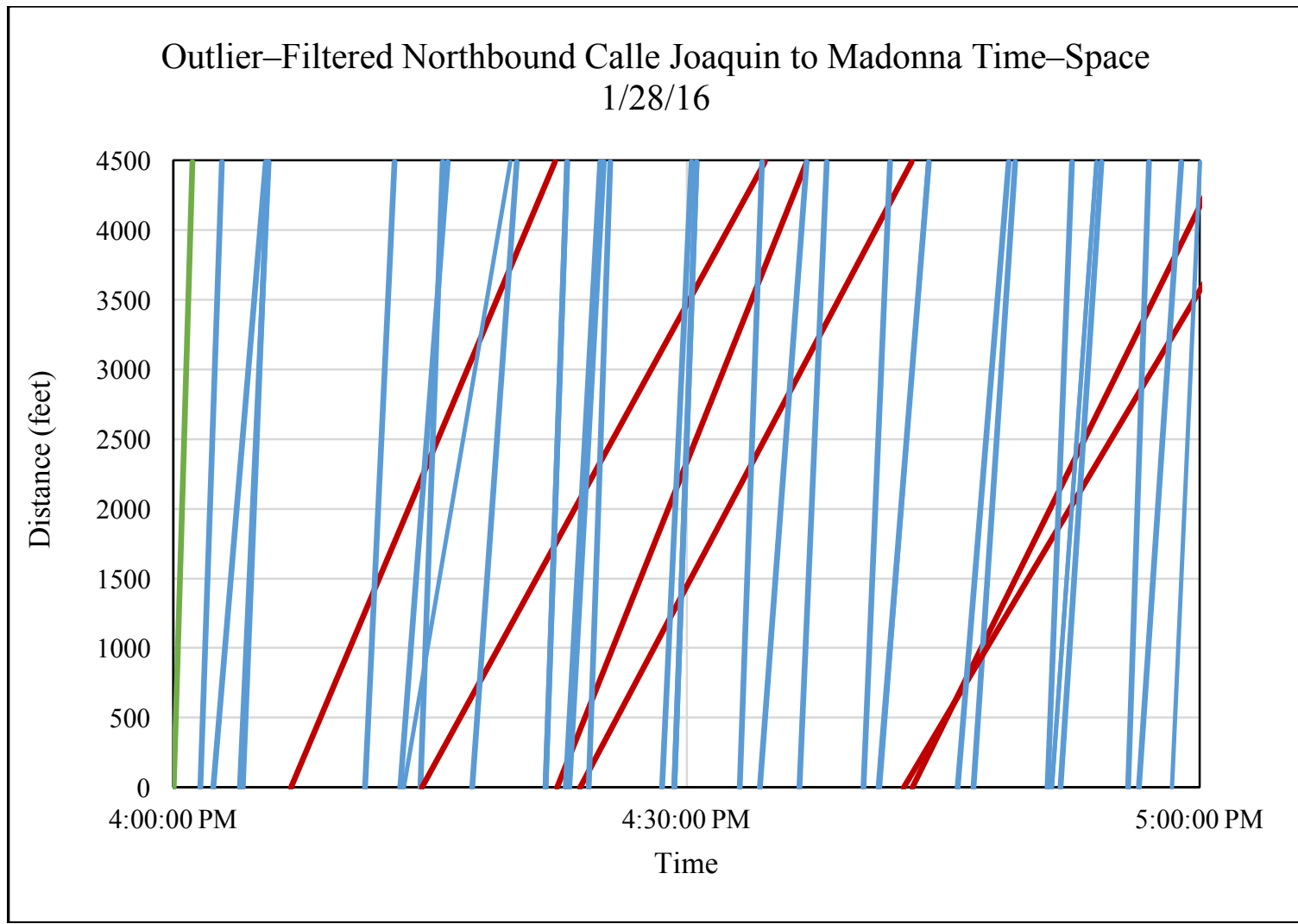

Figure 33: Outlier-Filtered Time-Space Diagram for Northbound Madonna to Calle Joaquin 


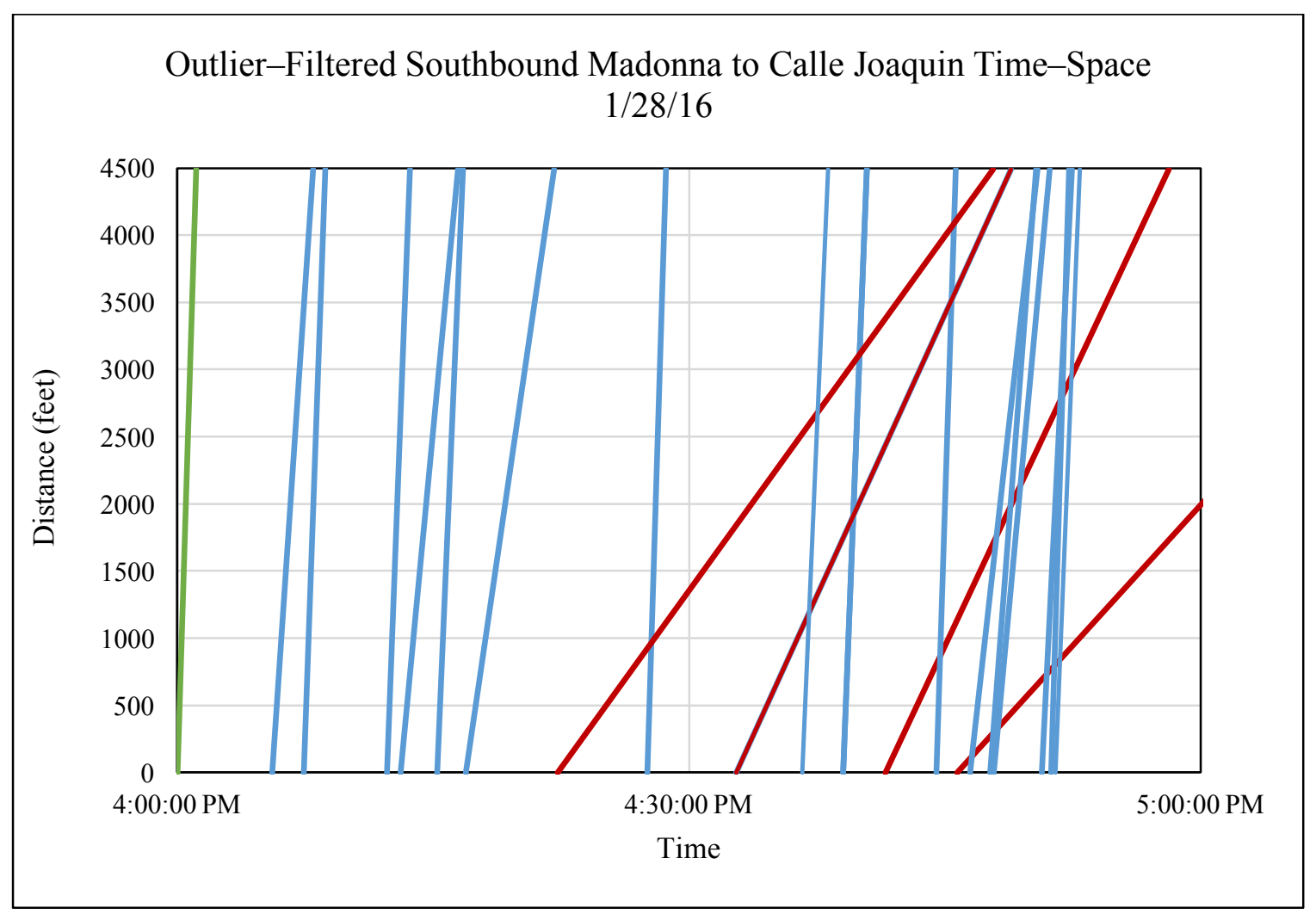

Figure 34: Outlier-Filtered Time-Space Diagram for Southbound Madonna to Calle

Joaquin

For outlier-filtered data, the errors were as follows:

\begin{tabular}{|c|c|c|c|c|}
\hline \multirow{2}{*}{ Segment } & \multirow{2}{*}{ Direction } & \multicolumn{3}{|c|}{ Error (mph) } \\
\cline { 3 - 5 } & & AM & MID & PM \\
\hline \multirow{2}{*}{ Calle Joaquin-Higuera } & Northbound & 0.41 & 0.30 & 0.26 \\
\cline { 2 - 5 } & Southbound & 0.24 & 0.28 & 0.32 \\
\hline \multirow{2}{*}{ Madonna-Calle Joaquin } & Northbound & 0.52 & 0.59 & 0.49 \\
\cline { 2 - 5 } & Southbound & 0.53 & 0.68 & $\mathbf{0 . 7 6}$ \\
\hline \multirow{2}{*}{ Laguna-Madonna } & Northbound & 0.47 & 0.49 & 0.34 \\
\cline { 2 - 5 } & Southbound & 0.35 & 0.39 & 0.38 \\
\hline \multirow{2}{*}{ Foothill-Laguna } & Northbound & 0.33 & 0.25 & 0.22 \\
\cline { 2 - 5 } & Southbound & 0.31 & 0.31 & 0.34 \\
\hline \multicolumn{2}{|c|}{$0.39 \mathrm{mph}$} \\
\hline
\end{tabular}

Table 7: Outlier-Filtered Error Summary

Error reduced for all but the southbound direction for Madonna to Calle Joaquin during the midday peak. While the standard deviation decreased from $14.6 \mathrm{mph}$ to 14.5 
mph, the sample size decreased from 1,815 data points to 1,745 data points. The maximum error increased by $0.01 \mathrm{mph}$ and remained within the acceptable range. The weighted error is $0.39 \mathrm{mph}, 0.09 \mathrm{mph}$ less than the weighted error for the raw data.

\subsubsection{Median Method}

An additional method in the literature review was a quartile-removal, in which any speeds below the first quartile or above the third quartile in a data set were removed (Li, Chai, \& Tang, 2013). However, the construction and congestion on Los Osos Valley Road indicates that some of these longer travel times may still be valid vehicular trips. Instead, the median travel times from the raw data for each segment, peak period, and direction were found. These values were then doubled, and any data points above these values were eliminated. The outlier filter was applied to the data after the median filter, yielding the Median Method results in Table 8, Figures 35, 36, 37, and 38. Raw data distributions are shown as faded dashed lines.

\begin{tabular}{|c|c|c|c|c|c|c|}
\hline Segment & Direction & $\overline{\mathrm{x}}$ & $S$ & $\mathrm{n}$ & $\begin{array}{c}\text { Number } \\
\text { Removed }\end{array}$ & $\begin{array}{c}\text { Percent } \\
\text { Removed }\end{array}$ \\
\hline \multirow{2}{*}{$\begin{array}{c}\text { Higuera - } \\
\text { Calle Joaquin }\end{array}$} & NB & 2.2 & 1.2 & 12,070 & 2,470 & $17.0 \%$ \\
\hline & SB & 1.8 & 0.6 & 13,614 & 1,078 & $7.3 \%$ \\
\hline \multirow{2}{*}{$\begin{array}{c}\text { Calle Joaquin } \\
\text { - Madonna }\end{array}$} & NB & 1.8 & 0.6 & 16,775 & 7,387 & $30.6 \%$ \\
\hline & SB & 2.0 & 0.8 & 11,797 & 5,355 & $31.2 \%$ \\
\hline \multirow{2}{*}{$\begin{array}{c}\text { Madonna - } \\
\text { Laguna }\end{array}$} & NB & 1.2 & 0.5 & 19,904 & 3,504 & $15.0 \%$ \\
\hline & SB & 1.4 & 0.5 & 16,609 & 2,633 & $13.7 \%$ \\
\hline \multirow{2}{*}{$\begin{array}{l}\text { Laguna - } \\
\text { Foothill } \\
\end{array}$} & NB & 1.8 & 0.3 & 20,849 & 1,735 & $7.7 \%$ \\
\hline & SB & 1.9 & 0.3 & 16,047 & 1,626 & $9.2 \%$ \\
\hline
\end{tabular}

Table 8: Median Method 1-Variable Statistics 


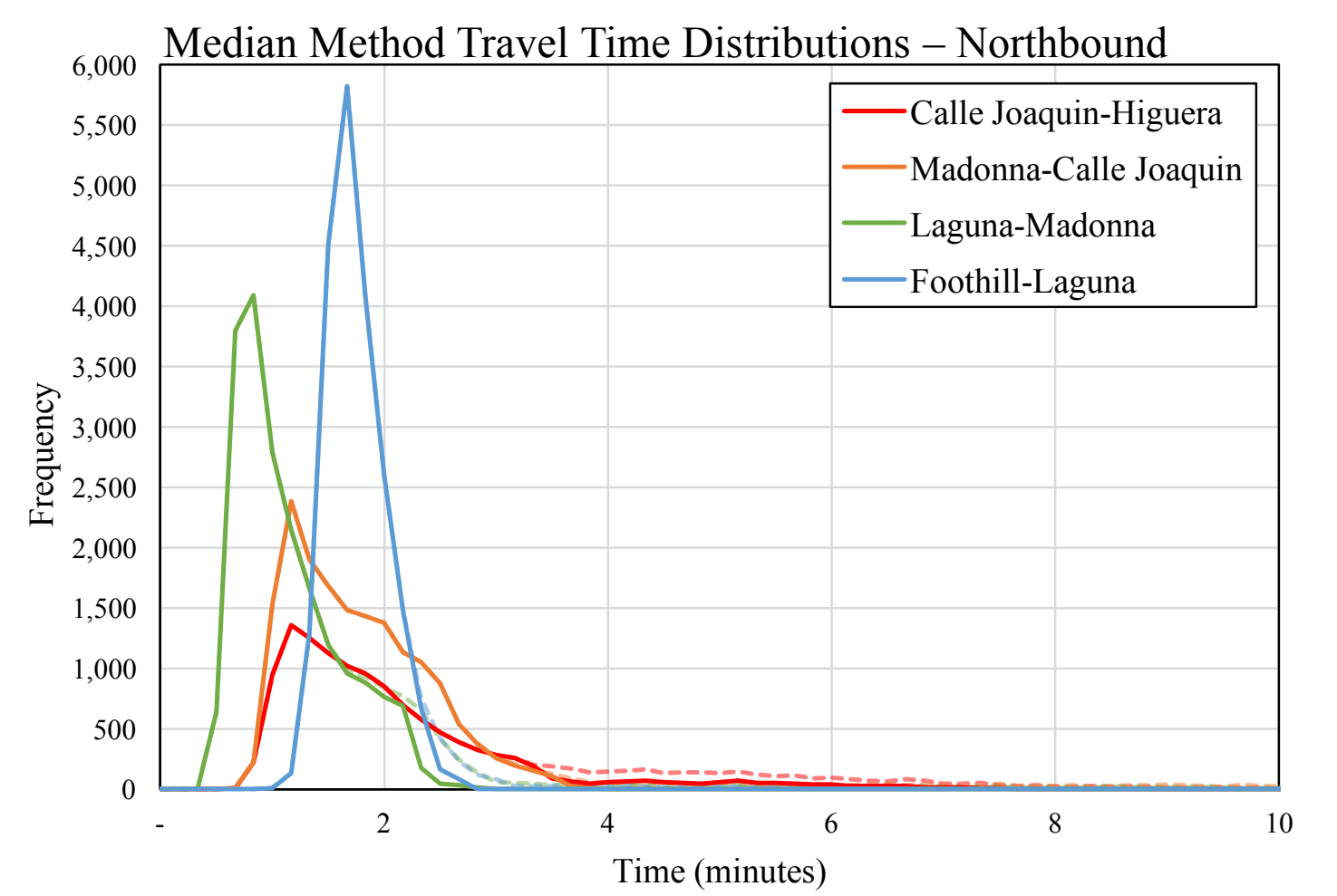

Figure 35: Median Method Travel Time Count Distributions - Northbound

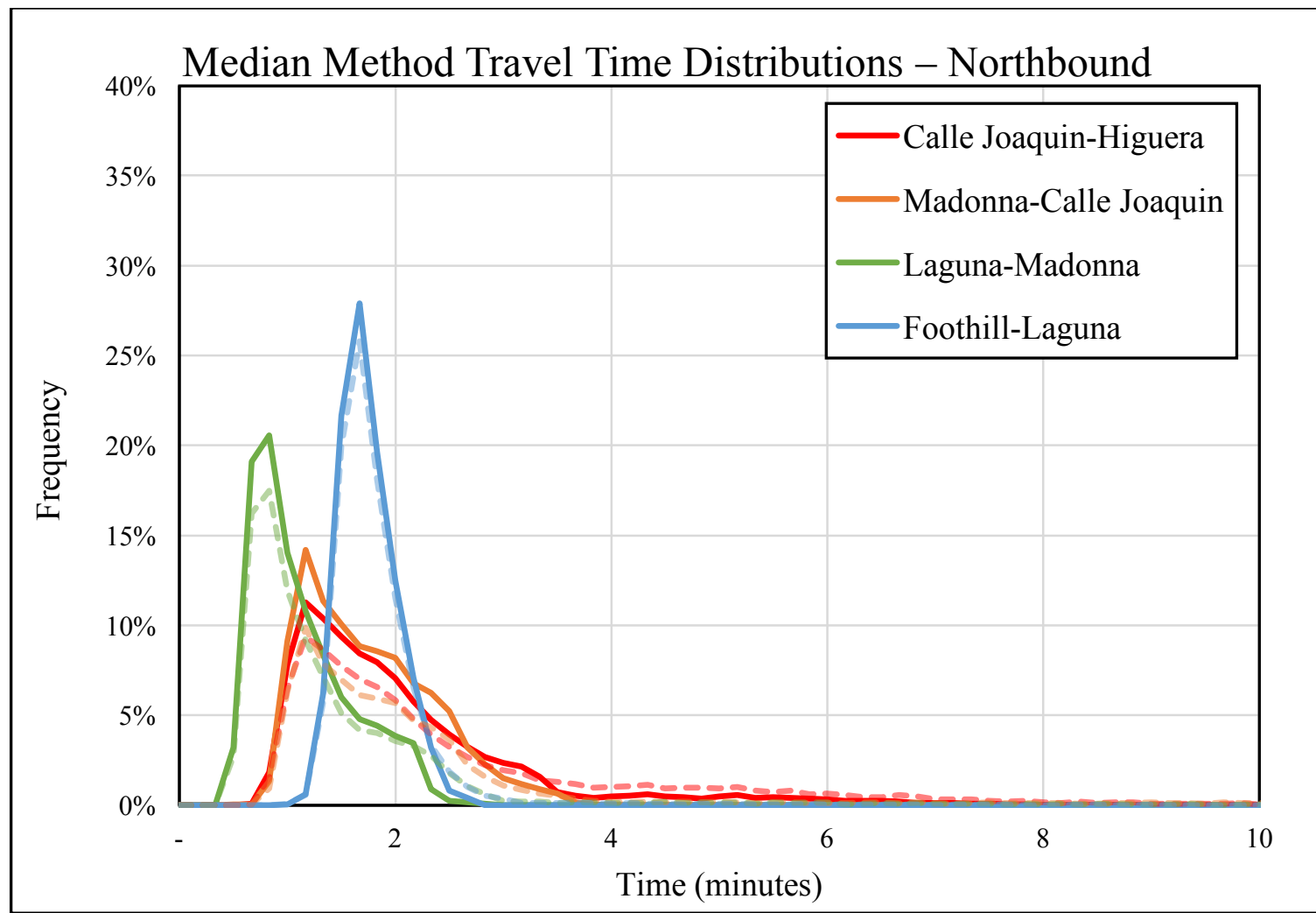

Figure 36: Median Method Travel Time Percentage Distributions - Northbound 


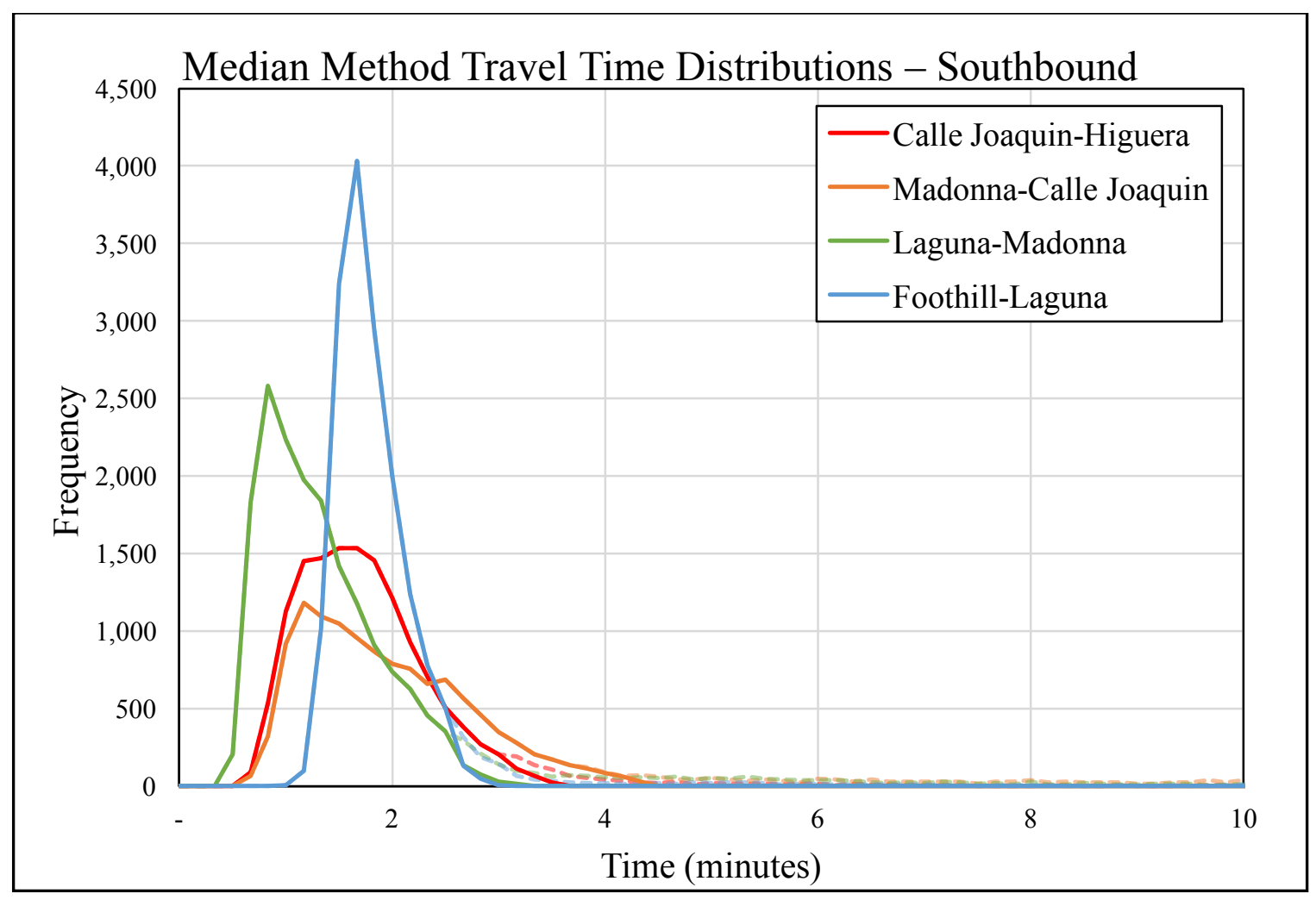

Figure 37: Median Method Travel Time Count Distributions - Southbound

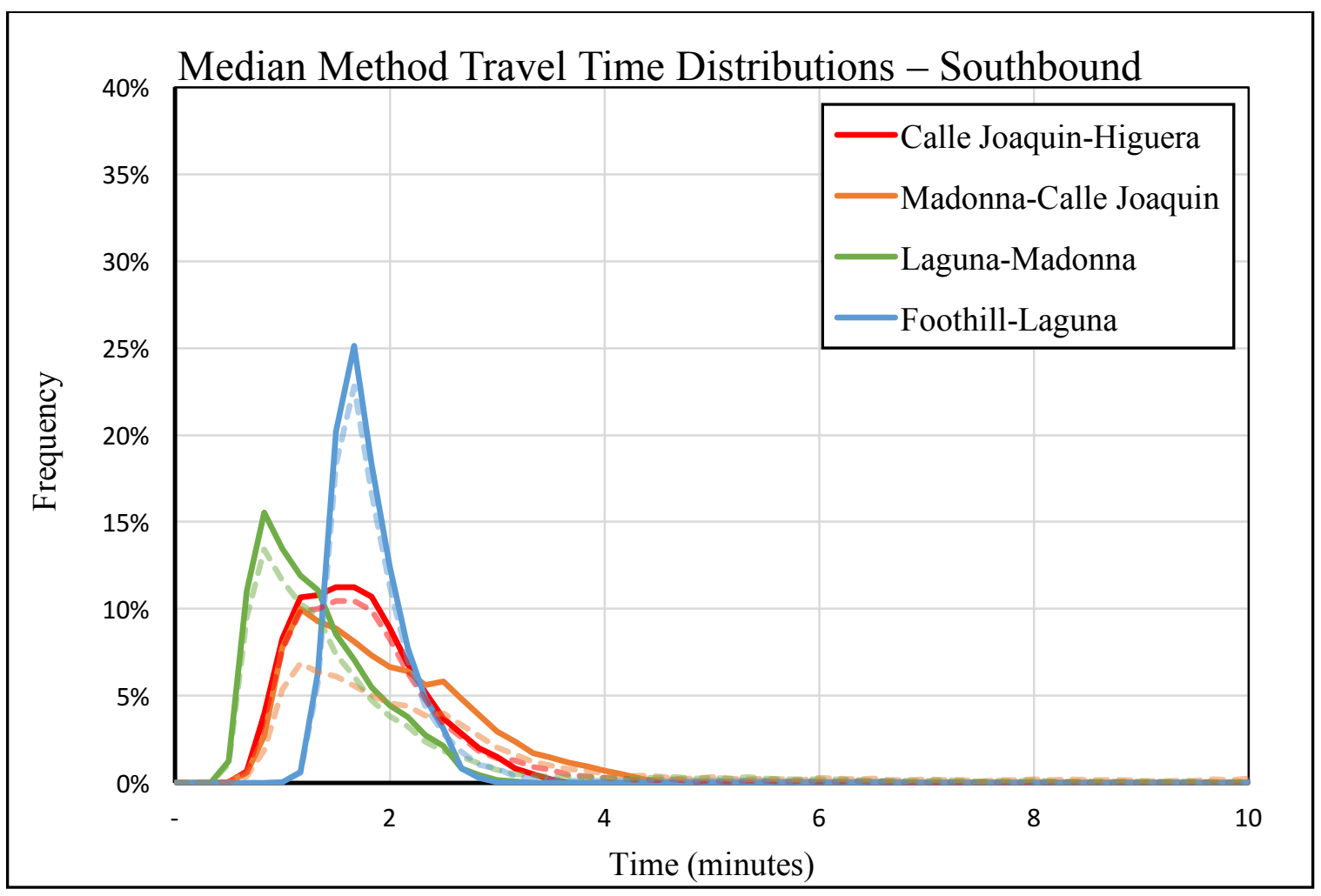

Figure 38: Median Method Travel Time Percentage Distributions - Southbound 
Figures 35 and 37 show no major changes to the travel time distributions. The right tail of the distributions has slimmed, with 6-7 minute trips on these short segments still present. Due to the construction and congestion, these are reasonable. The MadonnaCalle Joaquin segment was further analyzed with space-time diagrams, the results of which are seen in Figures 39 and 40.

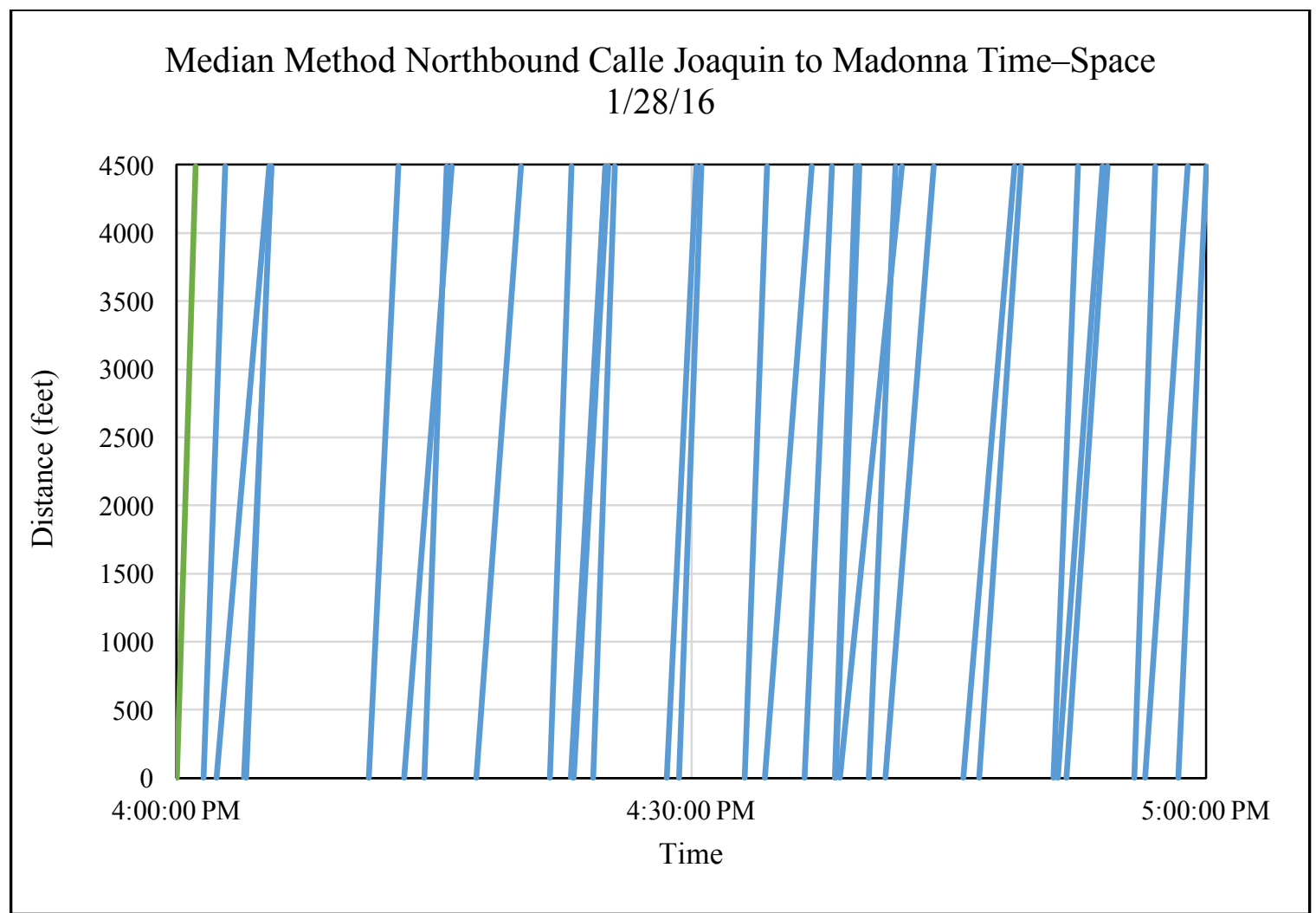

Figure 39: Median Method Time-Space Diagram for Northbound Madonna to Calle Joaquin 


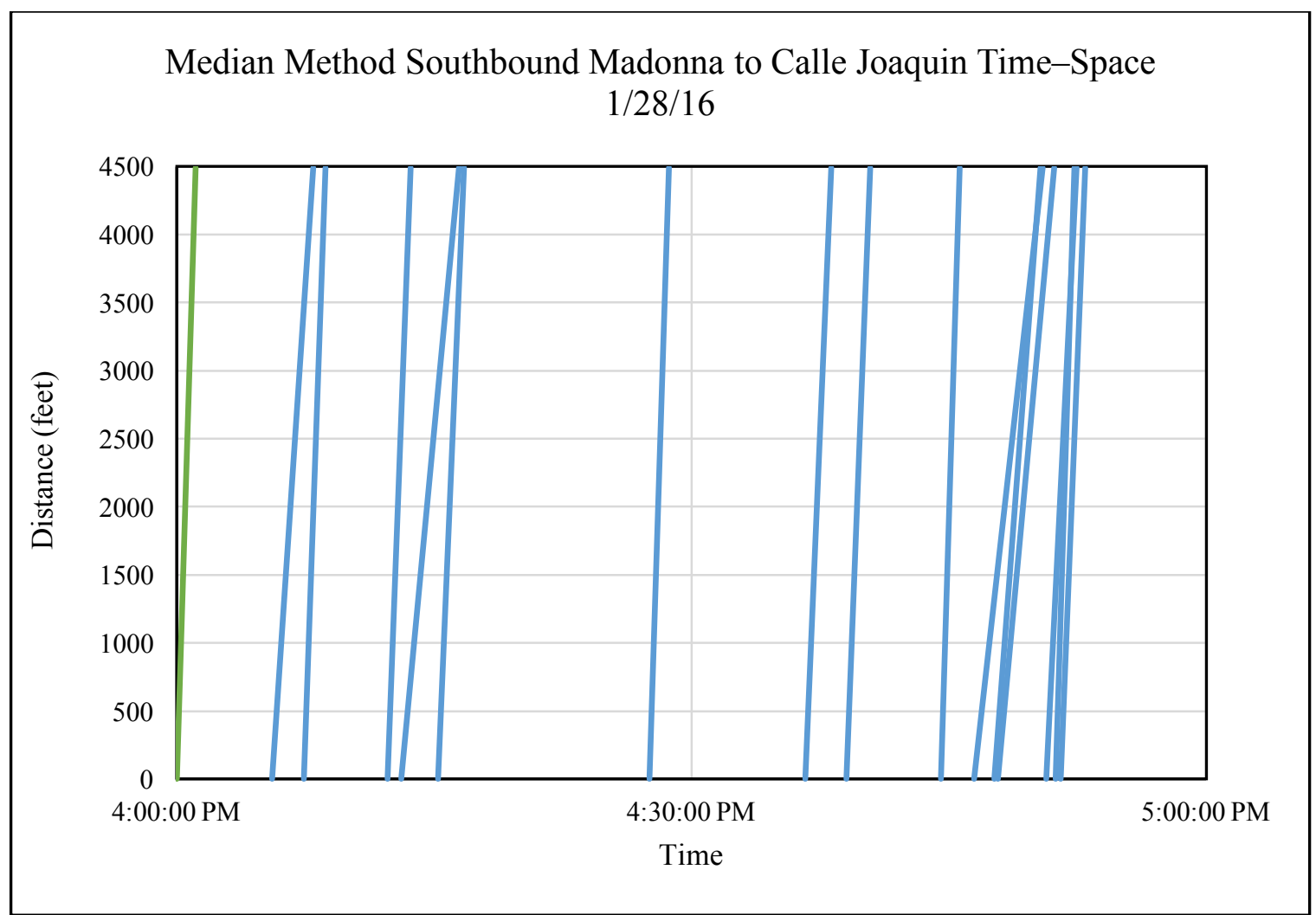

Figure 40: Median Method Time-Space Diagram for Southbound Madonna to Calle Joaquin

The time-space diagrams no longer show the unrealistic trips. In addition, a point-by-point examination of data from January 28, 2016 showed the eliminations to be reasonable and elimination of a valid data point to be unlikely.

For Median Method data, the errors were as follows: 


\begin{tabular}{|c|l|c|c|c|}
\hline \multirow{2}{*}{ Segment } & \multirow{2}{*}{ Direction } & \multicolumn{3}{|c|}{ Error (mph) } \\
\cline { 3 - 5 } & & AM & MID & PM \\
\hline \hline \multirow{2}{*}{ Calle Joaquin-Higuera } & Northbound & 0.40 & 0.29 & 0.26 \\
\cline { 2 - 5 } & Southbound & 0.24 & 0.28 & 0.32 \\
\hline \multirow{2}{*}{ Madonna-Calle Joaquin } & Northbound & 0.49 & 0.48 & 0.40 \\
\cline { 2 - 5 } & Southbound & 0.52 & 0.60 & 0.65 \\
\hline \multirow{2}{*}{ Laguna-Madonna } & Northbound & 0.47 & 0.41 & 0.33 \\
\cline { 2 - 5 } & Southbound & 0.34 & 0.39 & 0.37 \\
\hline \multirow{2}{*}{ Foothill-Laguna } & Northbound & 0.32 & 0.25 & 0.21 \\
\cline { 2 - 5 } & Southbound & 0.31 & 0.30 & 0.33 \\
\hline \hline \multicolumn{2}{|c|}{$0.36 \mathrm{mph}$} \\
\end{tabular}

Table 9: Median Method Error Summary

All errors have decreased from the raw data errors as well as the Outlier-Filtered

method. The maximum error is still well within acceptable means. In addition, the weighted error has decreased to $0.36 \mathrm{mph}, 0.03 \mathrm{mph}$ less than Outlier-Filtered method and $0.12 \mathrm{mph}$ less than the raw data. Therefore, the Median Method dataset will be used for delay analysis and travel time estimation. 


\section{RESULTS}

\subsection{Travel Time Reliability}

Travel times and travel time variability were analyzed and visualized for each segment and each direction. As mentioned earlier, standard reliability performance measures will be computed in this section.

\subsubsection{Calculation of Reliability Metrics}

The first visualization in Figure 41 shows the distribution of all trips and their travel times, with travel times binned in 0.25 -minute intervals. Free flow travel time, median travel time, mean travel time, and 95th percentile travel time are indicated on each graph. Free flow travel time is calculated by dividing the segment length by the 85th percentile speeds from the City of San Luis Obispo's Speed Surveys. Median travel time is the middle value of the dataset. Mean travel time is a sum of all sample travel times divided by the sample size. 95th percentile travel time is the travel time at which $95 \%$ of all trips are at or below this travel time. These values were further analyzed to yield the planning time index, buffer time, buffer index, and coefficient of variation. Equations for these values were defined in the literature review and are shown below (Neudorff, Randall, Reiss, \& Gordon, 2006):

$$
\begin{aligned}
& \text { Planning Time Index }=\frac{95 \text { th Percentile Travel Time }(\mathrm{min})}{\text { Free Flow Travel Time }(\mathrm{min})} \\
& \text { Buffer Time (min) } \\
& =\text { 95th Percentile Travel Time ( } \mathrm{min} \text { ) } \\
& \text { - Average Travel Time (min) } \\
& =\frac{95 \text { th Percentile Travel Time }(\mathrm{min})-\text { Average Travel Time }(\mathrm{min})}{\text { Average Travel Time }(\mathrm{min})}
\end{aligned}
$$




$$
\text { Coefficient of Variation }=\frac{\text { Standard Deviation of Travel Time }(\mathrm{min})}{\text { Average Travel Time }(\mathrm{min})}
$$

These metrics are reported for each segment and direction on their respective distribution figure. Distributions and standard deviations are also visualized for each segment and direction by time-of-day, with an overlay of detected devices.

\subsubsection{Reliability Results}

Figure 41 is a classic reliability plot, showing the distribution (percent of trips) measured at a range of travel times. As shown in the figure, the free flow travel time for this $0.52-$ mile segment is $0.76 \mathrm{~min}$ (corresponding to $41 \mathrm{mph}$ ). Travel times extend beyond the 5-minute mark, with all trips greater than 5 minutes condensed into the final point on Figure 41, hence the "spike" toward the right side of the graph. The most frequent travel time is the $1.25-1.49$ minutes bin, with $15 \%$ of trips. The median travel time is $1.90 \mathrm{~min}(16.4 \mathrm{mph})$ and the mean is $2.28 \mathrm{~min}(13.7 \mathrm{mph})$. The 95 th percentile travel time is $5.28 \mathrm{~min}(5.9 \mathrm{mph})$. Northbound Higuera to Calle Joaquin shows the highest buffer index of all the study segments and directions. Construction on this segment in addition to high congestion caused high variability in travel time. The maximum travel time in the processed data set is 7.93 minutes. Distributions are shown in Figure 41.

Figure 41 also reports the reliability measures defined above. The Planning Time Index is 6.94 , the Buffer Time is $3.00 \mathrm{~min}$, the Buffer Index is 1.32 and the Coefficient of Variation is $55.4 \%$.

Figure 42 shows the segment travel time for weekdays by hour. The horizontal green line indicates the free flow travel time based on the 85 th percentile speed provided by the City of San Luis Obispo. The blue line indicates how the mean travel time varies 
over the day, with the grey error bars indicating plus and minus one standard deviation.

This indicates that there was a low peak at noon and a higher peak at 5 PM, with a mean travel time of $4.42 \mathrm{~min}$ (corresponding to $7.1 \mathrm{mph}$ ) and a standard deviation of 1.61 minutes. Standard deviations decrease to 0.6 minutes or less for most of the day. The purple line shows the detection rates of Bluetooth devices over the day (right hand $y-$ axis) with a peak of nearly 25 devices detected per hour between 5-6 PM. This is consistent with historical traffic distributions. Figure 42 shows time-of-day performance in more detail.

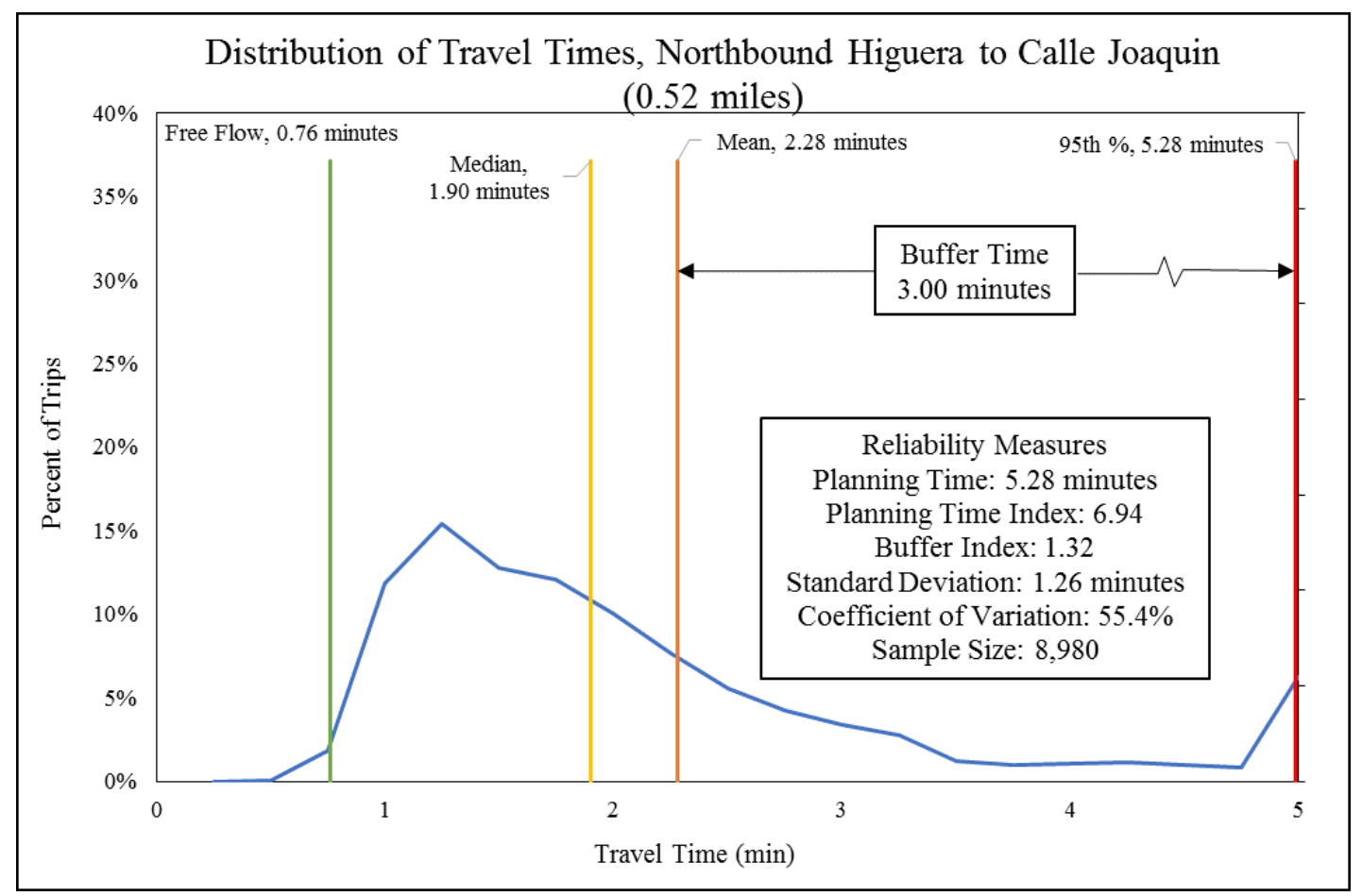

Figure 41: Northbound Higuera to Calle Joaquin Travel Time Reliability 


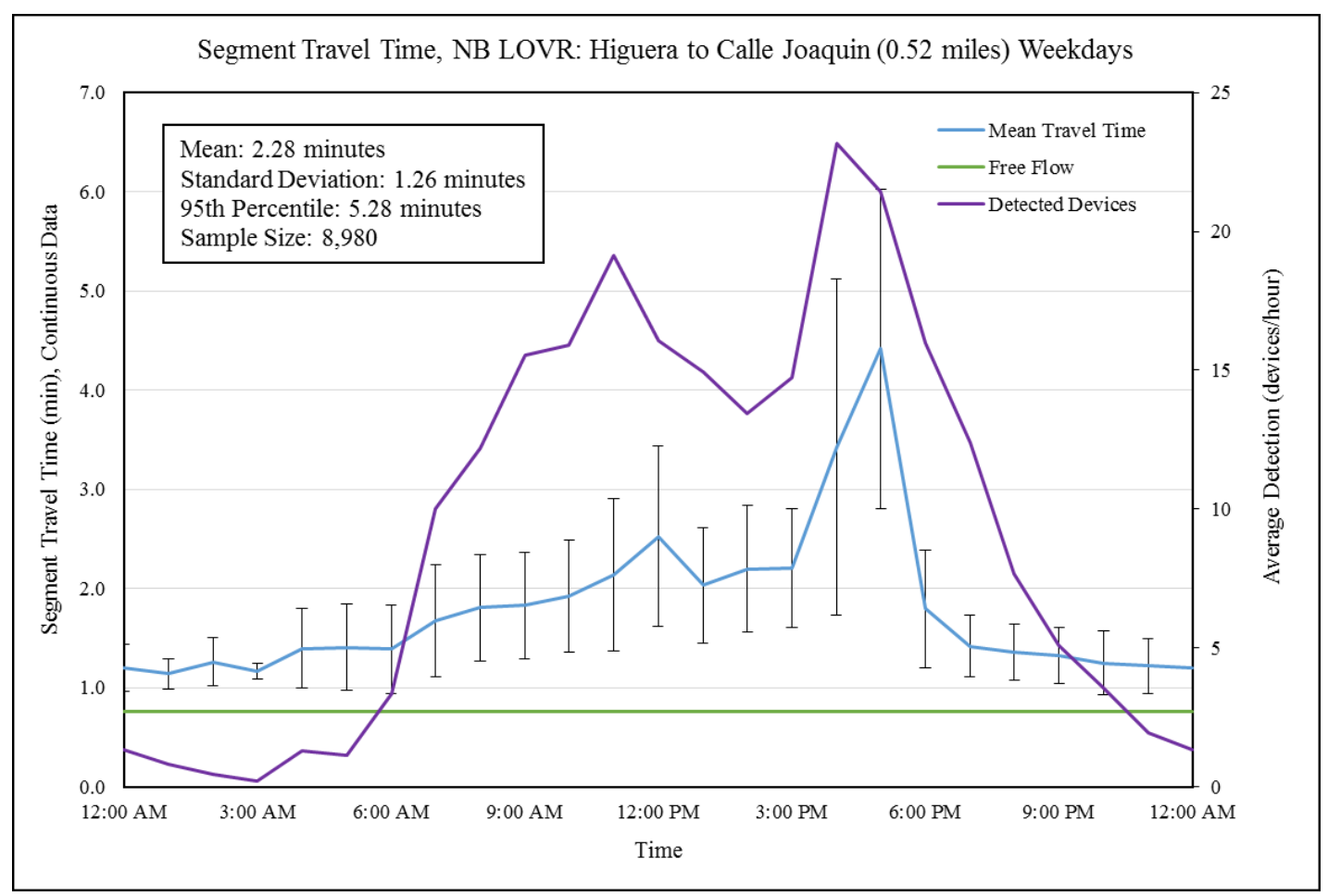

Figure 42: Northbound Higuera to Calle Joaquin Reliability by Time-of-Day

Figure 43 indicates that Northbound Calle Joaquin to Madonna shows a distribution shape similar to Northbound Higuera to Calle Joaquin. However, all of the reliability measures show values near half of the Higuera to Calle Joaquin values, reflecting the construction impact on congestion and reliability. The most frequent travel time on Northbound Calle Joaquin to Madonna is the 1.25-1.49 minute range, with 19\% of trips. The maximum travel time in the processed data set is 3.97 minutes. Figure 43 shows distributions in more detail.

Standard deviations on Northbound Calle Joaquin to Madonna are consistent throughout the day. The highest mean travel time of 2.02 minutes and highest standard deviation of 0.67 minutes occurred at 12 PM. This segment of Los Osos Valley Road has at least two lanes in each direction, with three lanes in each direction for the majority of the segment. This could mitigate variability at AM, MID, and PM peak periods with increased capacity. A signal at Froom Ranch Way provides access to major retail and 
service mid-study segment. The high traffic flows throughout the day to these commercial areas likely causes consistent delays at the intersection and therefore consistent travel times throughout the day. Figure 44 shows time-of-day performance in more detail.

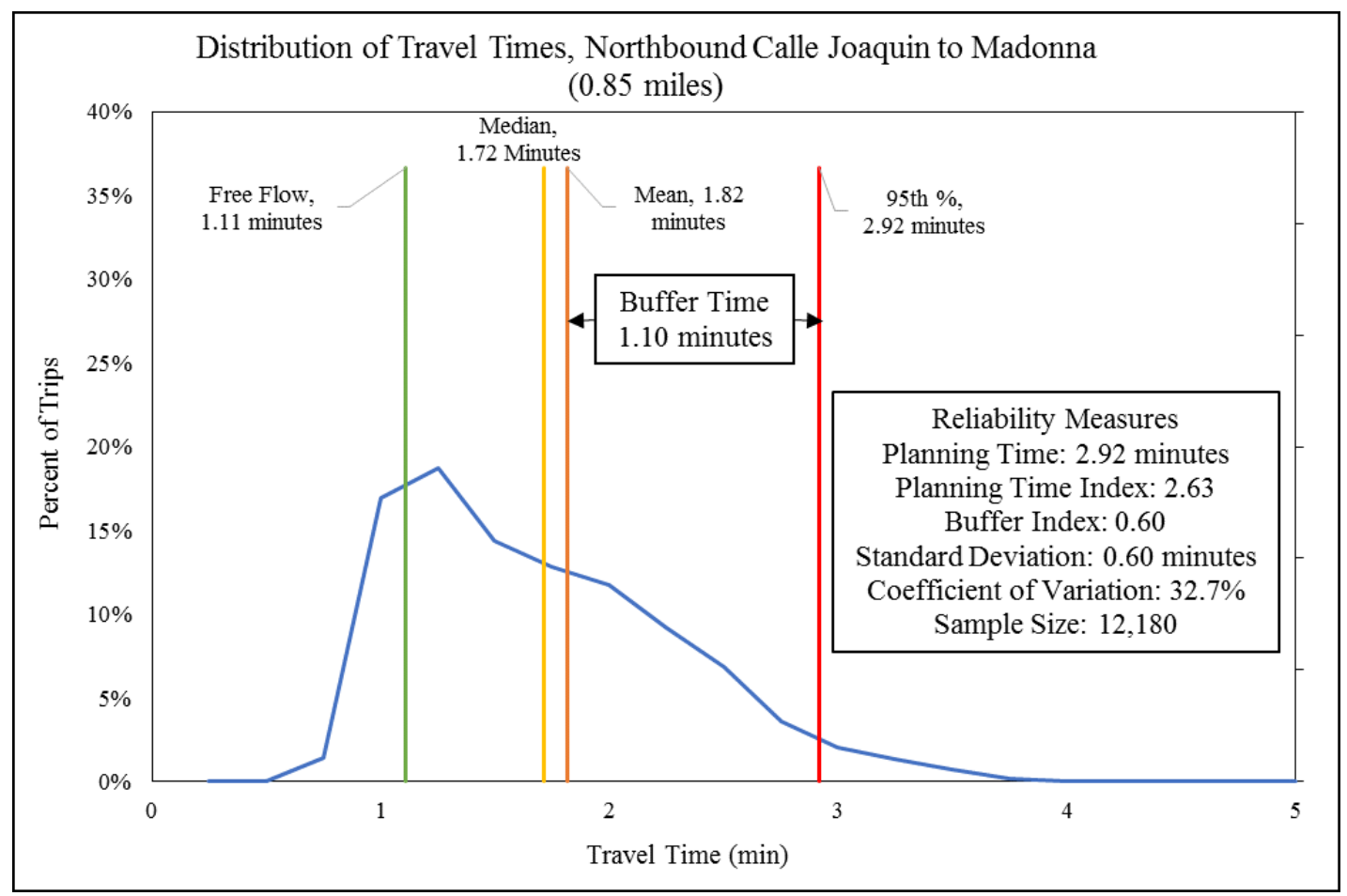

Figure 43: Northbound Calle Joaquin to Madonna Travel Time Reliability 


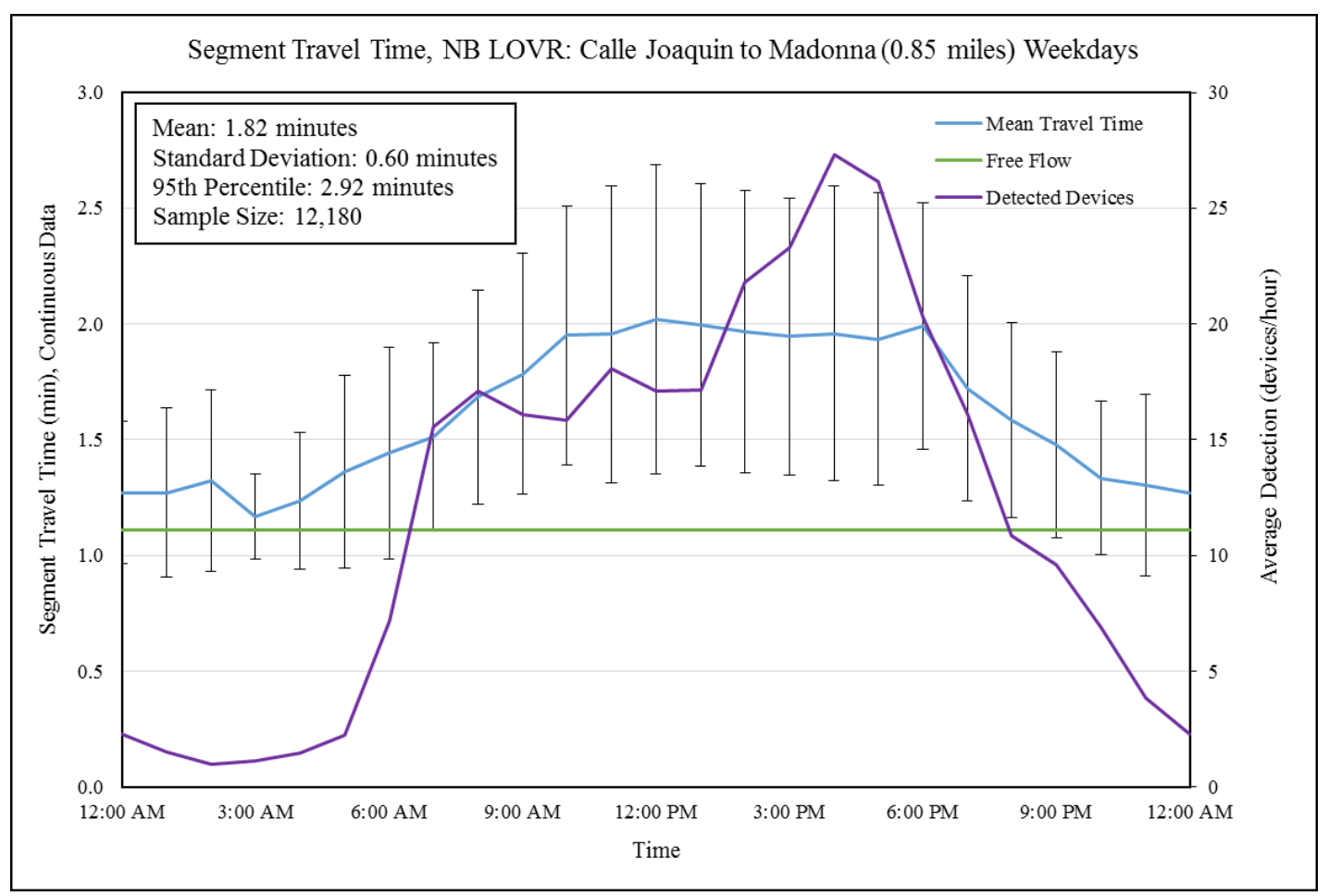

Figure 44: Northbound Calle Joaquin to Madonna Reliability by Time-of-Day

Northbound Madonna to Laguna shows a much sharper peak in travel times than the Higuera to Calle Joaquin or Calle Joaquin to Madonna segments. However, reliability measures show higher values than the Calle Joaquin to Madonna segment for each measure except planning time. The most frequent travel time on Northbound Madonna to Laguna is in the $0.75-0.99$ minute range, with $33 \%$ of trips. The maximum travel time from the processed data set is 2.93 minutes. Figure 45 shows distributions in more detail.

Northbound Madonna to Laguna shows standard deviations higher toward the AM and PM peak periods, with the highest mean travel time of 1.51 minutes and highest standard deviation of 0.59 minutes occurring at 8 AM. Laguna Middle School begins classes at 8:15 AM Tuesdays through Fridays and 9:25 AM on Mondays. The higher traffic flows and variability is likely due to student drop-off and queue spillback onto Los Osos Valley Road. Figure 46 shows time-of-day performance in more detail. 


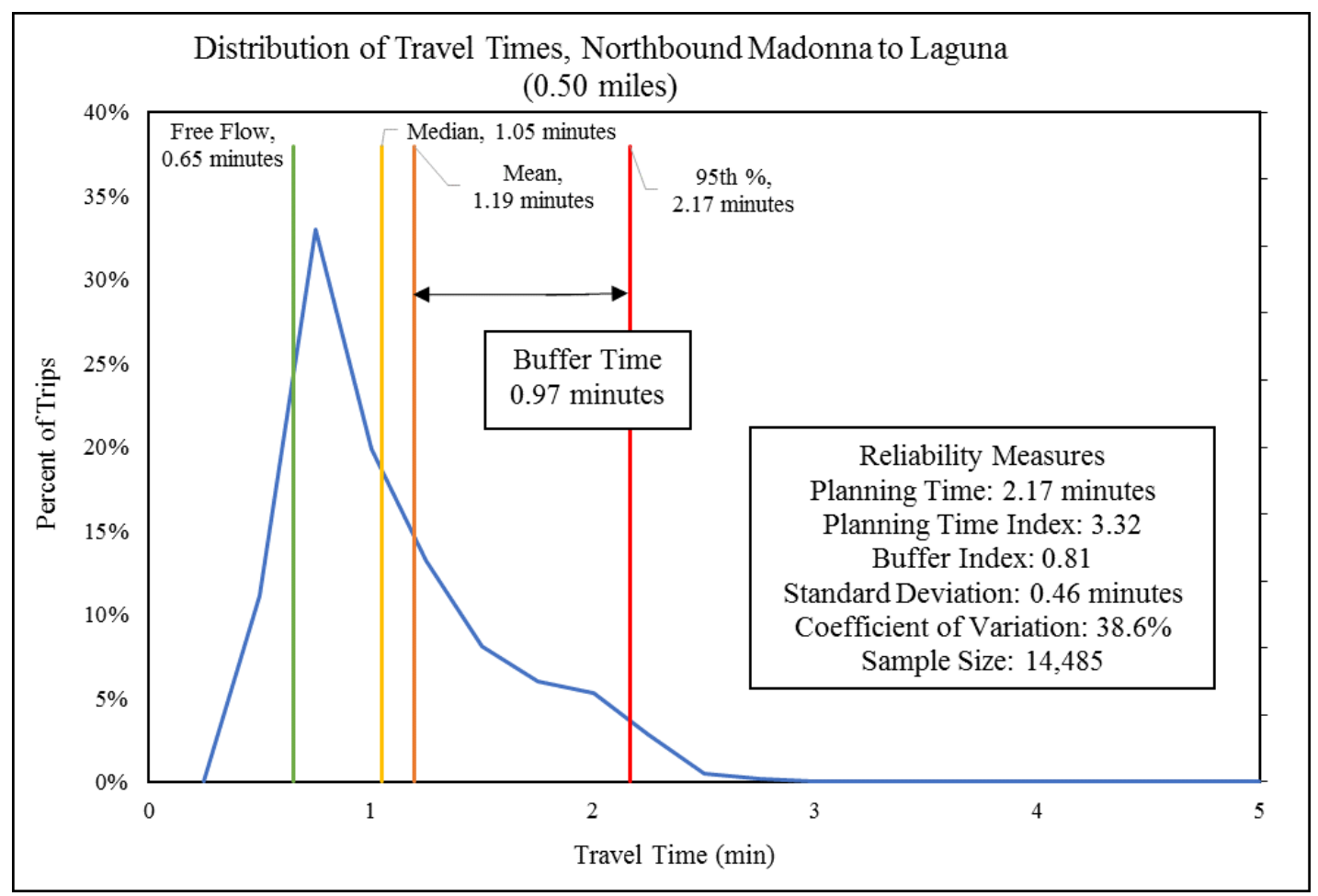

Figure 45: Northbound Madonna to Laguna Travel Time Reliability

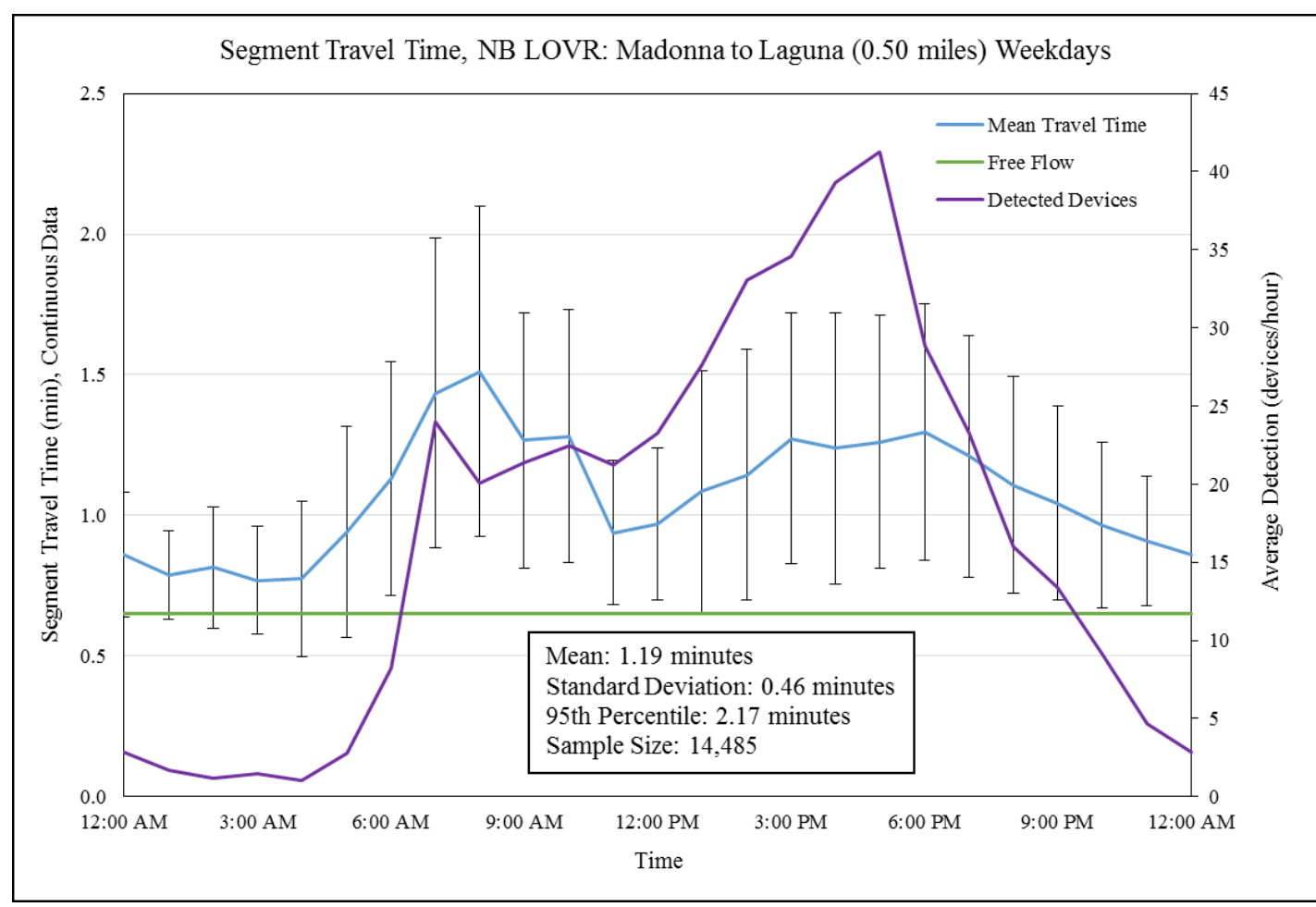

Figure 46: Northbound Madonna to Laguna Reliability by Time-of-Day

Northbound Laguna to Foothill's distribution is reflective of its lack of mid-

segment access points and signal delay. Reliability measures show higher performance 
here than on other portions of Los Osos Valley Road, with higher speeds and fewer interruptions. The most frequent travel time on Northbound Laguna to Foothill is in the $1.50-1.74$ minute range, with $33.4 \%$ of trips, followed closely by the $1.75-1.99$ minute range, with $33.3 \%$ of trips. The maximum travel time from the processed data set is 2.80 minutes. Figure 47 shows distribution in more detail.

Northbound Laguna to Foothill's mean travel times and standard deviations who consistency throughout the day. Slight peaks in the AM and PM periods reflect typical commuting patterns, with the highest mean travel time being 1.98 minutes between 5 PM and $6 \mathrm{PM}$ and the highest standard deviation of 0.31 minutes at $7 \mathrm{AM}$ and $8 \mathrm{AM}$, potentially due to the southern end's proximity to Laguna Middle School. Figure 48 shows time-of-day performance in more detail.

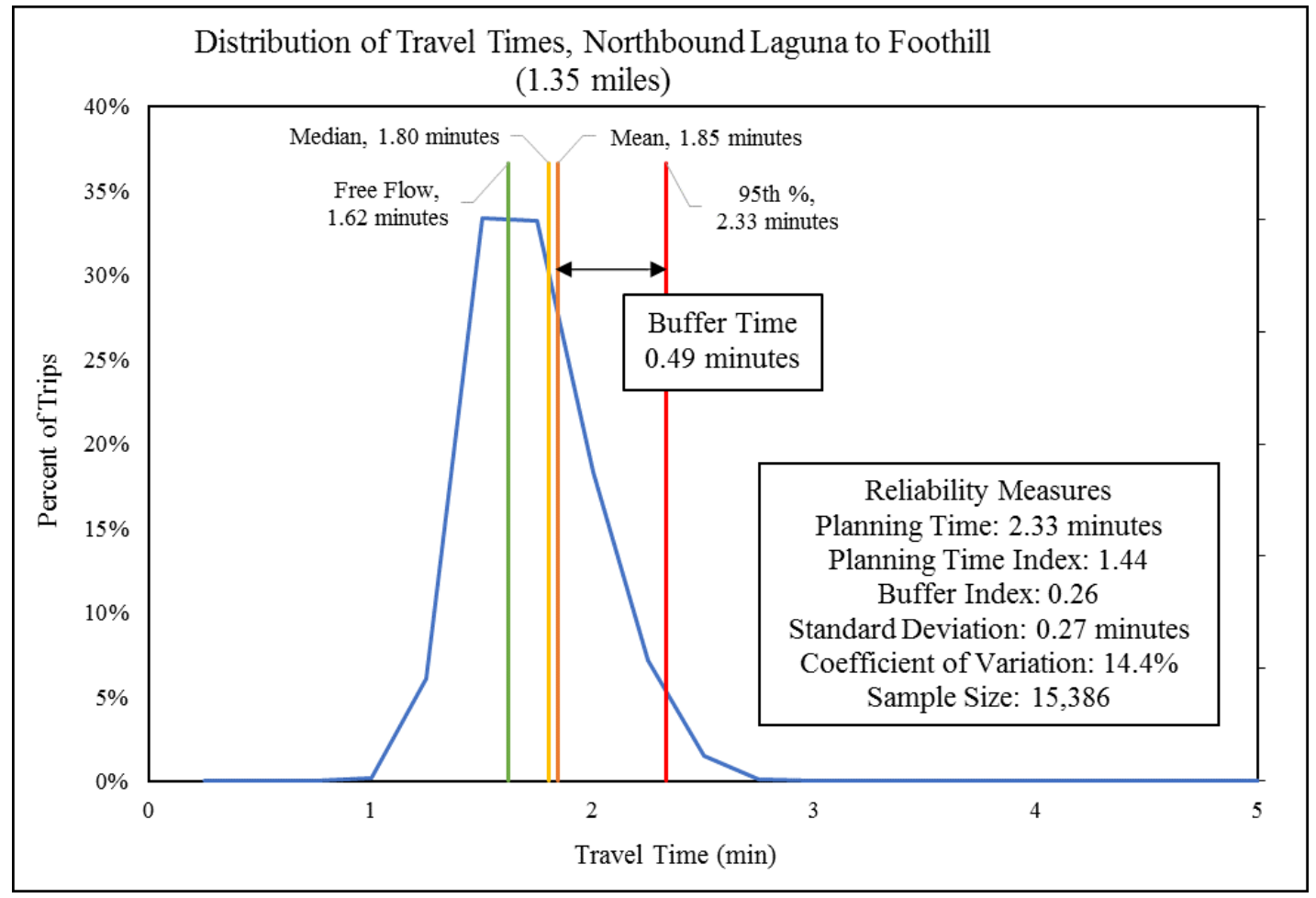

Figure 47: Northbound Laguna to Foothill Travel Time Reliability 


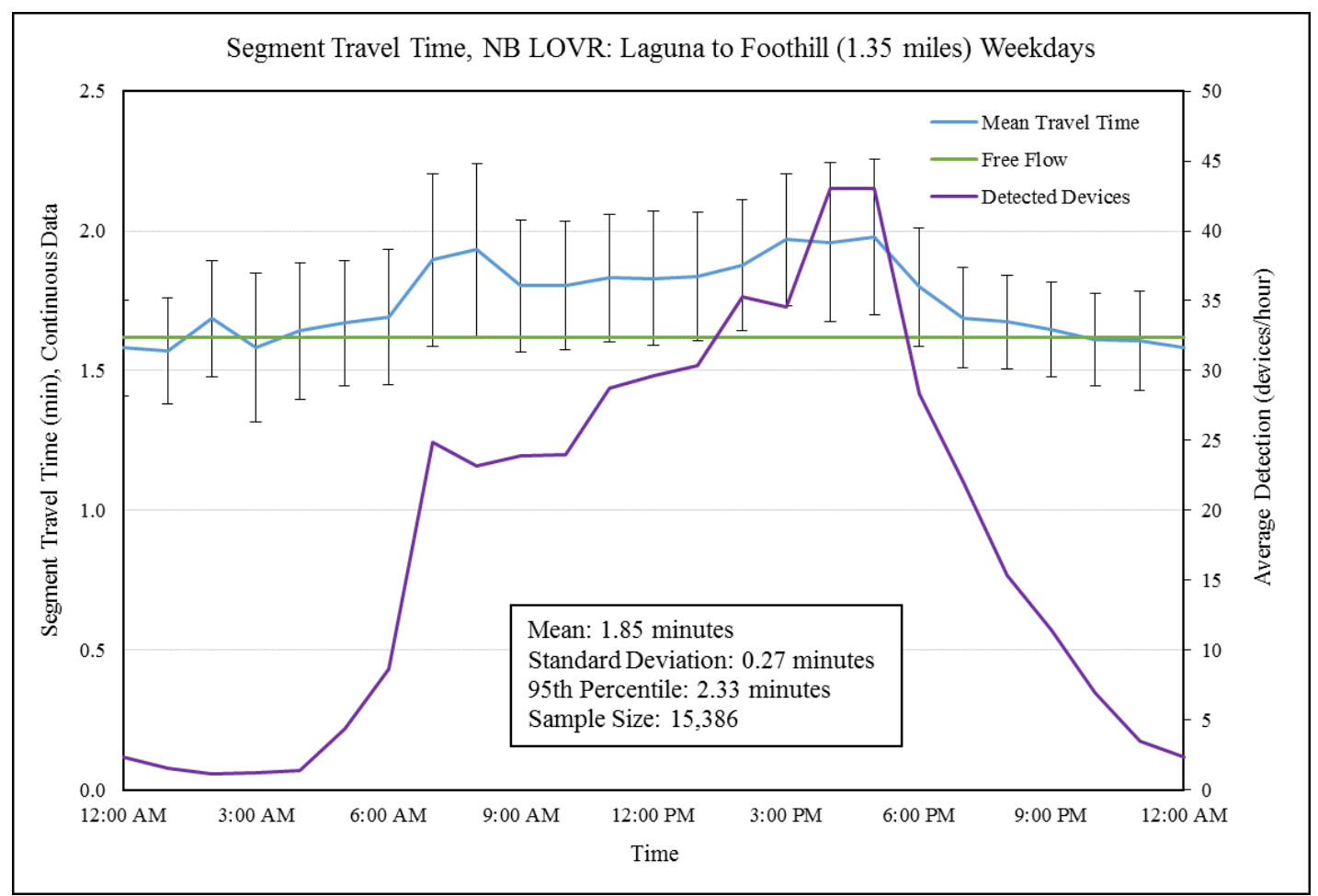

Figure 48: Northbound Laguna to Foothill Reliability by Time-of-Day

Southbound Calle Joaquin to Higuera performs better than its northbound

counterpart. Though it experiences the same construction activity, both on-ramps for US 101 are on the Western side of Los Osos Valley Road. Therefore, southbound vehicles with destinations using US 101 can make permitted right-turn movements at signals, whereas northbound vehicles must wait for left-turns at signals. While these vehicles exiting the roadway aren't accounted for in the Bluetooth detection, they slow down other vehicles on the segment. The most frequent travel time is the $1.50-1.74$ minute bin, with $17 \%$ of trips. No travel times extend beyond the 5-minute mark, with the maximum travel time in the processed data set being 3.62 minutes. Distributions are shown in Figure 49.

Mean travel times and standard deviations are consistent throughout the day. The highest mean travel time is 2.06 minutes in the $8 \mathrm{AM}$ to $9 \mathrm{AM}$ hour, with a standard deviation of 0.53 minutes. The highest standard deviation occurs in the 5 PM to 6 PM 
peak hour, with a mean travel time of 1.89 minutes and a standard deviation of 0.64 minutes. Detection rates of Bluetooth devices are consistent with historical traffic distributions. Figure 50 shows time-of-day performance in more detail.

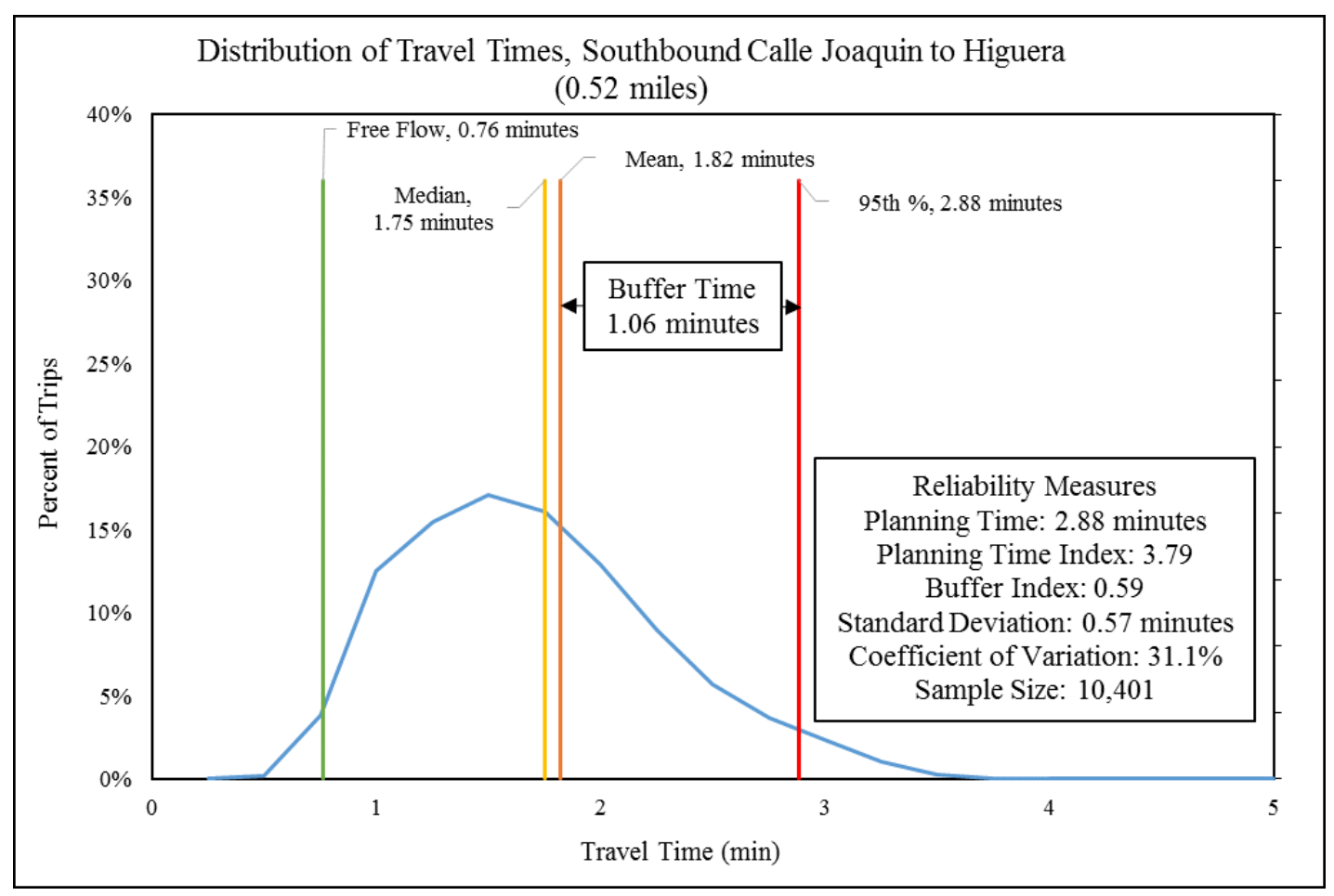

Figure 49: Southbound Calle Joaquin to Higuera Travel Time Reliability 


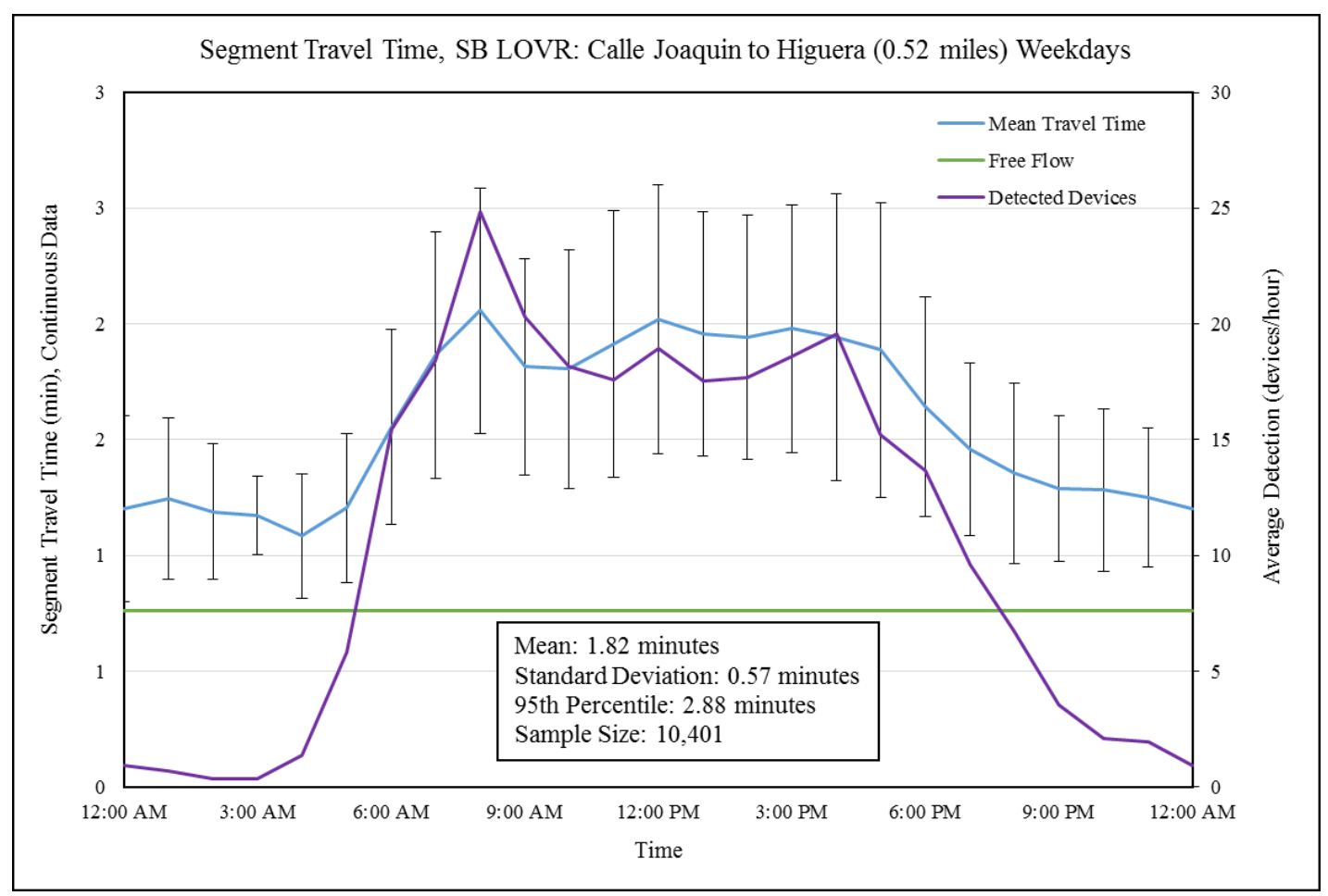

Figure 50: Southbound Calle Joaquin to Higuera Reliability by Time-of-Day

Southbound Madonna to Calle Joaquin performs similarly to the northbound

direction. The shape of the distribution is similar, though the slightly higher 95 th

percentile travel time results in worse reliability measures. Many of the strong attraction land uses are on the east side of Los Osos Valley Road on this portion, therefore northbound vehicles need only turn right while southbound vehicles need to wait to turn left, potentially slowing the vehicles behind them. The most frequent travel time on Southbound Madonna to Calle Joaquin is in the $1.25-1.49$ minutes range, with $16 \%$ of trips. The maximum travel time from the processed data set is 4.52 minutes. Figure 51 shows distributions in further detail.

Southbound Madonna to Calle Joaquin shows standard deviations and mean travel times to be fairly consistent throughout the day. The highest mean travel time, 2.35 minutes, occurs at $10 \mathrm{AM}$, and the highest deviation, 0.82 minutes, occurs at $11 \mathrm{AM}$. 
Several major surrounding land uses open their businesses at this time. Figure 52 shows more detail for time-of-day performance.

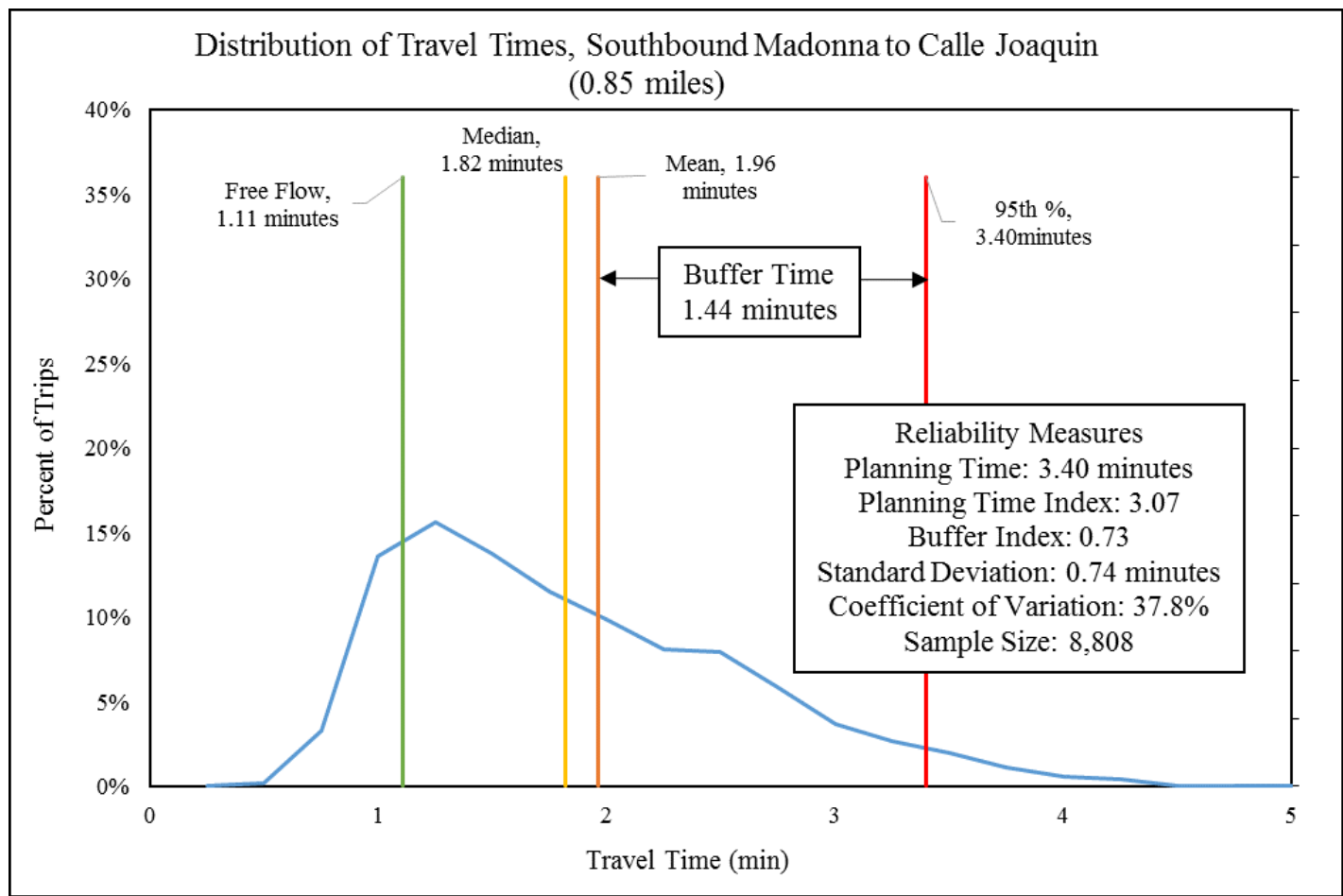

Figure 51: Southbound Madonna to Calle Joaquin Travel Time Reliability

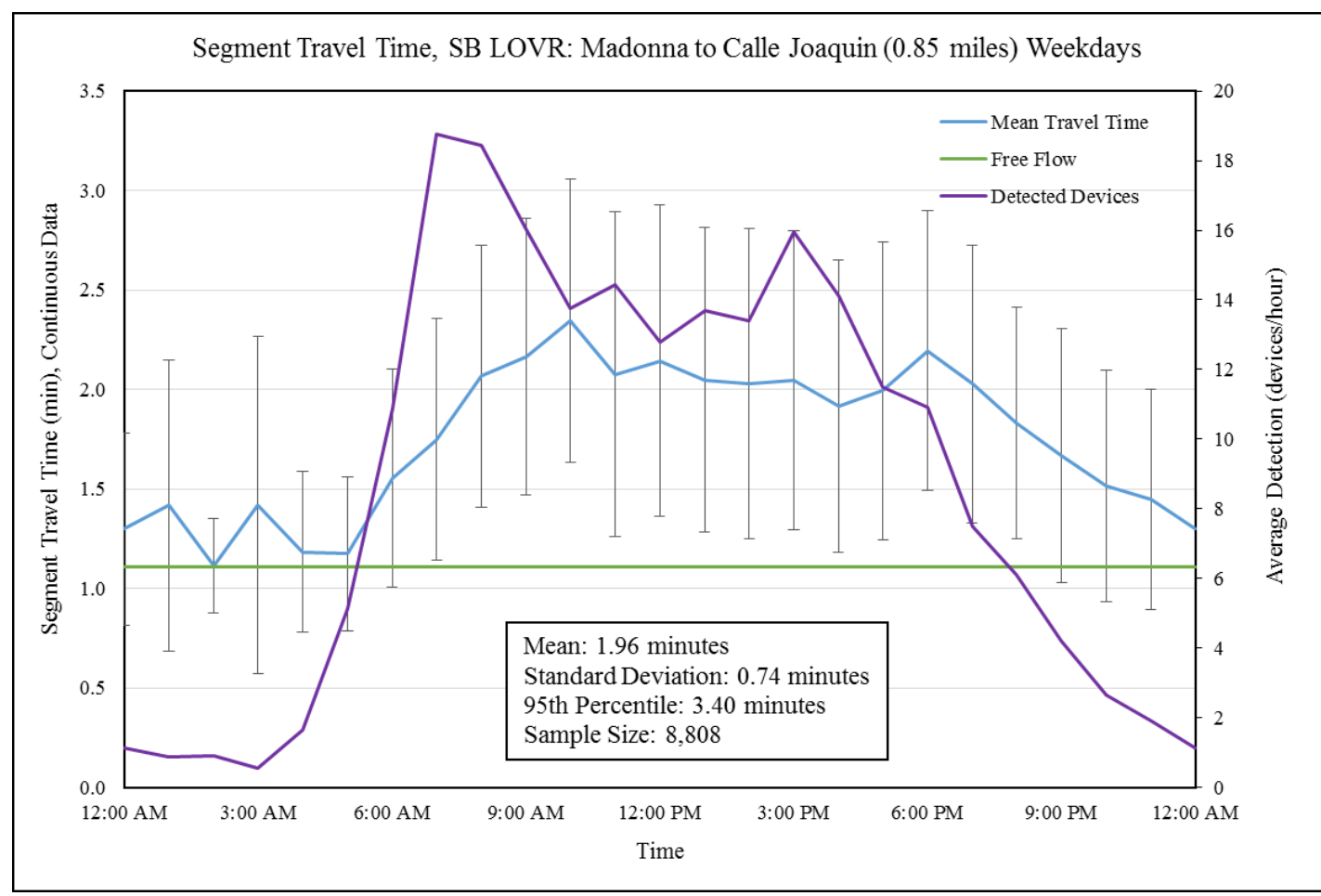

Figure 52: Southbound Madonna to Calle Joaquin Reliability by Time-of-Day 
Southbound Laguna to Madonna similarly to the northbound direction of this segment, with only slight improvement. The distribution shape for southbound doesn't have as sharp of a peak, but the right tail ends near the same 3-minute mark as the northbound. The most frequent travel time on Southbound Laguna to Madonna is in the $0.75-0.99$ minute range, with $22 \%$ of trips. The maximum travel time from the processed data set is 3.23 minutes. Figure 53 shows distributions in further detail.

Southbound Laguna to Madonna shows fluctuating mean travel times but similar standard deviations throughout the day. The AM and PM peak coincide with Laguna Middle School start and end times, hence increased congestion on the roadway at those times. The highest mean travel time, 1.69 minutes, occurs at 3 PM, while the highest standard deviation, 0.61 minutes, occurs at 7 AM. Figure 54 shows more detail for timeof-day performance.

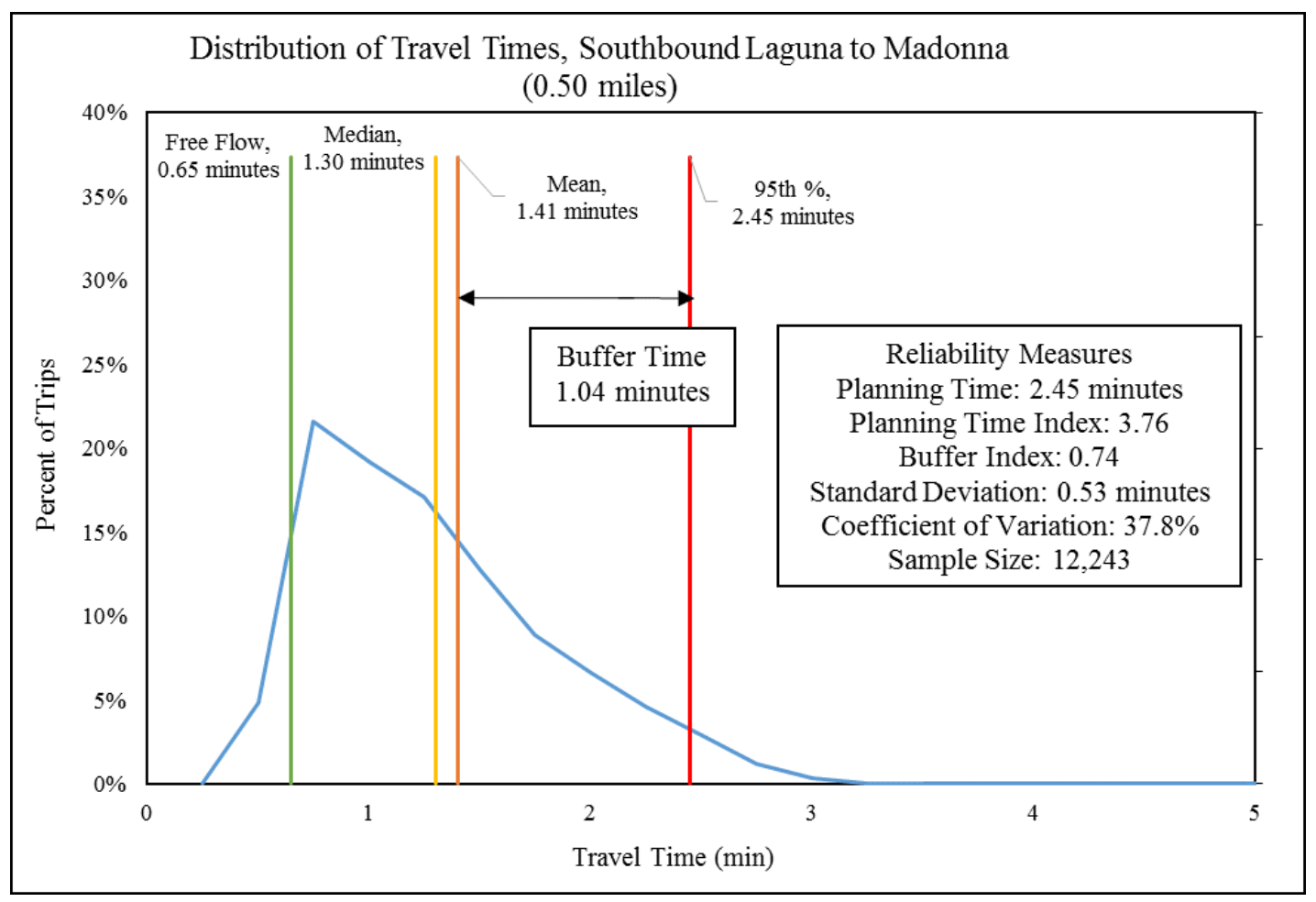

Figure 53: Southbound Laguna to Madonna Travel Time Reliability 


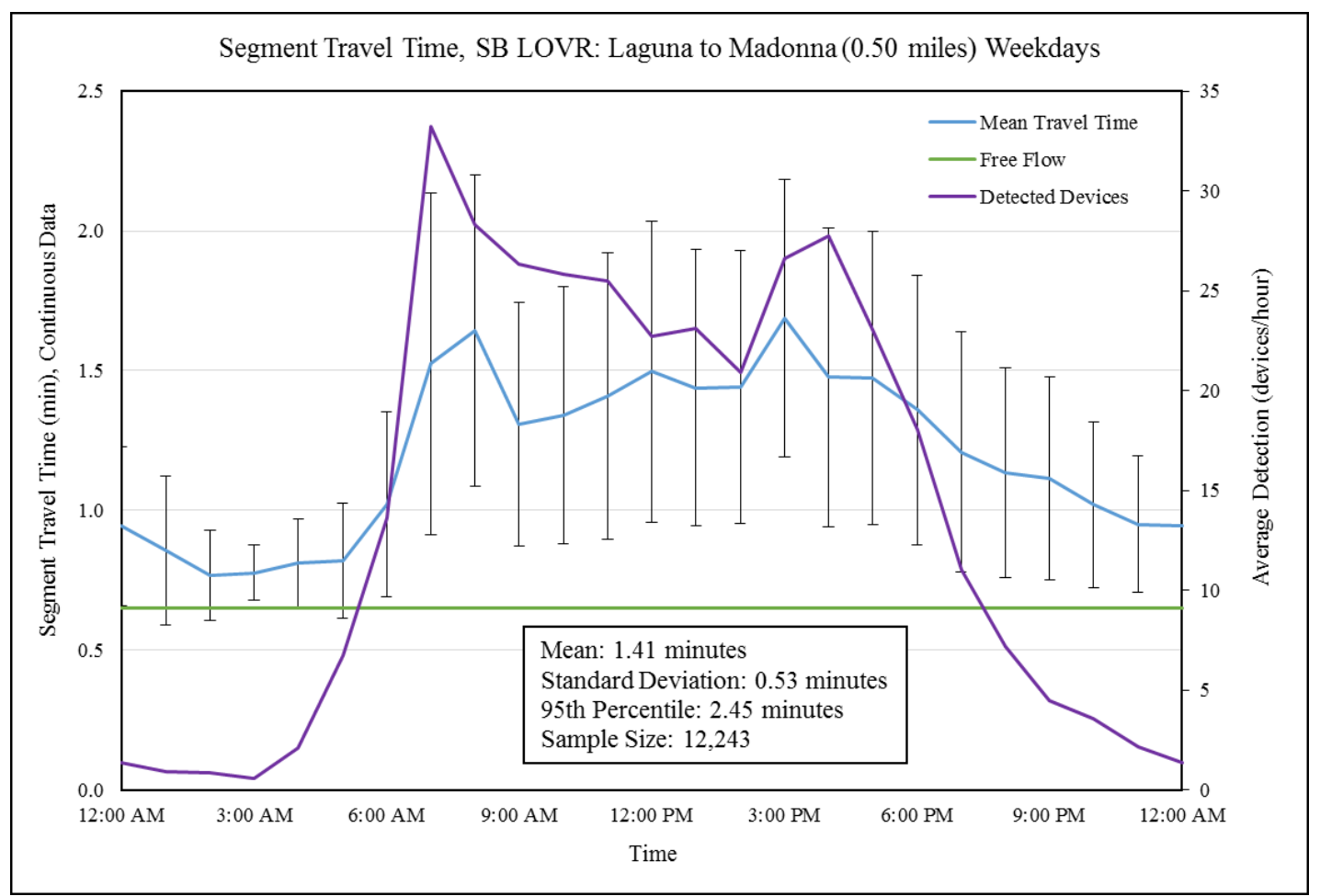

Figure 54: Southbound Laguna to Madonna Reliability by Time-of-Day

Southbound Foothill to Laguna appears to perform nearly the same as the northbound direction of the segment. Reliability measures are slightly worse, but the shape of distributions and spread of free flow, mean, and 95th percentile travel times shows similar results. The most frequent travel time on southbound Foothill to Laguna is in the $1.50-1.74$ minute range, with $32 \%$ of trips, followed closely by the $1.75-1.99$ minute range, with $31 \%$ of trips. The maximum travel time from the processed data set is 3.02 minutes. Figure 55 shows distributions in further detail.

Southbound Foothill to Laguna shows consistent mean travel times and standard deviations throughout the day. The highest mean travel time is at $3 \mathrm{PM}$ at 1.98 minutes. The highest standard deviation occurs at 4 PM and 5 PM, with 0.36 minutes for each hour. Figure 56 shows more detail for time-of-day performance. 


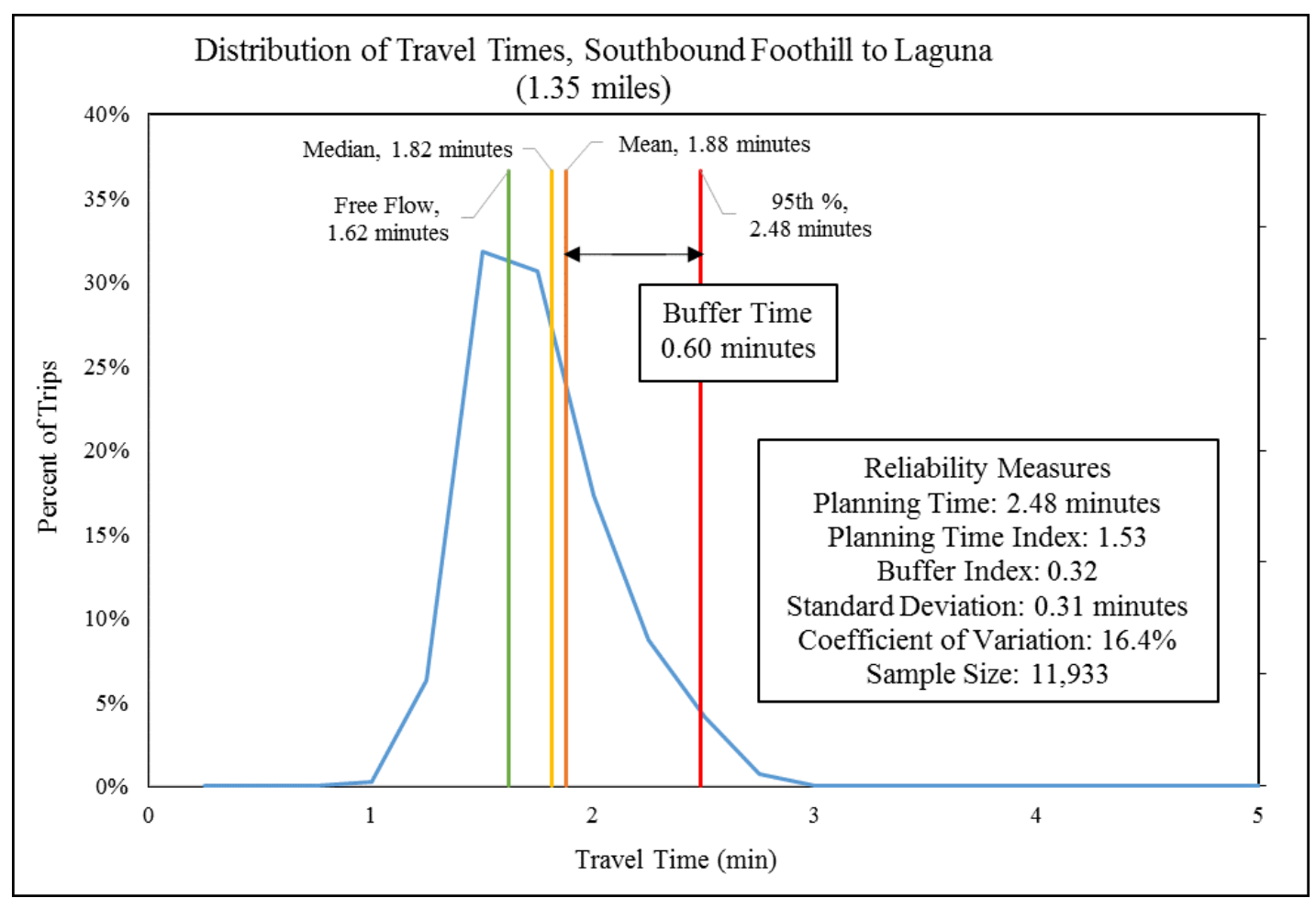

Figure 55: Southbound Foothill to Laguna Travel Time Reliability

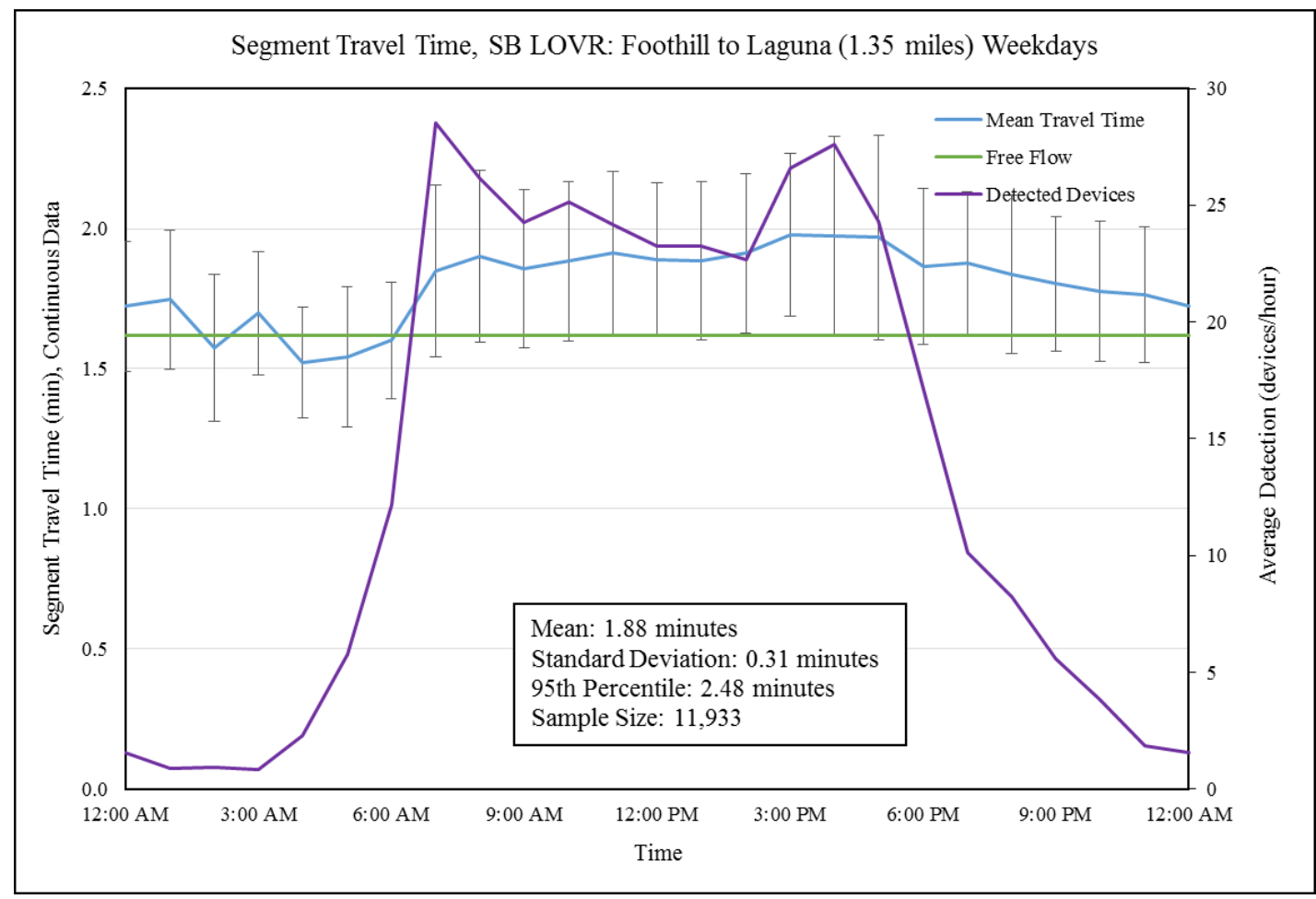

Figure 56: Southbound Foothill to Laguna Reliability by Time-of-Day

Comparing the coefficients of variation for each segment, direction, and peak period yields Figure 57. Higher coefficients of variation refer to higher standard 
deviations compared to average travel times. Based on this parameter, Higuera to Calle Joaquin in the PM peak period and northbound direction performs the worst, while Laguna to Foothill during the MID peak period and northbound direction performs the best.

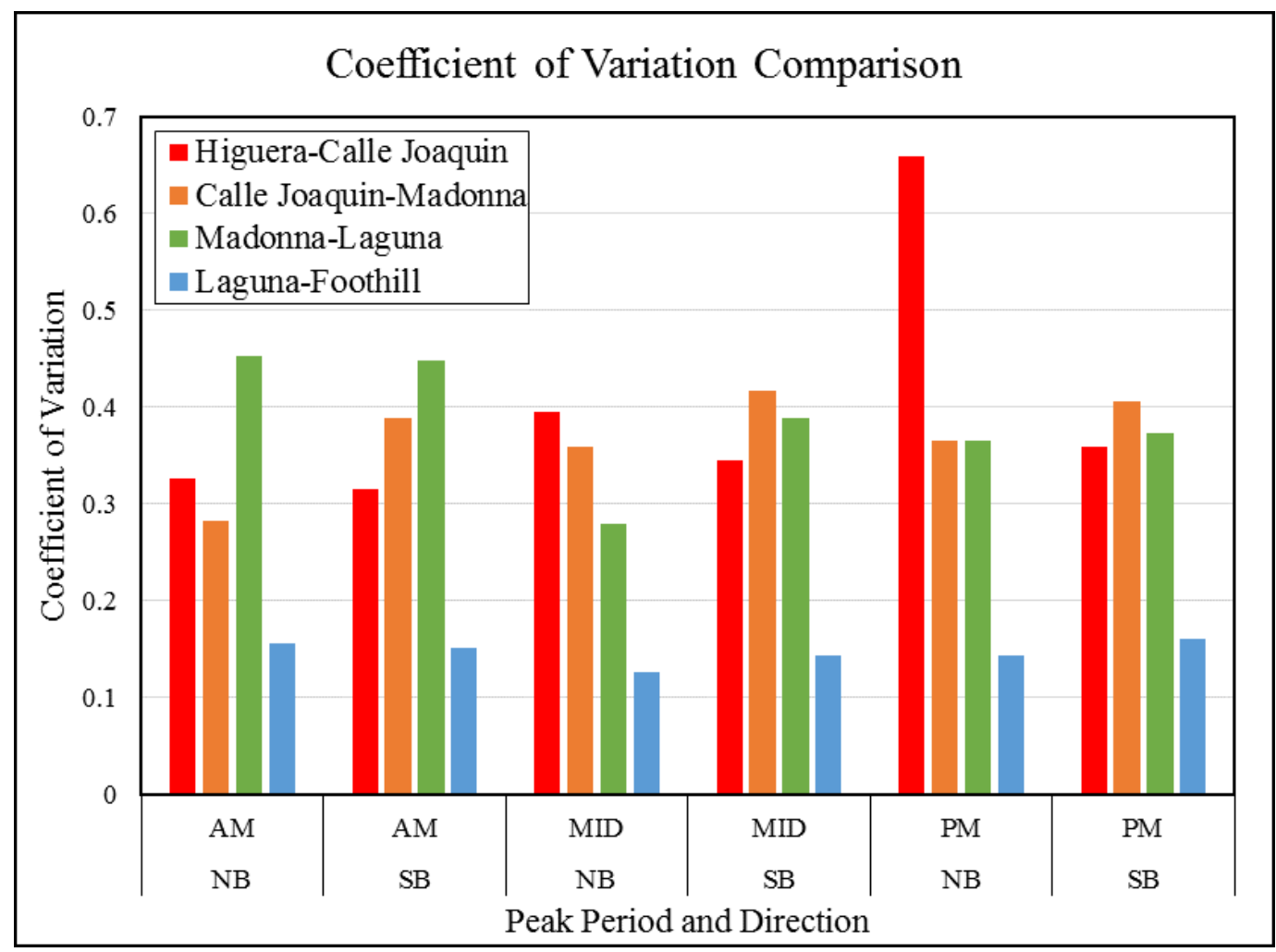

Figure 57: Coefficient of Variation Comparison

Overall, the corridor appears to be performing acceptably. Some delay is expected on arterials, and the amount of acceptable delay can be established in a General Plan, with input from community members and stakeholders. To relate reliability to an existing evaluation method, the coefficient of variation for each peak period, segment, and direction is plotted with the level of service of corridor signals in Figure 58. A lower coefficient of variation corresponds to higher reliability. The general trend shows level of service decreasing with a higher coefficient of variation. However, segments with 
coefficients of variation near 0.35 range in Level of Service from B to D, indicating the relationship is not reliably correlated.

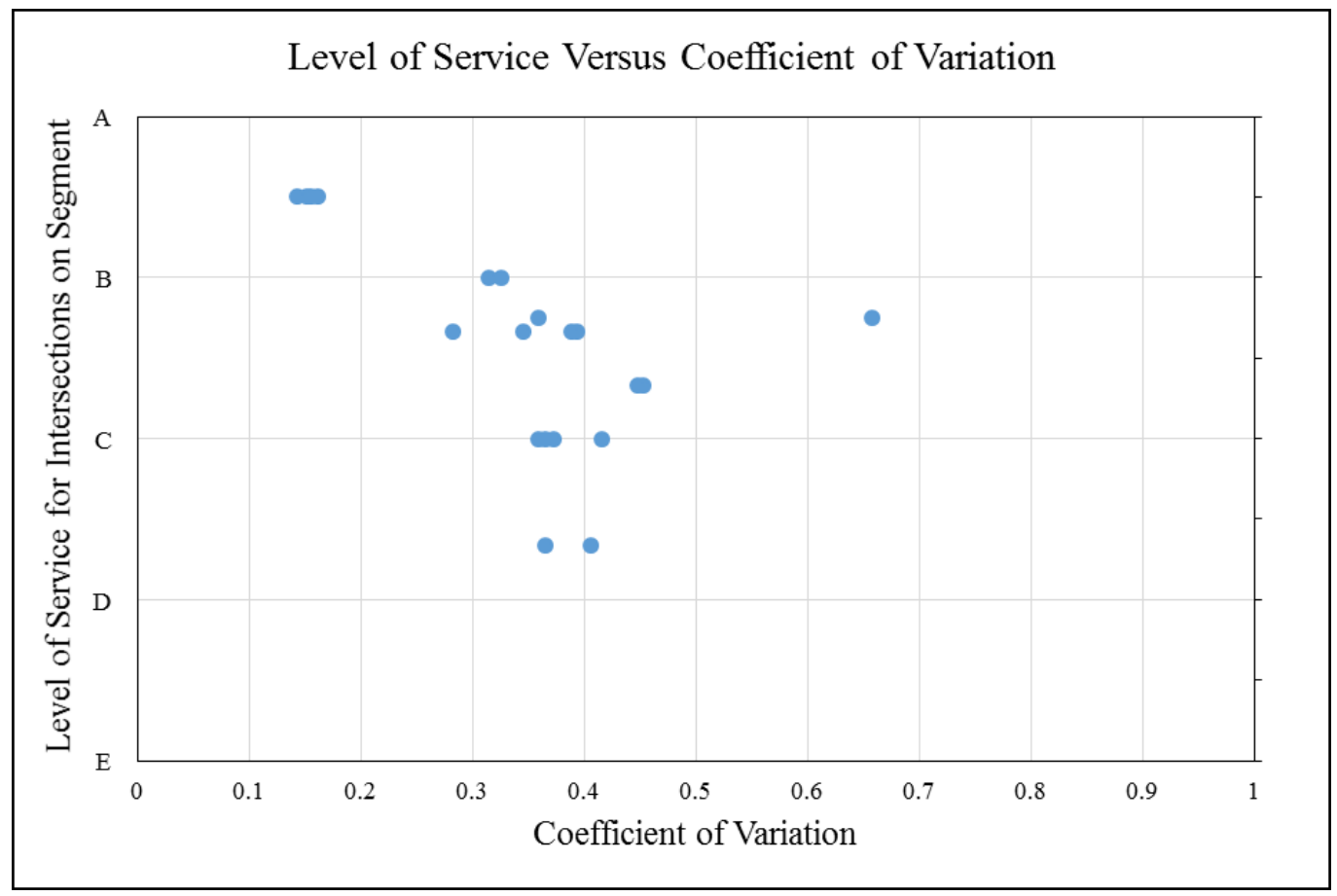

Figure 58: Level of Service vs. Coefficient of Variation

\subsection{Delay Analysis}

Delay has been calculated as the difference between mean travel time and the free flow travel time. The free flow travel time was previously defined as the length of the segment divided by the 85 th percentile speeds of the segment.

The northbound delay has been broken down by each segment's contribution to total delay. Higuera to Calle Joaquin shows significant contributions of delay, especially in the PM peak period. This is consistent with the time-of-day segment travel time results. Calle Joaquin to Madonna shows slightly higher delay in the MID and PM peak periods. Madonna to Laguna shows higher AM and PM delays. Laguna to Foothill's consistent travel times are further reflected in consistent delays across the peak periods. For the northbound direction, the PM peak period has the highest delays. This suggests a 
commute pattern with heavier northbound splits in the PM. As many residential areas and the unincorporated town of Los Osos to the north may use this corridor for commuting, the pattern is reasonable. Details can be seen in Figure 59.

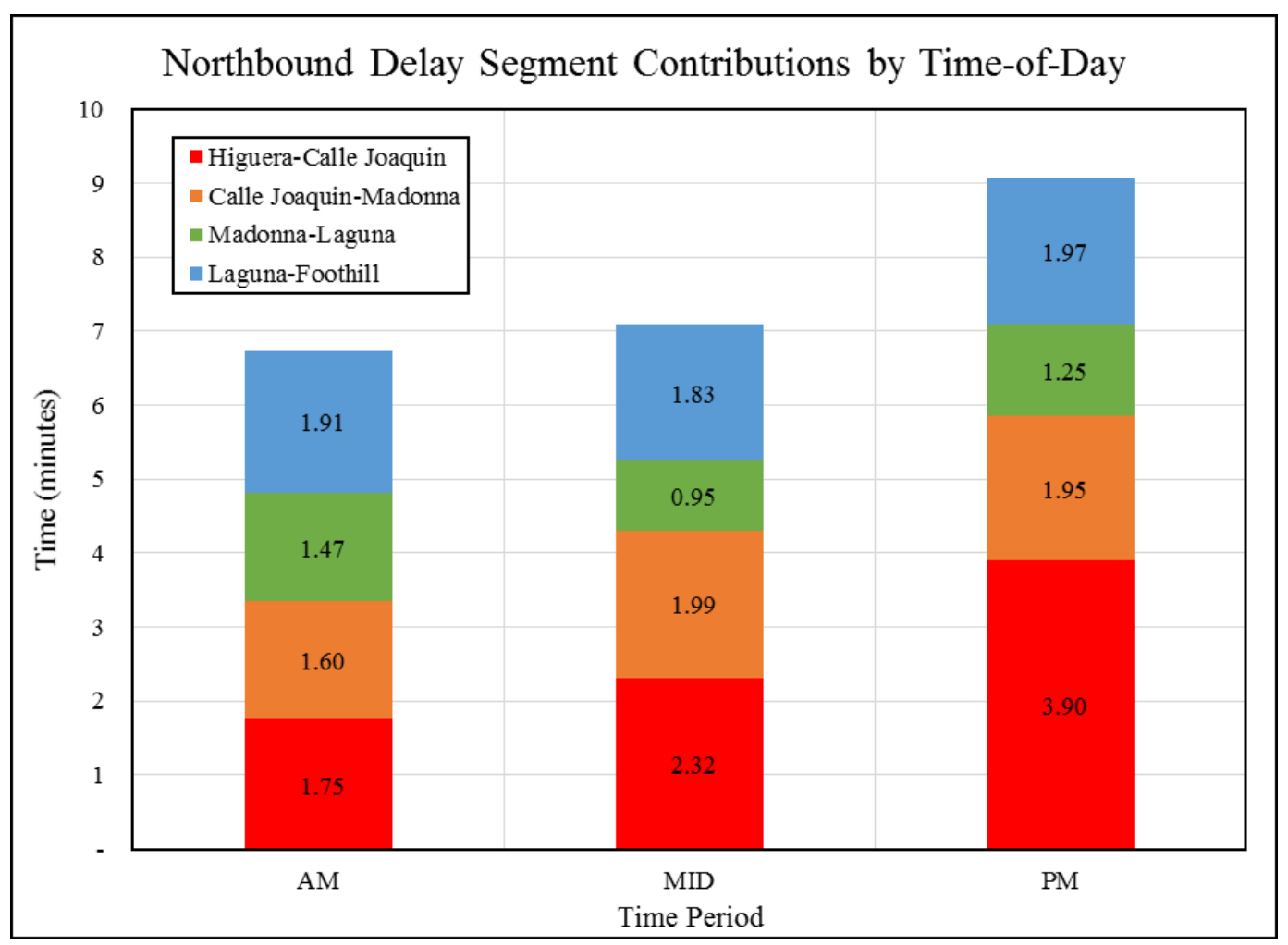

Figure 59: Segment Contributions to Northbound Delay by Time-of-Day

In addition to the segment-by-segment analyses, the Bluetooth devices detected along the entire corridor, from Higuera to Foothill for northbound or Foothill to Higuera for southbound, were analyzed. Theoretically, the mean travel time calculated for the entire corridor should be similar in value to the travel time calculated by summing each segment's mean delay. However, vehicles turning onto or off of the Los Osos Valley Road corridor may experience different travel times than a through-vehicle, and thus the values may differ. The same data processing methods were applied to the corridor-long data sets as the segment-by-segment data sets. Results are shown in Table 10. 


\begin{tabular}{|c|c|c|c|c|}
\hline Peak Period & Direction & $s$ & $\mathrm{n}$ & Error (mph) \\
\hline \multirow{2}{*}{ AM } & Northbound & 4.28 & 2 & 5.94 \\
\cline { 2 - 5 } & Southbound & 3.88 & 16 & 1.90 \\
\hline \multirow{2}{*}{ MID } & Northbound & 9.93 & 14 & 5.20 \\
\cline { 2 - 5 } & Southbound & 9.84 & 13 & 5.35 \\
\hline \multirow{2}{*}{ PM } & Northbound & 6.41 & 10 & 3.97 \\
\cline { 2 - 5 } & Southbound & 3.12 & 17 & 1.48 \\
\hline \hline \multicolumn{3}{|c|}{$3.47 \mathrm{mph}$} \\
\hline
\end{tabular}

Table 10: Higuera to Foothill Data Set Statistics

The southbound AM peak period and both directions of the PM peak period were within acceptable error. However, the northbound AM peak period and both directions of the MID peak period had maximum errors above the acceptable range. Low data sets are likely due to the higher speeds at the Foothill intersection, meaning slimmer chances of Bluetooth detection.

The northbound direction shows similar travel time results when comparing segment-by-segment cumulative mean travel times and Higuera to Foothill travel times. The higher slopes of the Higuera to Calle Joaquin and Madonna to Laguna lines indicate a higher delay per mile contribution. Calle Joaquin to Madonna and Laguna to Foothill have a lower delay per mile contribution. The MID peak shows several minutes of difference between the cumulative mean travel time and the Higuera to Foothill travel time. However, given the higher maximum error for the Higuera to Foothill data set, the Higuera to Foothill data set can be disregarded, and the cumulative mean travel time should be trusted due to its lower likelihood of error. Figures 60, 61, and 62 show each peak period in more detail. 


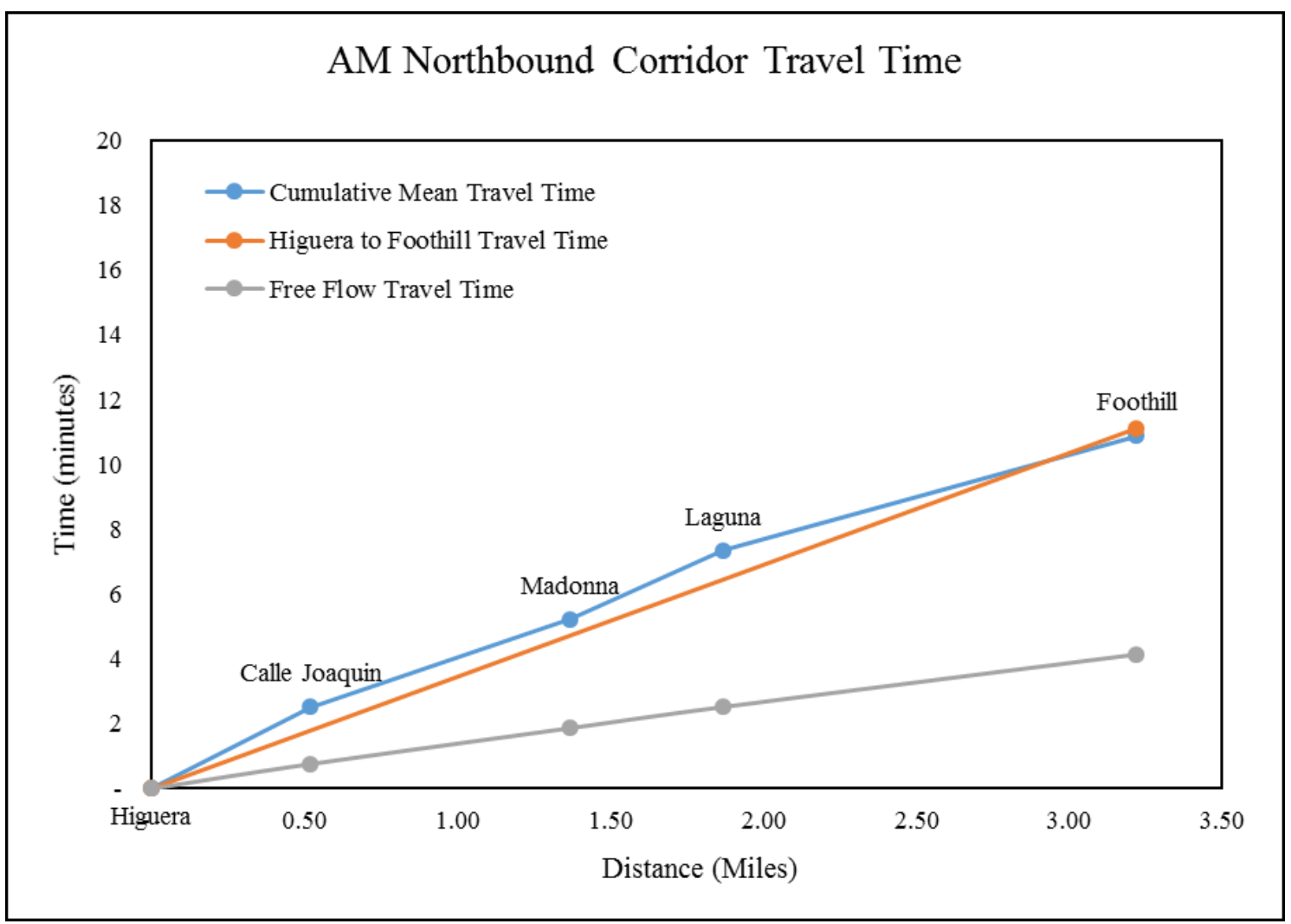

Figure 60: Corridor Northbound Travel Time in the AM Peak

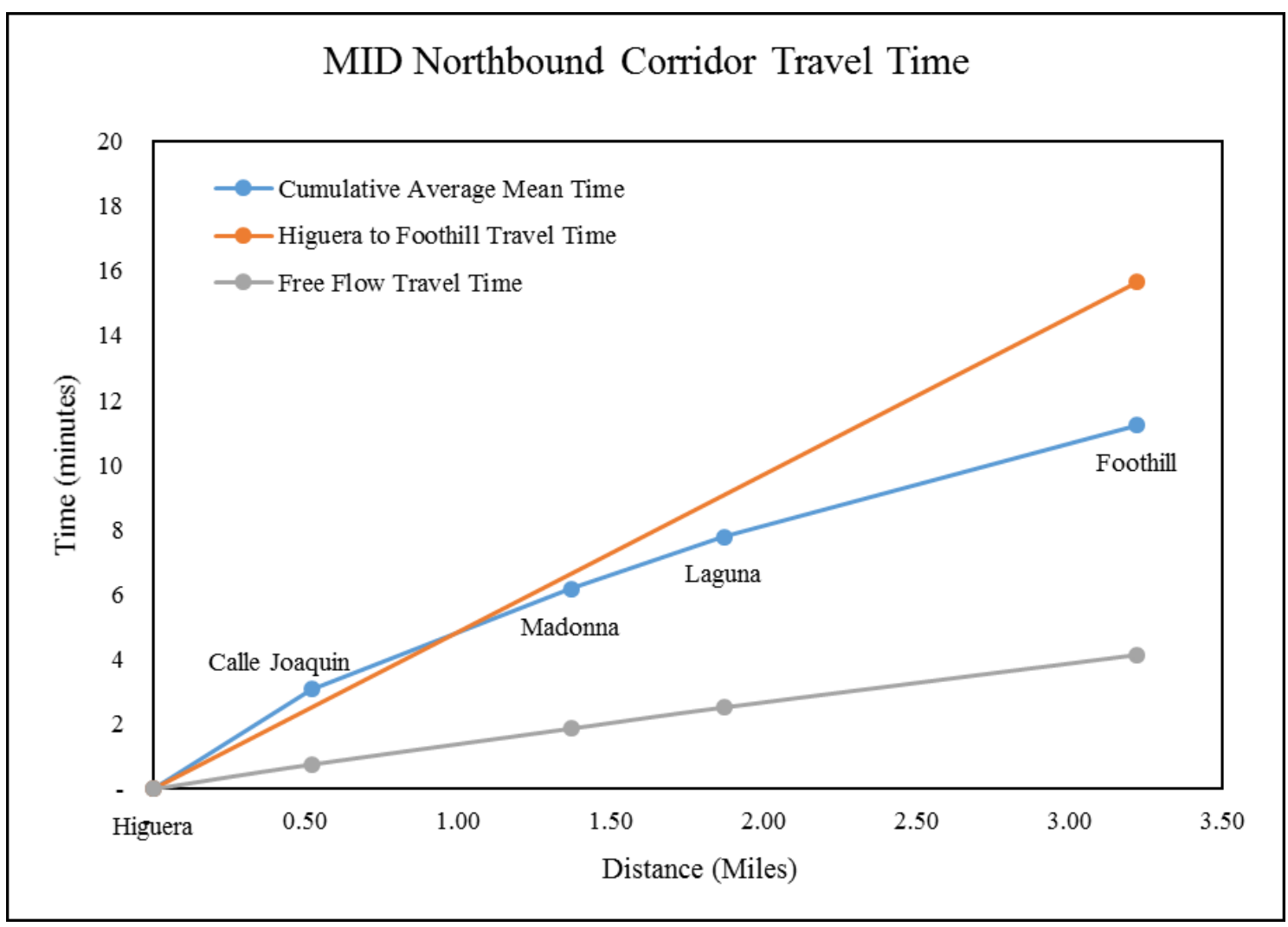

Figure 61: Corridor Northbound Travel Time in the MID Peak 


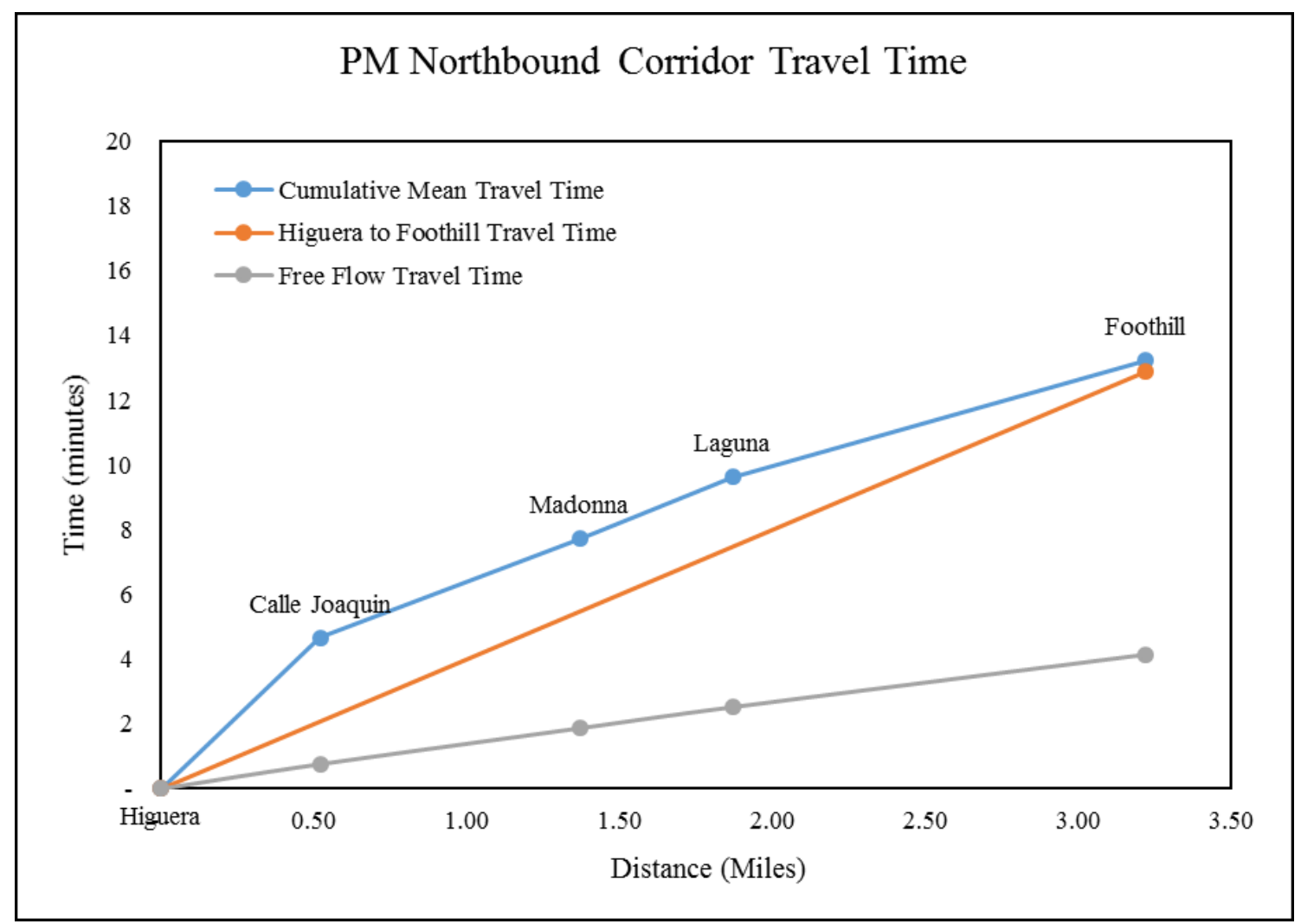

Figure 62: Corridor Northbound Travel Time in the PM Peak

The southbound delay has been broken down by each segment's contribution to total delay. Though Calle Joaquin to Higuera still shows substantial contributions to delay for its shorter length, the segment is on par with contributions from both Madonna to Calle Joaquin and Foothill to Laguna. Laguna to Madonna shows lower delay contributions than the other corridor segments, though it has a shorter length than most other segments. The highest delay period for the southbound direction occurs in the MID peak period, with 7.43 minutes of delay. Comparing this to 7.34 minutes for the AM peak period and 7.32 minutes for the PM peak period shows southbound delay to be consistent across the day's peaks. The higher AM peak delay for southbound affirms the prior hypothesis of a southbound AM-northbound PM commute pattern. Further segment contribution details can be seen in Figure 63. 


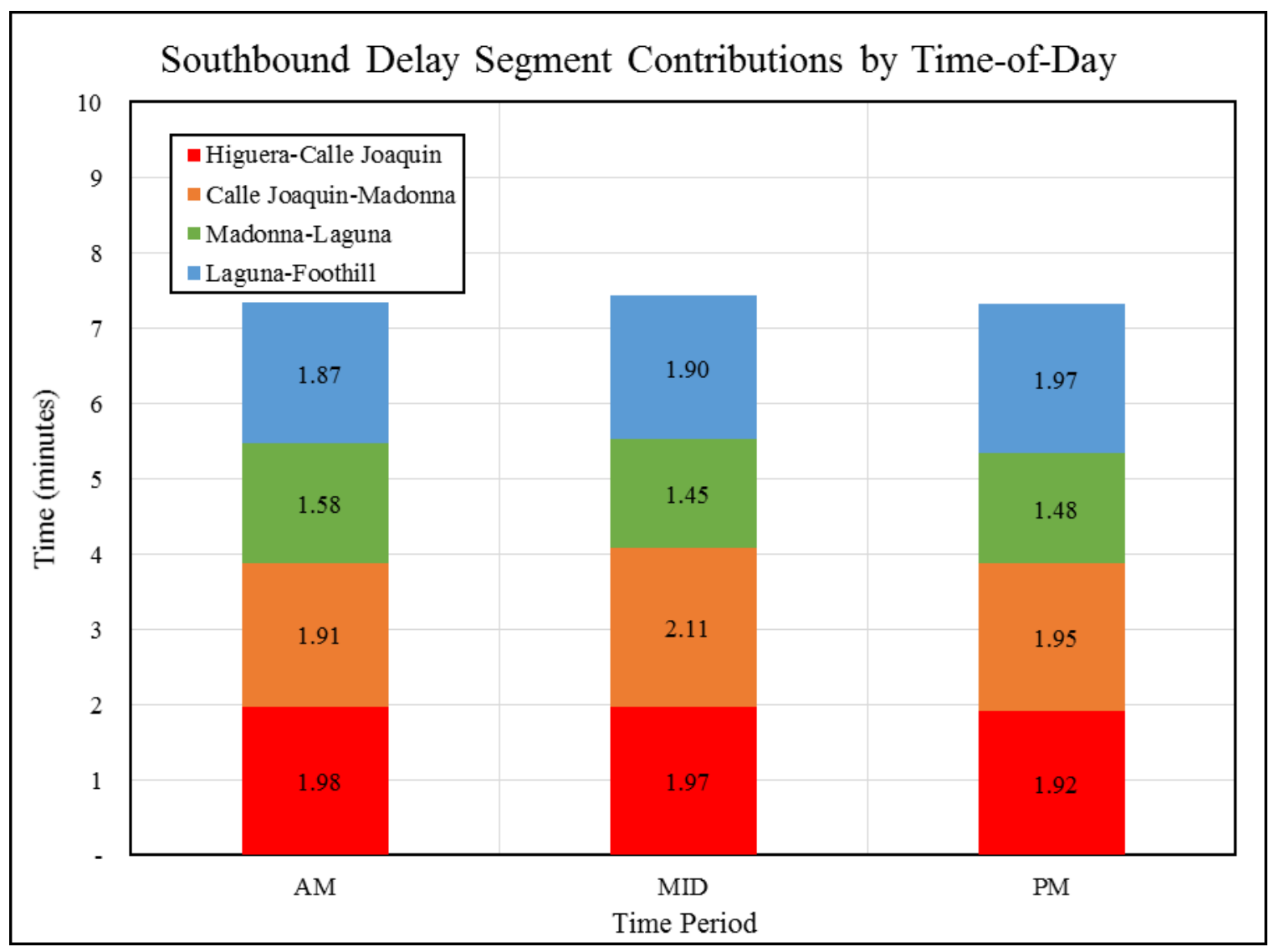

Figure 63: Segment Contributions to Southbound Delay by Time-of-Day

The cumulative mean travel times and Foothill to Higuera travel times for the southbound direction yield similar results to the northbound direction. AM peak period travel shows higher delay per mile contribution for Laguna to Madonna and Calle Joaquin to Higuera and lower delay per mile contributions for Foothill to Laguna and Madonna to Calle Joaquin for all peak periods. The several minutes of difference between the cumulative mean travel time and the Foothill to Higuera travel time are present in the MID peak period, yet the high error possibility for the Foothill to Higuera data set make the data set unreliable. The Foothill to Higuera data does not impact the validity of the cumulative mean travel times. Figures 64,65 , and 66 show each peak period in more detail. 


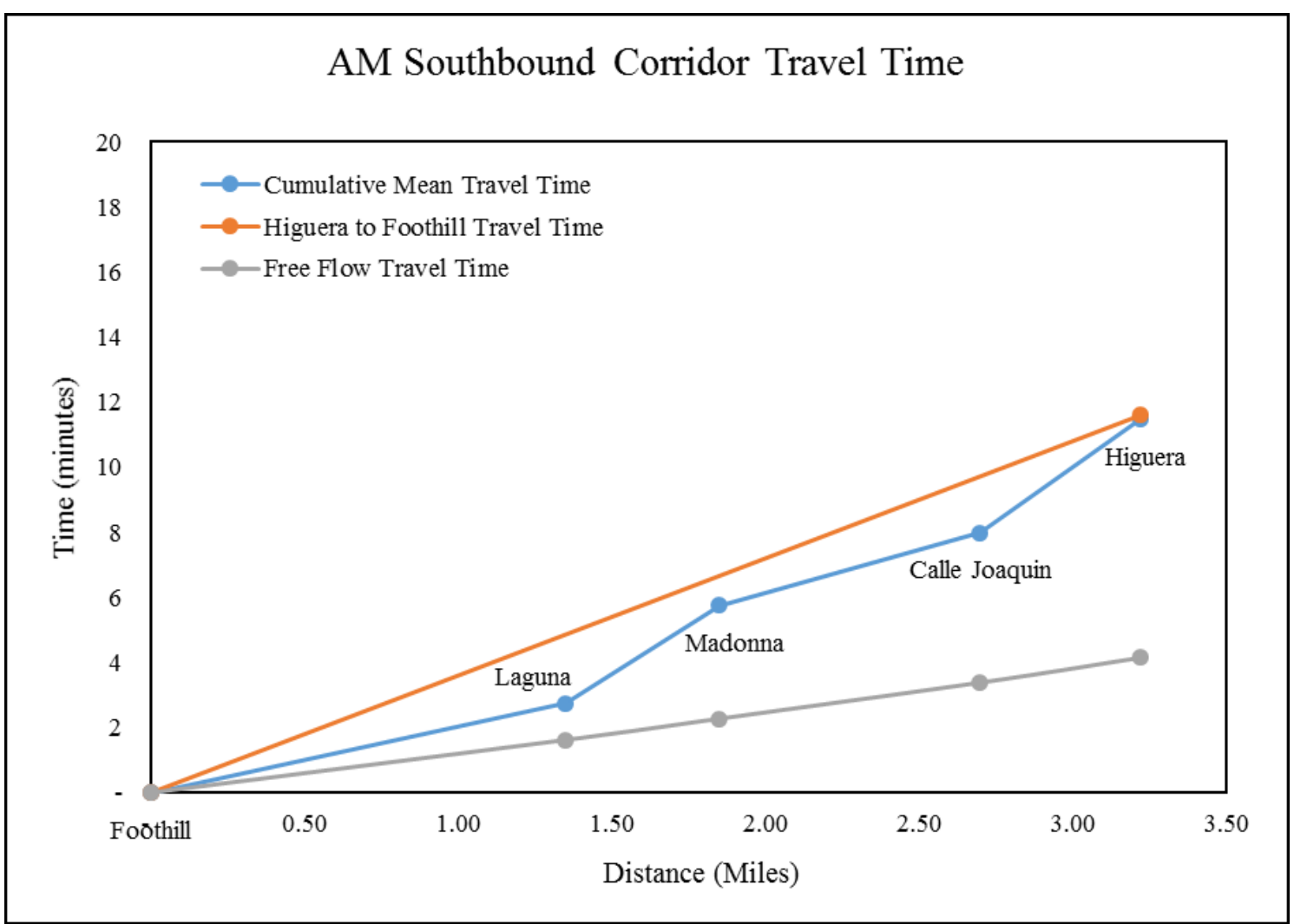

Figure 64: Corridor Southbound Travel Time in the AM Peak

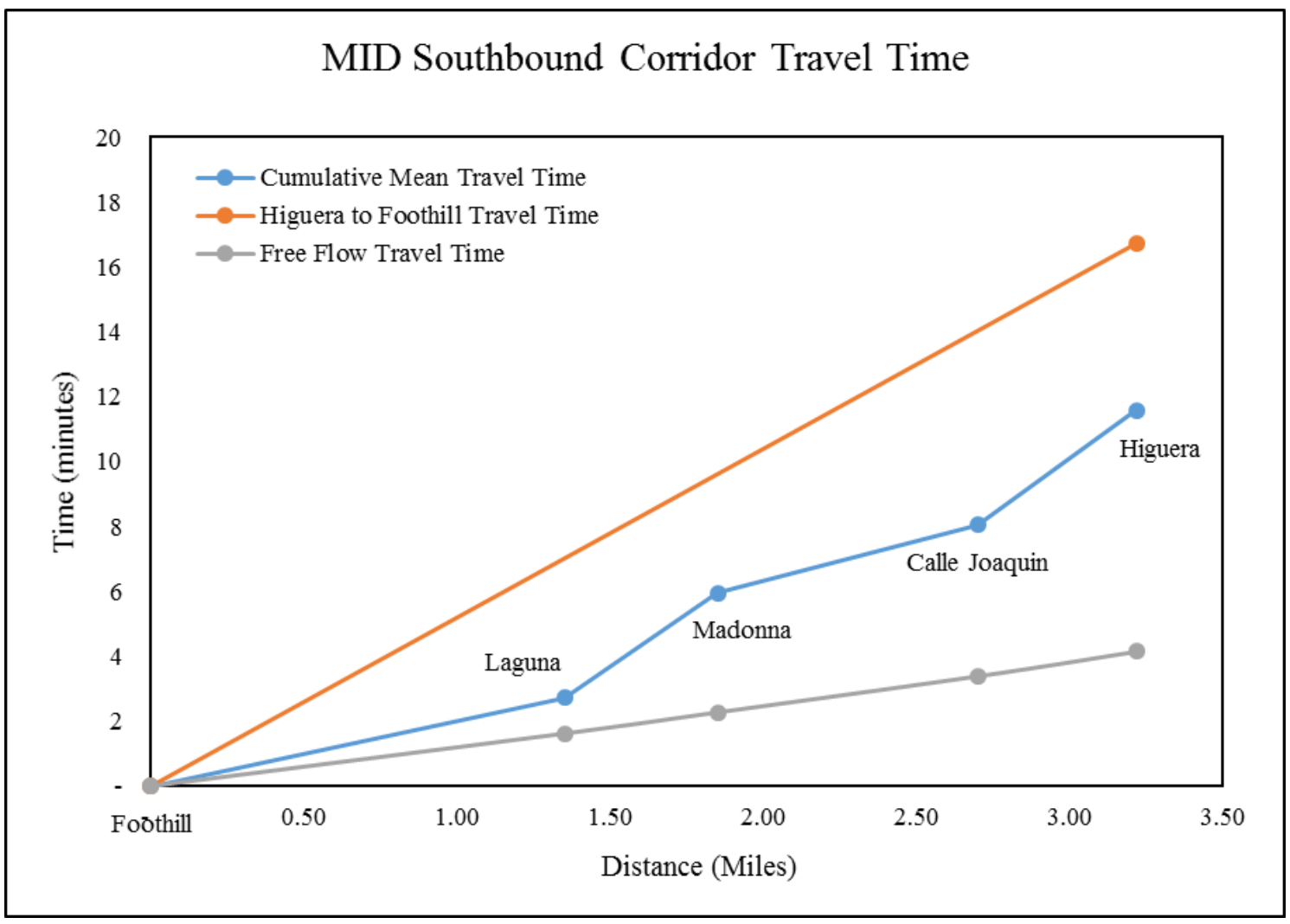

Figure 65: Corridor Southbound Travel Time in the MID Peak 


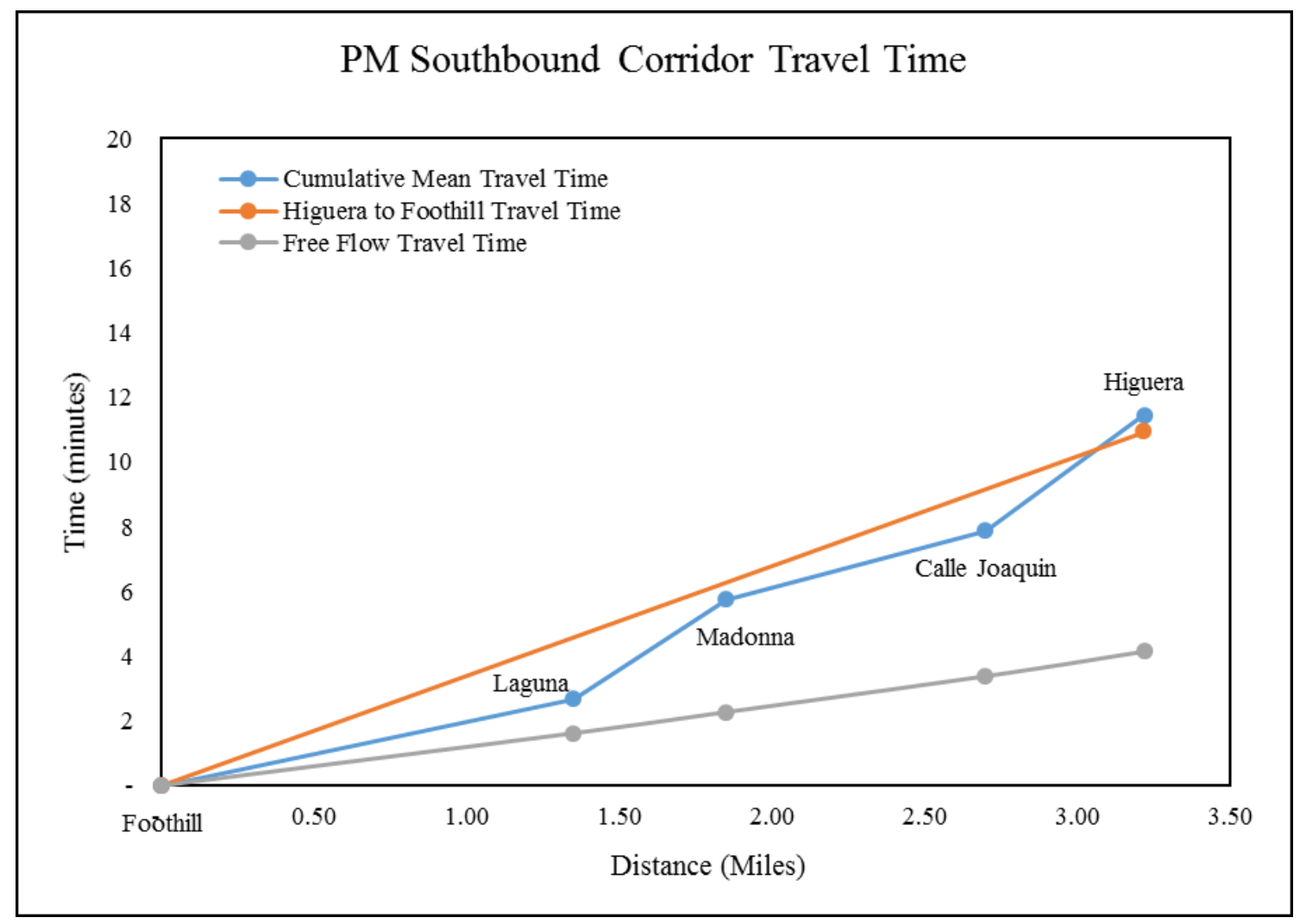

Figure 66: Corridor Southbound Travel Time in the PM Peak

\subsection{Multimodal Comparison}

Transit service along the corridor consists of Route 4 and 5 of SLO Transit. There are four trips per peak period per day per route, with ten weekdays of data, resulting in forty transit trips analyzed for each route and peak period. As transit travel times are perceived differently than automobile travel time, delay was calculated based on the transit schedule and arrivals at schedules stops. The mean minutes late, standard deviation of minutes late, and percent of trips over five minutes late are summarized by peak period for the Los Osos Valley Road Corridor as well as the entire route in Table 11. 


\begin{tabular}{|c|c|c|c|c|c|c|c|}
\hline & \multicolumn{3}{|c|}{ Route 4} & \multicolumn{3}{|c|}{ Route 5} \\
\hline & & AM & MID & PM & $\mathrm{AM}$ & MID & PM \\
\hline \multirow{3}{*}{ 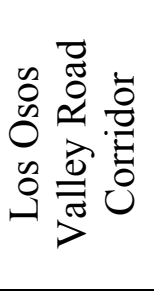 } & $\begin{array}{c}\text { Mean } \\
\text { Minutes Late }\end{array}$ & 1.92 & 4.40 & 5.89 & 3.62 & 3.98 & 6.09 \\
\hline & $\begin{array}{l}\text { Standard Dev. } \\
\text { (Min) }\end{array}$ & 2.15 & 2.41 & 3.15 & 2.73 & 2.61 & 2.85 \\
\hline & $\begin{array}{l}\text { Percent of } \\
\text { Trips Late }\end{array}$ & $9 \%$ & $42 \%$ & $46 \%$ & $26 \%$ & $34 \%$ & $66 \%$ \\
\hline \multirow{3}{*}{ 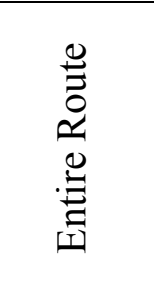 } & $\begin{array}{c}\text { Mean } \\
\text { Minutes Late }\end{array}$ & 2.30 & 3.51 & 4.40 & 3.16 & 3.80 & 4.47 \\
\hline & $\begin{array}{c}\text { Standard Dev. } \\
\text { (Min) }\end{array}$ & 2.49 & 2.73 & 4.03 & 3.06 & 3.28 & 3.16 \\
\hline & $\begin{array}{l}\text { Percent of } \\
\text { Trips Late }\end{array}$ & $10 \%$ & $21 \%$ & $31 \%$ & $22 \%$ & $28 \%$ & $34 \%$ \\
\hline
\end{tabular}

Table 11: Transit Reliability on Los Osos Valley Road

Similar to the vehicular delays, the transit routes experience higher delays in the PM peak. SLO Transit considers buses to be running on-time if the buses are 0 to 5 minutes late (Urbitran Associates, Inc., 2009). This results in $46 \%$ of Route 4 and $66 \%$ of Route 5 PM trips running late on the corridor, with the latest transit trip of both routes being 17 minutes late. Transit and auto reliability are compared on Madonna-Laguna in both the northbound and southbound directions in Figures 67, 68, 69, and 70.

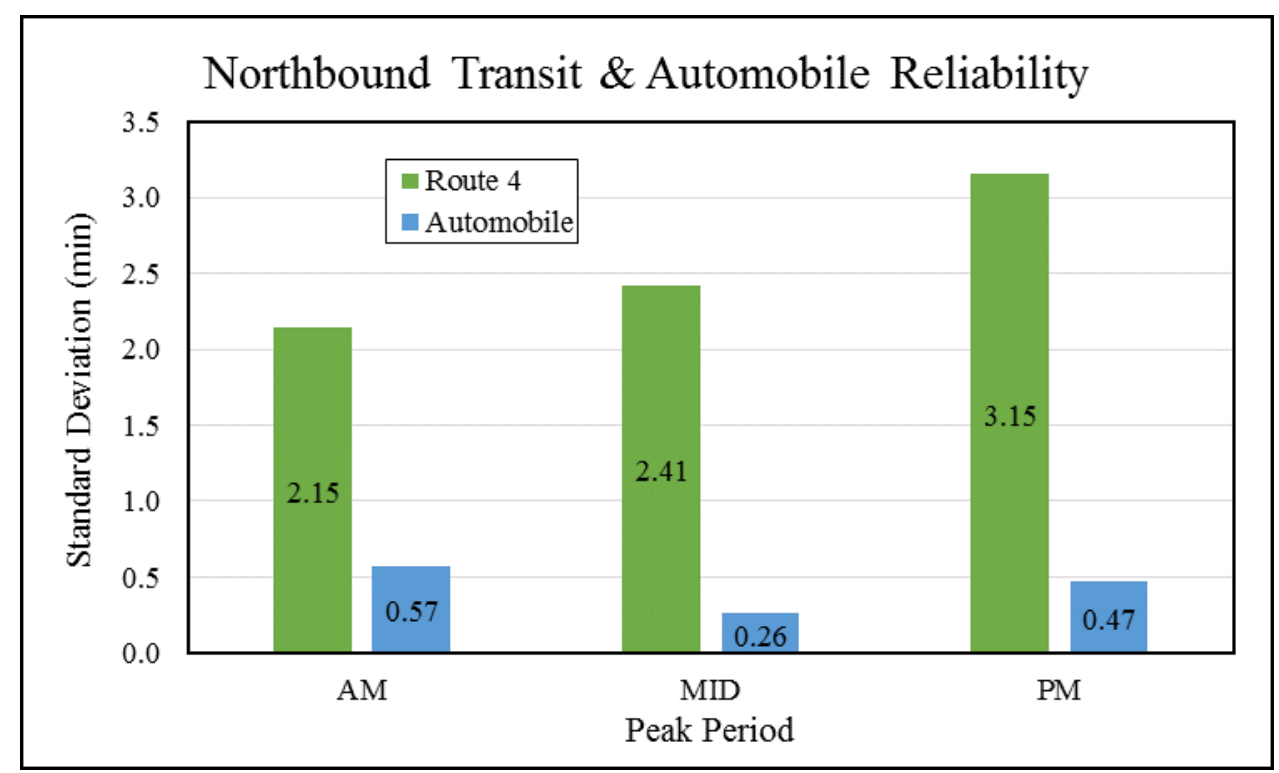

Figure 67: Northbound Transit and Automobile Standard Deviation 


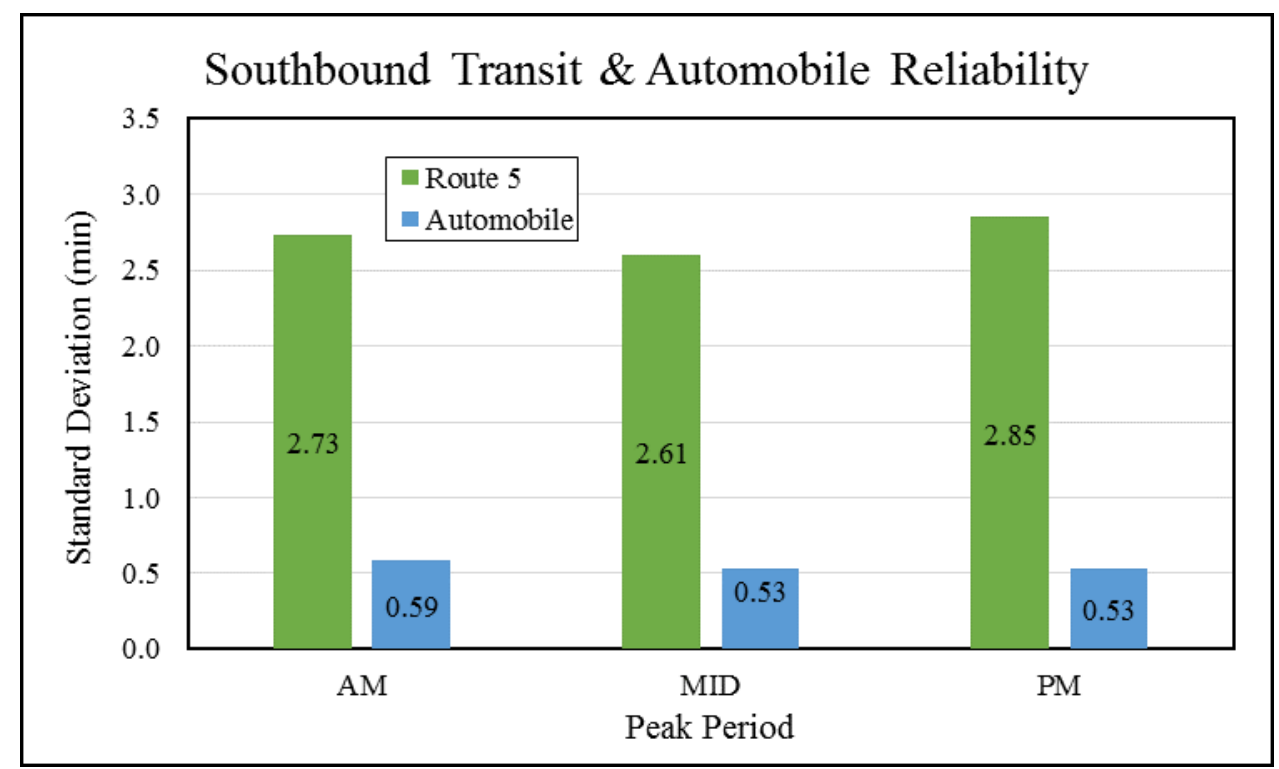

Figure 68: Southbound Transit and Automobile Standard Deviation

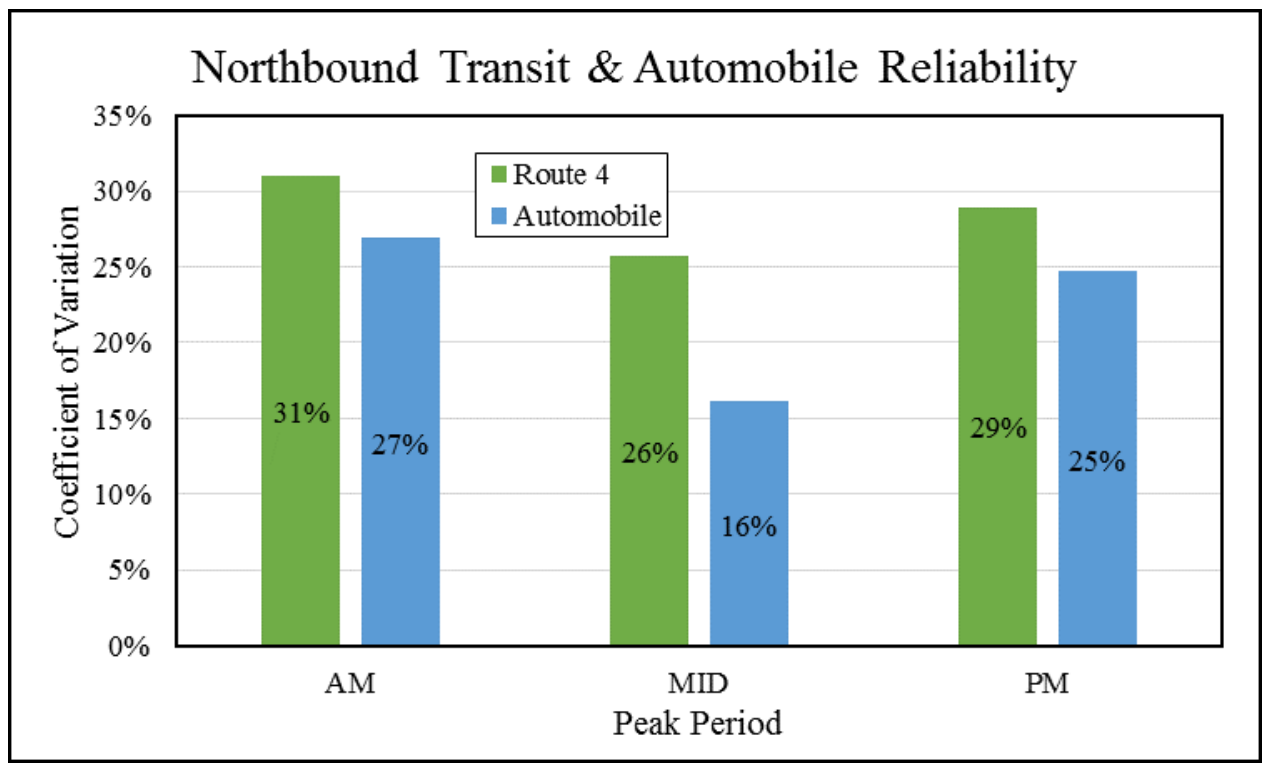

Figure 69: Northbound Transit and Automobile Coefficient of Variation 


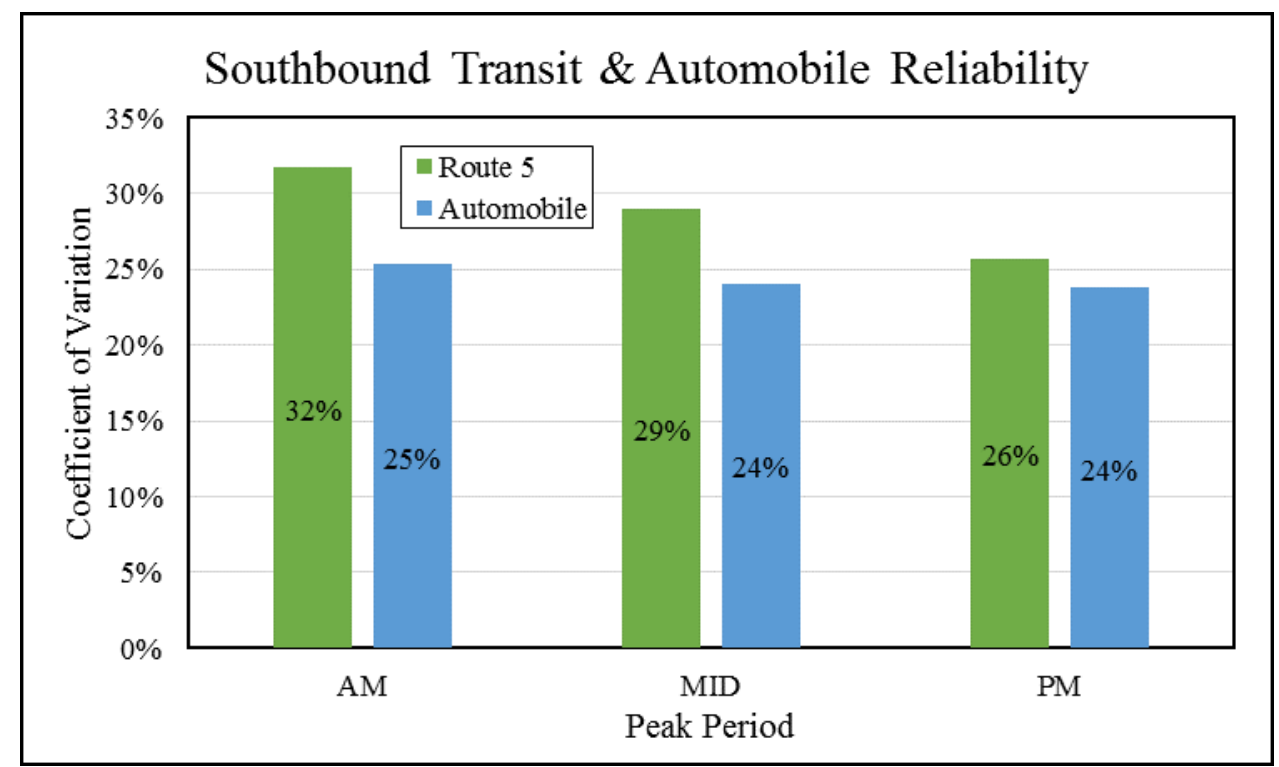

Figure 70: Southbound Transit and Automobile Coefficient of Variation

Although comparison of standard deviation shows transit performing far worse than automobiles, a comparison of the coefficient of variation shows transit to perform at a more comparable scale. This is due to the longer average trip times for transit.

While bicyclists and pedestrians do not experience congestion due to their lower volumes and dedicated right-of-way, they're still subject to signal delays. Other factors that are difficult to quantify for bicyclists and pedestrians include weather impacts, poor pavement conditions, and higher safety concerns due to vulnerabilities near a high-speed facility.

\subsection{Modeling Average Speed}

Along Los Osos Valley Road, vehicles may slow when another vehicle is entering or exiting a midblock driveway, stop behind an intersection queue, or change speed to merge. To estimate the effects of these corridor characteristics on corridor travel, an average speed model was developed using easily-attainable data inputs. 


\subsubsection{Identification of Model Data Inputs}

Data inputs were identified in the literature review; those that would be attainable for Los Osos Valley Road have been described in Table 12.

\begin{tabular}{|l|l|l|}
\hline Potential Data Input & $\begin{array}{l}\text { Variable } \\
\text { Name }\end{array}$ & Description \\
\hline Number of Lanes & LANE & $\begin{array}{l}\text { Discrete Variable } \\
\text { Minimum number of lanes on the segment. }\end{array}$ \\
\hline Merge Points & MERGE & $\begin{array}{l}\text { Discrete Variable } \\
\text { Number of merge points on the segment. }\end{array}$ \\
\hline Diverge Points & DIVERGE & $\begin{array}{l}\text { Discrete Variable } \\
\text { Number of diverge points on the segment. }\end{array}$ \\
\hline Peak Hour Volume & PHV & $\begin{array}{l}\text { Discrete Variable } \\
\text { Highest traffic volume in one hour of each peak } \\
\text { period, according to the City of San Luis } \\
\text { Obispo's 2014 traffic counts. }\end{array}$ \\
\hline $\begin{array}{l}\text { Peak Hour Volume } \\
\text { Per Lane }\end{array}$ & PHV/LANE & $\begin{array}{l}\text { Continuous Variable } \\
\text { PHV divided by LANE. }\end{array}$ \\
\hline Driveway Density & DRIVE & $\begin{array}{l}\text { Continuous Variable } \\
\text { Number of access points in the given direction } \\
\text { divided by the length of the segment. }\end{array}$ \\
\hline $\begin{array}{l}\text { Driveway Density/ } \\
\text { Peak Hour Volume } \\
\text { Through }\end{array}$ & DRIVE/PHV & $\begin{array}{l}\text { Continuous Variable } \\
\text { DRIVE divided by PHV. }\end{array}$ \\
\hline Signal Density & SIGNAL & $\begin{array}{l}\text { Discrete Variable } \\
\text { Number of signals encountered in each direction. }\end{array}$ \\
\hline $\begin{array}{l}\text { Signal } \\
\text { Coordination }\end{array}$ & COORD & $\begin{array}{l}\text { Discrete Variable } \\
\text { Whether signals are coordinated. }\end{array}$ \\
\hline $\begin{array}{l}\text { Weighted Average } \\
\text { Green Time }\end{array}$ & g/C & $\begin{array}{l}\text { Continuous Variable } \\
\text { Average green time per cycle time in each } \\
\text { direction weighted by through volume of the } \\
\text { segment. }\end{array}$ \\
\hline Length & LENGTH & $\begin{array}{l}\text { Continuous Variable } \\
\text { For standard Deviation only }\end{array}$ \\
\hline
\end{tabular}

Table 12: Travel Time Reliability Model Inputs

\subsubsection{Model Development}

Half of the Median Method dataset was selected at random to develop the model and later validated with the remaining half of the dataset. As travel times vary based on segment study length, travel times were converted to mean speeds and standard 
deviations of speeds to better compare segments of varying lengths. Stepwise regression was used to determine linear relationships and their statistical significance to the Bluetooth-collected mean speed and standard deviation of speeds (NCSS, n.d.). For average speed, $\overline{\mathrm{v}}$, parameters that showed statistical significance at $95 \%$ confidence provided the following correlations:

$$
\bar{v}=146.5-27.2 *(L A N E)+457.5 *\left(\frac{D R I V E}{P H V}\right)-31.4 *(S I G N A L)-28.3 *(g / C)
$$

The negative coefficient to the lanes and the effective green time seems counterintuitive, as increasing the number of lanes and green time for the approach should reduce delays and increase speeds. However, the more congested segments are likely to be addressed by increasing the number of lanes and/or green time for that approach. More lanes and green time show correlation, not necessarily causation, with higher travel times on Los Osos Valley Road. The driveway/PHV shows an expected positive coefficient, as higher peak hour volumes decreases the average speed.

Additionally, the negative signal coefficient is logical; more signals affecting a segment cause more mid-study segment delay and lower travel speeds. Table 13 summarizes the statistical significance of these parameters. The null hypothesis is that the correlation coefficient is zero; that the predictive parameter has no correlation to the speed.

\begin{tabular}{|c|c|c|c|}
\hline Parameter & Coefficient & $\mathrm{t}-$ stat & $\mathrm{p}$-value \\
\hline \multicolumn{4}{|c|}{ Average Speed } \\
\hline Intercept & 146.5 & 11.43481 & 0.00000 \\
\hline LANE & -27.2 & -8.74130 & 0.00000 \\
\hline DRIVE/PHV & 457.5 & 3.73309 & 0.00019 \\
\hline SIGNAL & -31.4 & -17.14627 & 0.00000 \\
\hline $\mathrm{g} / \mathrm{C}$ & -28.3 & -2.55257 & 0.01069 \\
\hline
\end{tabular}

Table 13: Statistical Significance of Data Model Inputs 
$\mathrm{P}$-values less than 0.05 reject the null hypothesis and that there is sufficient evidence at the $95 \%$ confidence level to conclude that there is a linear relationship between the parameter and the average speed.

\subsubsection{Findings of Model}

The developed model was then validated against the remaining half of the Median Method dataset. The model results versus Bluetooth-collected mean speeds are shown in Table 14, with error reported as the absolute value of the difference between the predicted and observed values.

\begin{tabular}{|c|c|c|c|c|c|}
\hline Segment & Peak & Direction & Predicted (mph) & Observed (mph) & Error (mph) \\
\hline \multirow{6}{*}{$\begin{array}{c}\text { Higuera - } \\
\text { Calle Joaquin }\end{array}$} & \multirow{2}{*}{$\mathrm{AM}$} & NB & 19.7 & 18.2 & 1.5 \\
\hline & & SB & 15.5 & 16.0 & 0.5 \\
\hline & \multirow{2}{*}{ MID } & NB & 13.3 & 13.7 & 0.4 \\
\hline & & SB & 14.5 & 16.1 & 1.6 \\
\hline & \multirow{2}{*}{ PM } & NB & 12.0 & 8.2 & 3.8 \\
\hline & & SB & 13.8 & 16.5 & 2.7 \\
\hline \multirow{6}{*}{$\begin{array}{l}\text { Calle Joaquin } \\
\text { - Madonna }\end{array}$} & \multirow{2}{*}{ AM } & NB & 31.0 & 31.7 & 0.7 \\
\hline & & SB & 28.5 & 27.0 & 1.5 \\
\hline & \multirow{2}{*}{ MID } & NB & 26.2 & 25.7 & 0.5 \\
\hline & & SB & 22.6 & 23.8 & 1.2 \\
\hline & \multirow{2}{*}{ PM } & NB & 24.8 & 26.1 & 1.3 \\
\hline & & SB & 23.2 & 26.2 & 3.0 \\
\hline \multirow{6}{*}{$\begin{array}{c}\text { Madonna - } \\
\text { Laguna }\end{array}$} & \multirow{2}{*}{ AM } & NB & 23.5 & 19.9 & 3.6 \\
\hline & & SB & 22.3 & 19.2 & 3.1 \\
\hline & \multirow{2}{*}{ MID } & NB & 24.0 & 31.2 & 7.2 \\
\hline & & SB & 22.8 & 20.5 & 2.3 \\
\hline & \multirow{2}{*}{ PM } & NB & 23.2 & 23.6 & 0.4 \\
\hline & & SB & 21.2 & 20.0 & 1.2 \\
\hline \multirow{6}{*}{$\begin{array}{l}\text { Laguna - } \\
\text { Foothill }\end{array}$} & \multirow{2}{*}{$\mathrm{AM}$} & NB & 43.8 & 42.2 & 1.6 \\
\hline & & SB & 43.5 & 43.0 & 0.5 \\
\hline & \multirow{2}{*}{ MID } & NB & 42.1 & 44.2 & 2.1 \\
\hline & & SB & 43.6 & 42.6 & 1.0 \\
\hline & \multirow{2}{*}{ PM } & NB & 40.4 & 41.0 & 0.6 \\
\hline & & SB & 42.2 & 40.8 & 1.4 \\
\hline
\end{tabular}

Table 14: Average Speed Model Findings 
Permissible errors in the estimate of average travel speed is \pm 2 to $\pm 4 \mathrm{mph}$ (Institute of Transportation Engineers, 2010). Only one estimate has an error above the acceptable $4 \mathrm{mph}$. The northbound direction of Madonna to Laguna in the MID peak period has an error of $7.2 \mathrm{mph}$. The observed versus predicted mean speeds are shown in Figure 71, yielding the aforementioned $\mathrm{R}^{2}$ value of 0.95 .

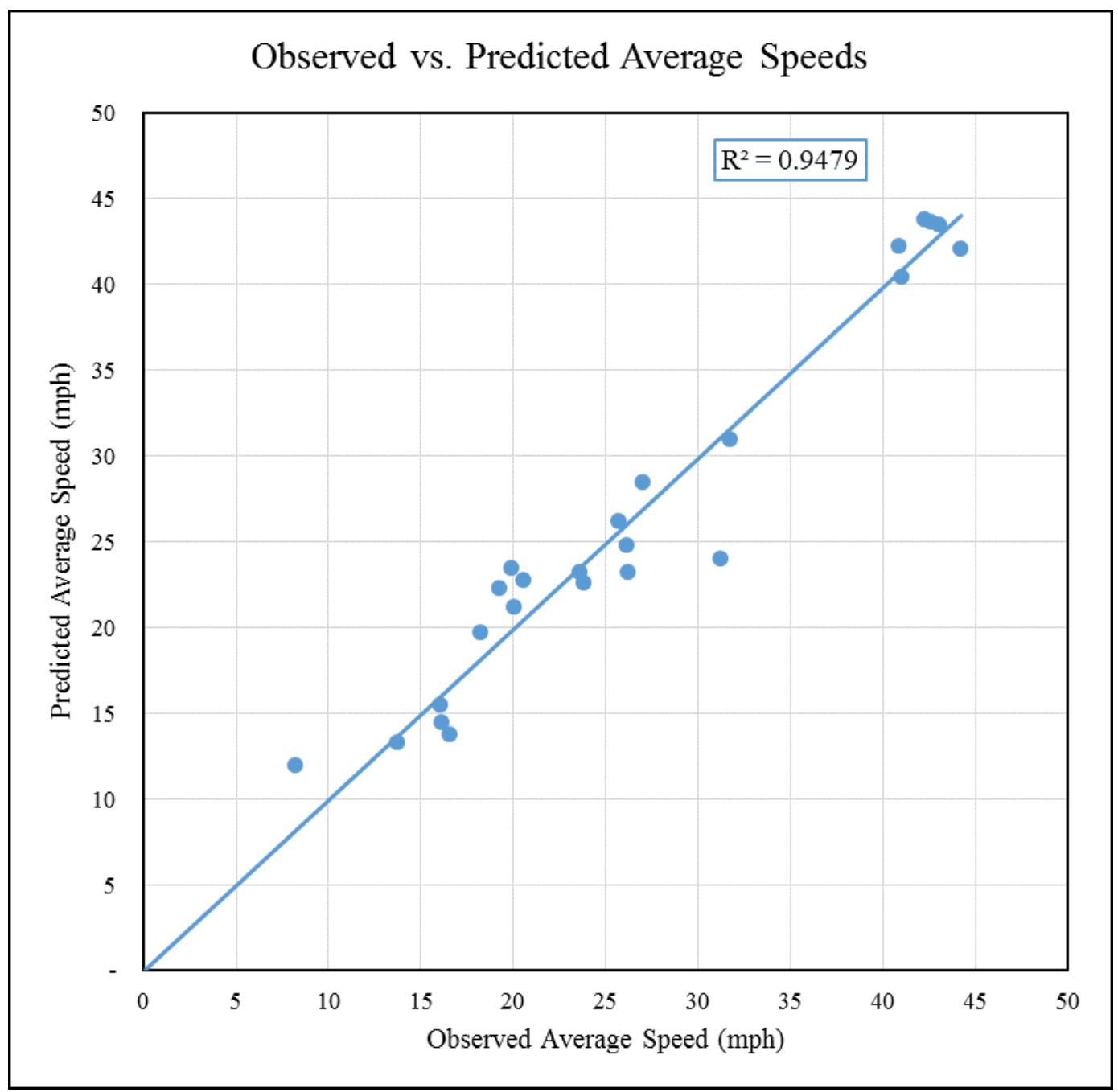

Figure 71: Observed vs. Multiple Linear Regression Model Predicted Speeds

Despite the one prediction outside of the suggested error range, the model predicts average speed with a substantial $R^{2}$ value. 


\subsection{Modeling Reliability}

To estimate reliability, a gamma density function can be modeled for each study segment.

\subsubsection{Identification of Model Inputs}

Gamma density functions first needed to be fit to each study segment by direction and peak period. The gamma density function is as follows:

$$
f(x)=\frac{\left(\lambda *(\lambda x)^{\kappa-1} * e^{-\lambda x}\right)}{\Gamma(\kappa)}
$$

$\kappa$ and $\lambda$ are positive parameters. $\Gamma$ is the gamma function. $\mathrm{x}$ refers to the travel time and $f(x)$ refers to the percentage of trips completed at $x$ travel time. This function was fit to the known travel time distribution, maximizing $\mathrm{R}^{2}$ for an optimized fit. This resulted in the following values: 


\begin{tabular}{|c|c|c|c|c|c|}
\hline Segment & Peak & Direction & $\lambda$ & $\kappa$ & $\mathrm{R}^{2}$ \\
\hline \multirow{6}{*}{$\begin{array}{l}\text { Higuera - } \\
\text { Calle Joaquin }\end{array}$} & \multirow{2}{*}{ AM } & NB & 3.12 & 4.32 & 0.94 \\
\hline & & SB & 2.93 & 4.75 & 0.88 \\
\hline & \multirow{2}{*}{ MID } & NB & 2.23 & 4.29 & 0.95 \\
\hline & & SB & 2.55 & 4.34 & 0.95 \\
\hline & \multirow{2}{*}{ PM } & NB & 0.76 & 3.25 & 0.41 \\
\hline & & SB & 1.69 & 2.95 & 0.82 \\
\hline \multirow{6}{*}{$\begin{array}{c}\text { Calle Joaquin } \\
\text { - Madonna }\end{array}$} & \multirow{2}{*}{$\mathrm{AM}$} & NB & 3.43 & 4.35 & 0.92 \\
\hline & & SB & 2.76 & 4.28 & 0.98 \\
\hline & \multirow{2}{*}{ MID } & NB & 2.53 & 4.19 & 0.94 \\
\hline & & SB & 2.48 & 4.15 & 0.92 \\
\hline & \multirow{2}{*}{ PM } & NB & 1.87 & 3.25 & 0.86 \\
\hline & & SB & 2.10 & 3.25 & 0.81 \\
\hline \multirow{6}{*}{$\begin{array}{c}\text { Madonna - } \\
\text { Laguna }\end{array}$} & \multirow{2}{*}{ AM } & $\mathrm{NB}$ & 4.07 & 4.25 & 0.95 \\
\hline & & SB & 3.21 & 4.30 & 0.96 \\
\hline & \multirow{2}{*}{ MID } & NB & 2.50 & 1.95 & 0.70 \\
\hline & & SB & 1.66 & 2.25 & 0.71 \\
\hline & \multirow{2}{*}{ PM } & NB & 2.50 & 2.65 & 0.78 \\
\hline & & $\mathrm{SB}$ & 2.00 & 2.65 & 0.83 \\
\hline \multirow{6}{*}{$\begin{array}{l}\text { Laguna - } \\
\text { Foothill }\end{array}$} & \multirow{2}{*}{$\mathrm{AM}$} & NB & 2.25 & 3.55 & 0.21 \\
\hline & & SB & 2.62 & 3.55 & 0.22 \\
\hline & \multirow{2}{*}{ MID } & $\mathrm{NB}$ & 2.40 & 3.35 & -0.13 \\
\hline & & SB & 2.21 & 3.35 & 0.04 \\
\hline & \multirow{2}{*}{ PM } & NB & 2.74 & 4.35 & 0.12 \\
\hline & & SB & 2.07 & 3.35 & 0.18 \\
\hline
\end{tabular}

Table 15: Gamma Density Function Best-Fit Parameters

The mean $\lambda$ is 2.45 . The Laguna-Foothill segment is not well-modeled by a gamma density function. Ignoring these data would result in a $\lambda$ of 2.47 , a negligible impact to the model development.

\subsubsection{Model Development}

Based on these inputs, theoretical $\kappa$ is then found for each segment using the following equation:

$$
\kappa=\lambda * \mu
$$

Mean travel times, $\mu$, are known. $\lambda$ for the corridor should be set as 2.45 .

Predicted and observed $\kappa$ values are then visualized on a cumulative density plot. The D 
value, or the $\mathrm{K}-\mathrm{S}$ test statistic, is then defined as the maximum difference between the observed and predicted cumulative densities (NIST Sematech, 2012). Figure 72 shows the cumulative density plot for Madonna - Laguna, with the dashed line indicating the location of the $\mathrm{D}$ value and the $\mathrm{K}-\mathrm{S}$ test statistic.

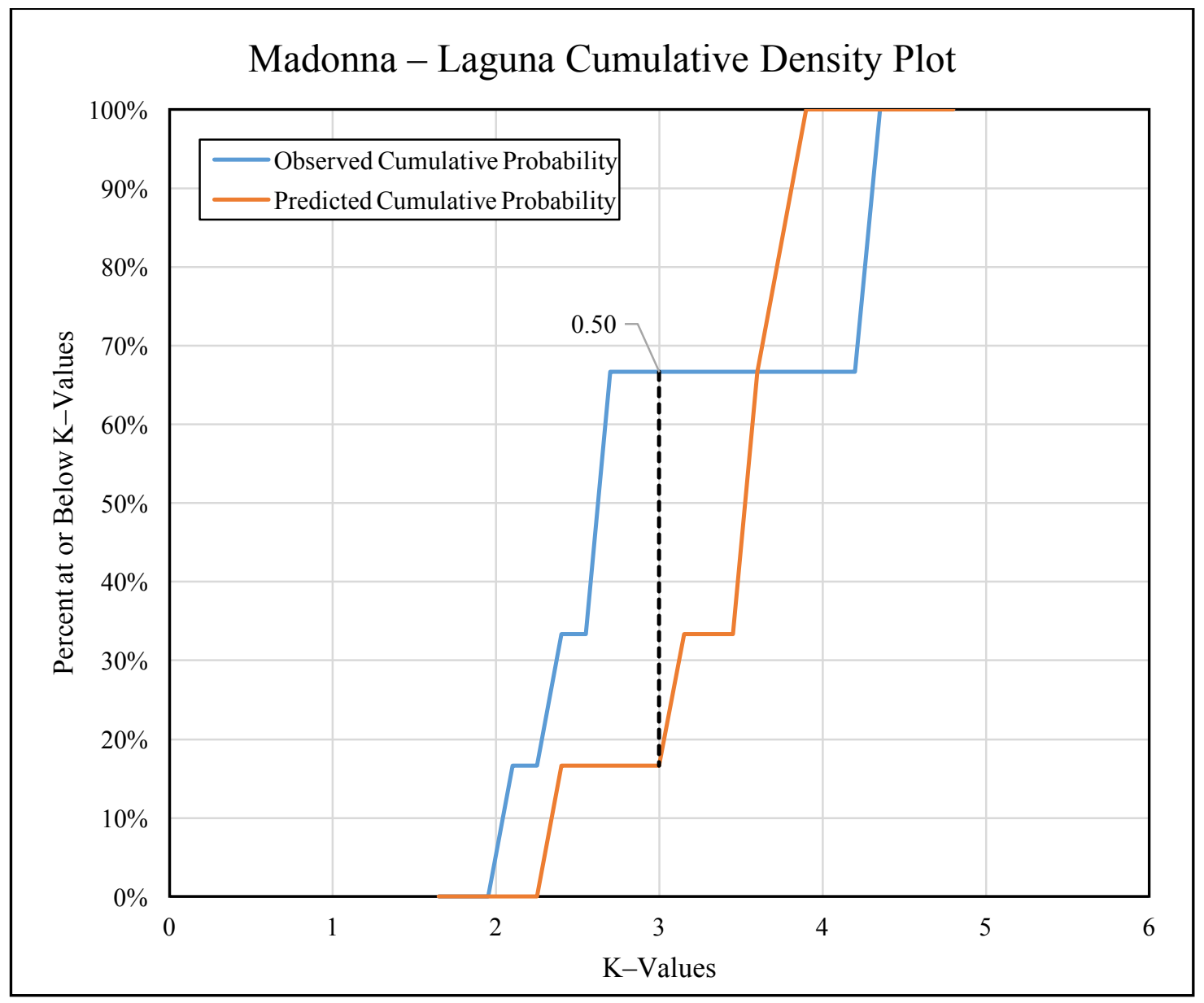

Figure 72: Madonna - Laguna Cumulative Density Plot

$67 \%$ of observed $\mathrm{k}$-values are at or below a value of 3 and $17 \%$ of predicted $\mathrm{k}-$ values are at or below a value of 3. Each segment had six observations: Northbound and Southbound for the AM, MID, and PM peak periods. This results in a K-S statistic of 0.50. To reject the assumed distribution with $95 \%$ confidence, the $\mathrm{K}-\mathrm{S}$ statistic needs to be above 0.51926 given six observations per segment (O’Connor, 2012). As the K-S statistic value is less than 0.51926 , the test fails to reject at the $95 \%$ confidence level that 
the travel time distribution as a gamma density function. Table 16 shows the $\mathrm{K}-\mathrm{S}$ test statistic results for each segment.

\begin{tabular}{|c|c|c|}
\hline Segment & $\begin{array}{c}\mathrm{K}-\mathrm{S} \\
\text { Statistic }\end{array}$ & Decision at $\alpha=0.05$ \\
\hline \hline Higuera - Calle Joaquin & 0.50 & Do Not Reject \\
\hline Calle Joaquin - Madonna & 0.67 & Reject \\
\hline Madonna - Laguna & 0.50 & Do Not Reject \\
\hline Laguna - Foothill & 0.83 & Reject \\
\hline
\end{tabular}

Table 16: K-S Results for Variability Model

Calle Joaquin - Madonna and Laguna - Foothill are rejected as gamma density functions. However, the $\mathrm{K}-\mathrm{S}$ test failed to reject Higuera - Calle Joaquin and Madonna Laguna. Therefore, Higuera - Calle Joaquin and Madonna - Laguna will be used to test the model's performance.

\subsubsection{Findings of Model}

For the segments that were not rejected with $95 \%$ confidence, reliability will be estimated with the following equation:

$$
R=\frac{\sqrt{\lambda}}{\sqrt{\mu}}
$$

Given $\lambda$ as 2.45 for the corridor, reliability can be estimated given mean travel time. This equation can be validated to the true reliability; given by the inverse of standard deviation (Polus, 1979). Reliability model results are shown in Table 17. 


\begin{tabular}{|c|c|c|c|c|c|}
\hline Segment & Peak & Direction & Predicted $\left(\mathrm{min}^{-1}\right)$ & Observed $\left(\min ^{-1}\right)$ & Error $\left(\min ^{-1}\right)$ \\
\hline \multirow{6}{*}{$\begin{array}{l}\text { Higuera } \\
\text { - Calle } \\
\text { Joaquin }\end{array}$} & \multirow{2}{*}{ AM } & NB & 1.34 & 1.79 & 0.20 \\
\hline & & SB & 1.22 & 1.85 & 0.41 \\
\hline & \multirow{2}{*}{ MID } & NB & 0.98 & 1.11 & 0.02 \\
\hline & & SB & 1.14 & 1.72 & 0.34 \\
\hline & \multirow{2}{*}{ PM } & NB & 0.44 & 0.59 & 0.02 \\
\hline & & SB & 0.94 & 1.59 & 0.42 \\
\hline \multirow{6}{*}{$\begin{array}{l}\text { Madonna } \\
\text { - Laguna }\end{array}$} & \multirow{2}{*}{ AM } & NB & 1.67 & 1.75 & 0.01 \\
\hline & & SB & 1.42 & 1.69 & 0.07 \\
\hline & \multirow{2}{*}{ MID } & NB & 1.62 & 3.85 & 4.95 \\
\hline & & SB & 1.07 & 1.89 & 0.67 \\
\hline & \multirow{2}{*}{ PM } & NB & 1.41 & 2.13 & 0.51 \\
\hline & & SB & 1.16 & 1.89 & 0.53 \\
\hline
\end{tabular}

Table 17: Reliability Model Findings

Permissible errors are not established for standard deviations and reliability. Plotting the predicted and observed values produces Figure 73.

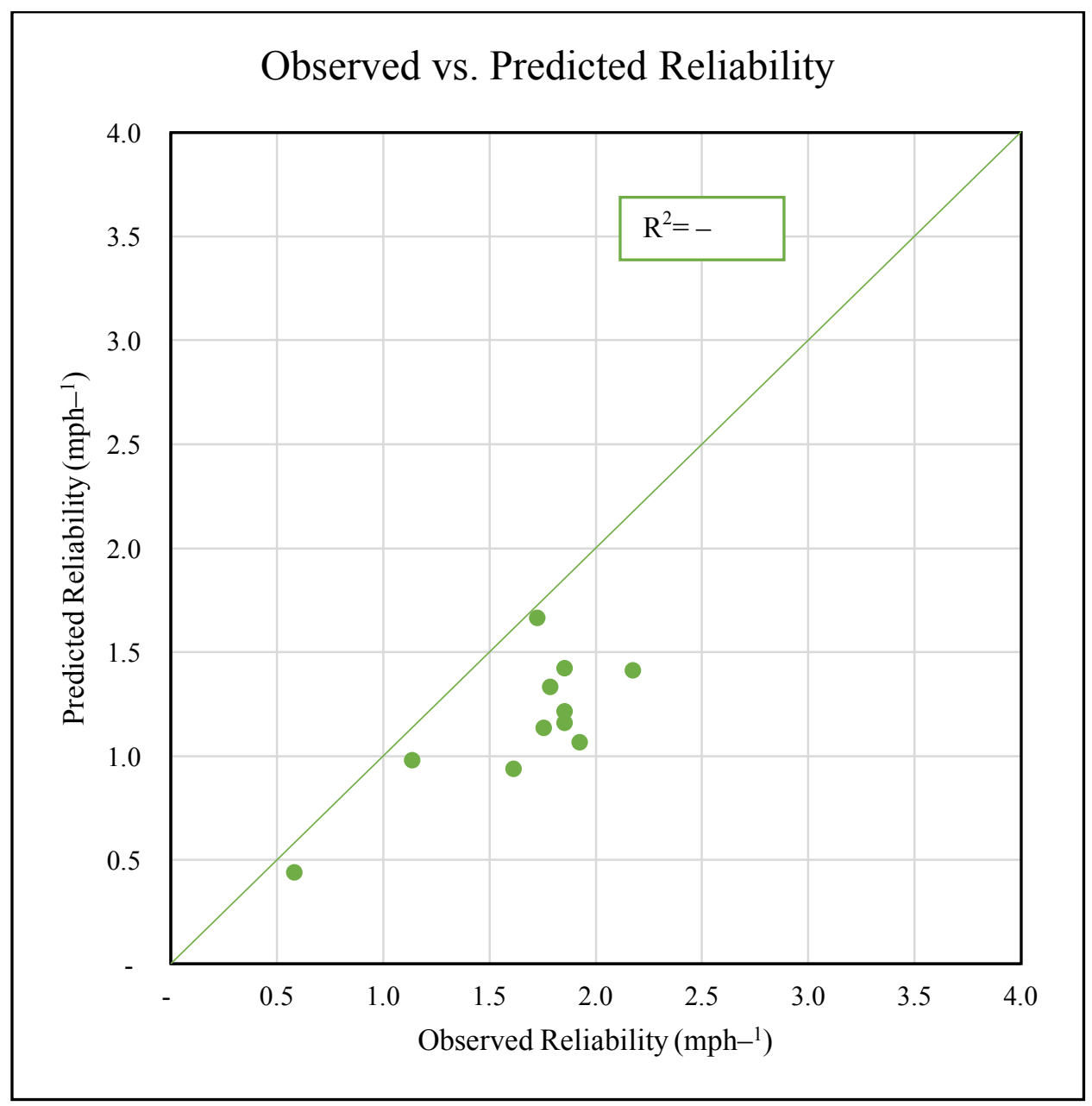

Figure 73: Observed vs. Gamma Density Function Predicted Reliability 
Predicted values are consistently lower than observed reliability. Although gamma density functions are not rejected for Higuera - Calle Joaquin and Madonna Laguna segments, their high $\mathrm{K}-\mathrm{S}$ statistic is reflected in the unreliable model. Prior studies have found $\mathrm{R}^{2}$ for this method to be near 0.37 , while this model results in an $\mathrm{R}^{2}$ of -0.40 (Polus, 1979). 


\section{CONCLUSIONS}

\subsection{Travel Time and Delay}

The Bluetooth data collection and filtering methodologies produced reasonable results, showing impacts of construction and congestion as well as commute patterns. A potential implication of the construction delay on northbound Los Osos Valley Road between South Higuera and Calle Joaquin may be a "starved" northbound Calle Joaquin to Madonna; the construction bottleneck may have limited traffic flows being fed to the Calle Joaquin to Madonna segment and potentially improved travel times. Alternatively, vehicles may have avoided the construction and cause heavier turning movements from Calle Joaquin onto northbound Calle Joaquin to Madonna, potentially increasing delay and travel time on the segment. Sufficient traffic volumes traveled past each detector throughout the day, providing travel times throughout multiple days and time periods. In addition, the fewer data for the entire corridor affirmed that Bluetooth data collection benefits from Bluetooth collection devices being placed at major intersections where vehicles are likely to enter or exit the corridor. The corridor travel time plots for the delay analysis showed delay-per-mile to be a useful means of comparing segments with varying lengths. In the comparison to the City's reported Level of Service, the corridor appears to be performing acceptably.

\subsection{Multimodal Comparison}

Comparison of automobile reliability to transit reliability showed worse standard deviations for transit trips, but similar coefficient of variations for automobile and transit modes. Transit riders, whether captive or choice riders, may not weigh the several minutes of standard deviation heavily in comparison to the longer average travel times, 
whereas the driver of a personal vehicle may be more conscious of higher coefficients of variation. In addition, bicycle and pedestrian travel time reliability do not provide quality comparison between modes. As with transit riders, users of bicycle and pedestrian modes value travel time, trip distance, and user experience such as weather and comfort differently.

\subsection{Average Speed and Reliability Model}

Modeling results showed counterintuitive correlations for the average speed model and unreliable estimations for reliability. Congestion, construction, or roadway characteristics could have altered the effectiveness of each model. Alternate models may be needed along similar arterials.

\subsection{Limitations of Research}

Limitations of data sources, filtering methodologies, and model development are described in the next subsection.

\subsubsection{Bluetooth Data}

The BlueMAC devices need up to ten seconds to first detect a personal Bluetooth device. Likely due to higher speeds and lack of congestion on the northern end of the roadway, the probe automobile's Bluetooth device was not detected at several BlueMAC devices. Though origin-destination data were originally intended to be used in this research, the uncertainty in true origin and destination points resulted in no use of these data.

Data filtering also poses uncertainty in either direction; filtering methods could be either too aggressive or not aggressive enough in narrowing data sets. While overall trip distributions and one PM peak period was shown to eliminate unreasonable data points 
and leave reasonable data points in place, the data filtering method could have eliminated reasonable trips or failed to eliminate unreasonable trips in some instances.

In addition, an original intention to categorize trips to different modes based on speed thresholds could not be completed on the corridor. The probe bicycle found an average speed of $11.8 \mathrm{mph}$ while the lowest probe automobile speed was $16.2 \mathrm{mph}$. On days with particularly high congestion, an automobile's speed may be as low as a bicycle's speed. Los Osos Valley Road also serves as a truck route, and slower moving trucks could also average lower speeds regularly. Situations when vehicles turned off the roadway between Bluetooth detectors along the corridor could not be distinguished from bicycle or pedestrian trips with confidence.

\subsubsection{Traffic Counts}

Traffic count information was drawn from 2014, when no construction was underway along the corridor. Traffic may have increased over time or decreased on the corridor due to construction and users choosing alternate routes to avoid congestion. In addition, counts were one portion of each count segment and do not reflect how many vehicles traveled the entire corridor from one Bluetooth device to another Bluetooth device. Thus, detection rates may have been higher than $5.7 \%$. In addition, a statistically significant result from the average speed model was DRIVE/PHV, with PHV being a peak hour volume drawn from the 2014 traffic counts. Changes to the traffic volumes could change the average speed model. 


\subsubsection{Collision and Incident Comparison}

Collision and incident information was unavailable for the study period of January-February 2016 at the time of analysis. Comparison of incidents to high travel times may help determine whether comparatively high travel times were reasonable.

\subsubsection{Modeling Speed and Variability}

The average speed model and variability models were not tested with off-peak,

free-flow data. In addition, the segments that failed to be rejected had test statistics very close to the rejection value, hence the poor $\mathrm{R}^{2}$ value on the final result. The model distributions may be better fit to corridors without construction and high congestion variability. A different model or methodology may be more fitting in estimating variability during construction.

\subsection{Further Analysis and Research}

Comparison to bicycle and pedestrian traffic counts and travel times would benefit a complete picture of the Los Osos Valley Road corridor, though Bluetooth does not appear to be an adequate collection method for these modes. In addition, data collection and analysis post-construction may provide better comparison of construction effects to travel time and travel time variability. In the City of San Luis Obispo, travel time reliability on other major arterials may help to prioritize corridors in need of signal timing updates, transit routes needing modifications, or multi-use paths separate from high-speed facilities. Reliability of these modes could be a useful performance measure or threshold for new development's traffic impact studies.

Further research is needed to validate the effectiveness of the data filtering methodologies on similar roadways. Though the method appears to work well for Los 
Osos Valley Road, arterials with varying signal or driveway densities, congestion levels, or lanes may require different methods or levels of filtering. In addition, construction segments or corridors may require filtering that is either more or less aggressive than non-construction segments.

The average speed model should be validated along similar roadways due to the counterintuitive correlations. The $\mathrm{K}-\mathrm{S}$ model may be more effective when built on more observations or built with segments of similar characteristics. The construction and heavy congestion on the southern end of Los Osos Valley Road differed vastly in distribution to the light congestion on the northern end. The literature review noted previous studies that had aligned distributions to normal, lognormal, and Weibull distributions, which could be used to assess arterial travel times. Further evaluation of modeling approaches would benefit arterial travel time estimations. 


\section{REFERENCES}

Abedi, N., Bhaskar, A., Chung, E., \& Miska, M. (2015). Assessment of antenna characteristic effects on pedestrian and cyclists travel-time estimation based on Bluetooth and WiFi MAC addresses. Transportation Research Part C: Emerging Technologies, 124-141.

Asudegi, M. (2009). Optimal Number and Location of Bluetooth Sensors for Travel Time Data Collection in Networks. University of Maryland, College Park, MD.

Bertini, R. (2006). Unlocking the Mysteries of Freeway Sensor Data to Diagnose Detailed Bottleneck Dynamics. Proceedings of the Conference on Traffic and Transportation Studies.

Bluetooth. (n.d.). Bluetooth Technology Basics. Retrieved December 5, 2015, from http://www.bluetooth.com/what-is-bluetooth-technology/bluetooth-technologybasics

Box, S. (2011). Arterial Roadway Traffic Data Collection Using Bluetooth Technology.

Cambridge Systematics. (2004). Traffic Congestion and Reliability: Linking Solutions to Problems. Retrieved from http://www.ops.fhwa.dot.gov/congestion_report_04/congestion_report.pdf

Cameron, I. (2013). Effective Range Reliability Testing of BlueMAC (Rep.). DigiWest.

City of San Luis Obispo. (2015). City of San Luis Obispo General Plan.

City of San Luis Obispo. (2015). City of San Luis Obispo Transit Map. Retrieved May 21, 2016, from http://www.slocity.org/government/department-directory/publicworks/slo-transit

City of San Luis Obispo. (2013). 2013 Bicycle Transportation Plan.

Eisele, W., Zhang, Y., Park, E., Zhang, Y., \& Stensrud, R. (2011). Developing and Applying Models for Estimating Arterial Corridor Travel Time Index for Transportation Planning in Small to Medium-Sized Communities. Transportation Research Record: Journal of the Transportation Research Board, 2244, 81-90. doi:10.3141/2244-11

Filgueiras, J., Rossetti, R., Kokkinogenis, Z., Ferreira, M., Olaverri-Monreal, C., Paiva, M., Gabriel, J. (2014). Sensing Bluetooth Mobility Data: Potentials and Applications. Advances in Intelligent Systems and Computing Computer-based Modelling and Optimization in Transportation, 419-431. doi:10.1007/978-3-319-04630-3_31 
FHWA. (2015). SHRP2 Solutions. Retrieved June 01, 2016, from http://www.fhwa.dot.gov/goshrp2/

Institute of Transportation Engineers. (2000). Manual of Transportation Engineering Studies. ITE, Washington, D.C., pp. 55.

Kieu, L., Bhaskar, A., \& Chung, E. (2012). Benefits and issues of bus travel time estimation and prediction. Australasian Transport Research Forum 2011 Proceedings.

Kittelson \& Associates, Inc. (2014). US 101 Corridor Mobility Master Plan.

Koprowski, Y. (2012, March 1). Bluetooth vs. GPS Travel Time Data. Lecture presented at Managing Operational Performance...Exceeding Expectations. 2012 ITE Technical Conference and Exhibit, Pasadena.

Kuzmyak, J., Walters, J., Bradley, M., \& Kockelman, K. (2014). NCHRP Report 770: Estimating bicycling and walking for planning and project development: A guidebook. Washington, D.C.: Transportation Research Board.

Li, R., Chai, H., \& Tang, J. (2013). Empirical Study of Travel Time Estimation and Reliability. Mathematical Problems in Engineering, 2013, 1-9.

Libelium. (2012). Smartphone Detection. Retrieved May 20, 2016, from http://www.libelium.com/products/meshlium/smartphone-detection/

Liu, X., Chien, S., \& Kim, K. (2012). Evaluation of floating car technologies for travel time estimation. Journal of Modern Transportation, 1(1), 49-56.

doi:10.1007/BF03325777

Meyer, M. D. (1998). A Toolbox for Alleviating Traffic Congestion and Enhancing Mobility.

NCSS. (n.d.). Stepwise Regression. Retrieved from http://www.ncss.com/wpcontent/themes/ncss/pdf/Procedures/NCSS/Stepwise_Regression.pdf

Neudorff, L. G., Randall, J., Reiss, R., \& Gordon, R. (2006). Freeway Management and Operations Handbook (Report FHWA-OP-04-003). Washington, D.C.: Federal Highway Administration.

NIST Sematech. (2012, April). Kolmogorov-Smirnov Goodness-of-Fit Test. Retrieved May 04, 2016, from http://www.itl.nist.gov/div898/handbook/eda/section3/eda35g.htm

O'Connor, P. D., \& Kleyner, A. (2012). Practical Reliability Engineering (5th ed.). Hoboken, NJ: Wiley. 
Polus, A. (1979). A Study of Travel Time and Reliability on Arterial Routes. Transportation, 8(2), 141-151. doi:10.1007/bf00167196

Porter, J., Kim, D., Magaña, M., Poocharoen, P., \& Arriaga, C. (2013). Antenna Characterization for Bluetooth-Based Travel Time Data Collection. Journal of Intelligent Transportation Systems, 142-151.

Quayle, S., \& Koonce, P. (2010, June 23). Arterial Performance Measures using MAC Readers - Portland's Experience. Lecture presented at NATMEC Conference.

Rako, P. (2010, May 13). Punching through the ether with RF-range extenders. Retrieved March 09, 2016, from http://www.edn.com/design/communicationsnetworking/4312049/Punching-through-the-ether-with-RF-range-extenders Table A

Ryus, P., Ferguson, E., Laustsen, K., Schneider, R., Proulx, F., Hull, T., \& MirandaMoreno, L. (2014). NCHRP Report 797: Guidebook on Pedestrian and Bicycle Volume Data Collection. Washington, D.C.: Transportation Research Board.

Schneider, W. H., Turner, S., Roth, J., \& Wikander, J. (2010). Statistical Validation of Speeds and Travel Times Provided by a Data Service Vendor. FHWA.

Stevanovic, A., Olarte, C., Galletebeitia, Á, Galletebeitia, B., \& Kaisar, E. (2014). Testing Accuracy and Reliability of MAC Readers to Measure Arterial Travel Times. International Journal of Intelligent Transportation Systems Research Int. J. ITS Res., 50-62. doi:10.1007/s13177-014-0081-4

Tantiyanugulchai, S., \& Bertini, R. (2003). Arterial performance measurement using transit buses as probe vehicles. Proceedings of the 2003 IEEE International Conference on Intelligent Transportation Systems.

Transportation Research Board. (2010). HCM 2010: Highway Capacity Manual. Washington, D.C.: Transportation Research Board.

Turner, S., Eisele, W., Benz, R., \& Holdener, D. (1998). Travel Time Data Collection Handbook. Washington, DC: Federal Highway Administration Office of Highway Information Management.

Urbitran Associates, Inc. (2009). City of San Luis Obispo. Oakland, CA: Urbitran Associates.

Versichele, M., Groote, L., Bouuaert, M., Neutens, T., Moerman, I., \& Van De Weghe, N. (2014). Pattern mining in tourist attraction visits through association rule learning on Bluetooth tracking data: A case study of Ghent, Belgium. Tourism Management, 67-81. 
Wasson, J., Sturdevant, J., \& Bullock, D. (2008). Real-Time Travel Time Estimates Using Media Access Control Address Matching. ITE Journal, 78(6), 20-23.

Weather History for KSBP. (2016). Retrieved March 05, 2016, from https://www.wunderground.com/history/airport/KSBP/2016/MonthlyHistory.html?req _city=San Luis Obispo

Weinzerl, J. \& Hagemann, W. 2007. Automatische Erfassung von Umsteigern per Bluetooth Technologie. Nahverkehrspraxis, 3, 18-19.

Wright, J. (n.d.). Security Laboratory. Retrieved March 09, 2016, from http://www.sans.edu/research/security-laboratory/article/bluetooth

Zhang, X., Hamedi, M., \& Haghani, A. (2015). Arterial Travel Time Validation and Augmentation with Two Independent Data Sources. Transportation Research Record: Journal of the Transportation Research Board, 2526, 79-89. doi:10.3141/2526-09 